\title{
Designing to support Mobile Work with Mobile Devices
}

Christina Nielsen Ph.D. Dissertation

University of Aarhus

December 2001 


\section{Contents}

1 Foreword $\quad 7$

1.1 Structure of this dissertation . . . . . . . . . . . . . 7

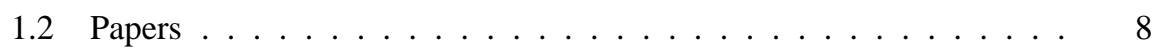

1.3 Acknowledgements . . . . . . . . . . . . . . . . 10

2 Danish Abstract $\quad 11$

3 Introduction 13

3.1 Designing to support.. . . . . . . . . . . . . . . . . 15

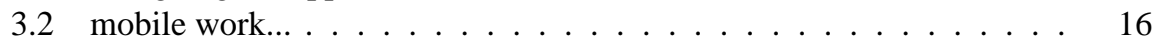

3.2.1 The SmartWindows Project . . . . . . . . . . . . 17

3.2.2 The Vision2000 Project . . . . . . . . . . . . . . . . . 17

3.2.3 The CIS Project . . . . . . . . . . . . . . . . 17

3.3 with mobile devices . . . . . . . . . . . . . . . . . . . 18

3.4 My contribution in the scope of things . . . . . . . . . . . . 20

4 Theoretical basis $\quad \mathbf{2 3}$

4.1 A foundation for analysing meaningful human work . . . . . . . . . . 24

4.1.1 Mediation, transparency and breakdowns . . . . . . . . 24

4.1.2 The social aspects of work ............. . . 26

4.2 Activity theory and mobile work . . . . . . . . . . 28

5 Research method

5.1 Interdisciplinarity and design orientation . . . . . . . . . . . 30

5.2 Mobile work research . . . . . . . . . . . . . . . . 34

6 Developing usability practice in the BIDI-project 35

6.1 The Scandinavian approach-from the 70 s to the present . . . . . 36

6.2 Ethnographically inspired field studies . . . . . . . . . . . . 38

6.3 Design and usability methods . . . . . . . . . . . . . . . . . 39

6.3.1 Prototypes and mock-ups . . . . . . . . . . . . 39

6.3.2 Metaphors and caricatures .............. 40

6.3.3 Scenarios and work descriptions . . . . . . . . . . . . . . 42

6.4 Taking usability methodology even further . . . . . . . . . . . . . . . . . . 42

6.5 Concrete examples of use in the BIDI project . . . . . . . . . . . . 43

6.5.1 Interrelations between field and lab ........... 43

6.5.2 Using theoretical constructs to inform design . . . . . . . . . 44

6.5.3 Design in multidisciplinary groups and mobile work . . . . 46 
7 Mobile work in a process environment 47

7.1 The CIS case . . . . . . . . . . . . . . . . . . . . 47

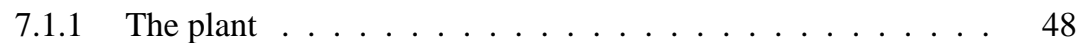

7.1 .2 The work . . . . . . . . . . . . . . . 48

7.1.3 The existing web-of-technology . . . . . . . . . . . . 49

7.2 General characteristics of process work . . . . . . . . . . . 50

7.2.1 The complexity of the technical system . . . . . . . . 50

7.2.2 Dynamics in process work ................. 50

7.2.3 Central control versus distributed work . . . . . . . . . 51

7.3 Process plant environments versus control rooms . . . . . . . . . 52

7.4 Process plants as learning environments . . . . . . . . . . . 53

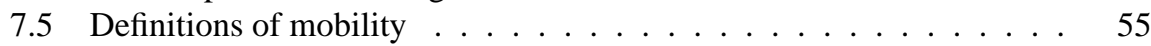

7.6 Other empirical studies of mobile work . . . . . . . . . . 58

8 Mobile technology and design 59

8.1 Mobile technology-an overview . . . . . . . . . . . . . . 59

8.1.1 A general lack of design principles . . . . . . . . . . . . . 60

8.1.2 Interface design for mobile technology . . . . . . . . . 62

8.1.3 New interaction paradigms for mobile devices . . . . . . . . 62

8.2 Our prototypes . . . . . . . . . . . . . . . 69

8.2.1 The integrated approach . . . . . . . . . . . . . 69

8.2.2 Augmented Reality prototypes . . . . . . . . . . . . 71

8.3 Mobile technology and integration . . . . . . . . . . 73

9 Conclusion $\quad 77$

9.1 Designing to support... . . . . . . . . . . . . . . 77

9.2 mobile work... . . . . . . . . . . . . . . . 78

9.3 with mobile devices. . . . . . . . . . . . . . . . . . . 79

9.4 Future work . . . . . . . . . . . . . . . . . . . . 79

9.4.1 Designing a mobile EPJ . . . . . . . . . . . . 79

9.4.2 A Post-WIMP analysis of mobile technology interfaces . . . . 80

9.4.3 Fluid links on mobile interfaces ... . . . . . . . . 80

A The SmartWindows project $\quad \mathbf{8 1}$

A.1 Introducing the work setting and methods used . . . . . . . . 81

A.2 Summary ............................ 82

B The Vision2000 project $\quad \mathbf{8 5}$

B.1 Introducing the work setting and methods used . . . . . . . . . . 86

B.2 Summary ...................... 87

$\begin{array}{lr}\text { Bibliography } & 89\end{array}$ 


\section{List of Figures}

8.1 The foldable Palm keyboard . . . . . . . . . . . . . . . . . . . 63

8.2 The Half-QWERTY keyboard layout . . . . . . . . . . . . . . . . . . . . 64

8.3 The Palm with the half-qwerty keyboard . . . . . . . . . . . . . . . . . . 64

8.4 The Quickwriting layout for the PalmPilot device . . . . . . . . . . . . . . 65

8.5 Using marking menus for text input-T-Cube . . . . . . . . . . . . . 66

8.6 Two ways of interaction with the CyPhone . . . . . . . . . . . . . . 66

8.7 Scroll painting prototype . . . . . . . . . . . . . . . 67

8.8 Quickset device layout . . . . . . . . . . . . . . . . . . 68

8.9 Quickset-using multiple technologies . . . . . . . . . . . . . . 68

8.10 First view-PC and PDA plant overview . . . . . . . . . . . . . . . . . . 69

8.11 Second view-PC and PDA inlet water . . . . . . . . . . . . . . 69

8.12 Third view-PDA single sensor information . . . . . . . . . . . . . 70

8.13 Prototype based on the augmenting the user strategy . . . . . . . . . . . . 71

8.14 Prototype based on the augmenting the object strategy . . . . . . . . . . . 72

8.15 Second prototype based on augmenting the object . . . . . . . . . . 72

8.16 Prototype based on the augmenting the environment strategy . . . . . . . . 72

\section{List of Tables}

A.1 Timeline of user-involved and cooperative sessions 


\section{Chapter 1}

\section{Foreword}

\subsection{Structure of this dissertation}

This report forms the first part of my Ph.D. dissertation titled "Designing to support mobile process work with mobile devices". This part summarises my work and relates it to the design and usability research fields. The second part is formed by the five papers described in Section 1.2 that deal with different parts of the triadic structure of my work, namely issues of design (the design process and the usability methods), the work environment (mobile, distributed work in a process environment) and technology (mobile and stationary).

Foreword This chapter

Danish Summary A summary of the dissertation in Danish.

Introduction Presents the triadic structure mentioned above and the relations between the three constituents in detail. I problematise each element, draw forward the key issues for this dissertation and present my contribution in the scope of things, amongst these the concept of 'web-of-technology'

Theoretical basis Based on elements from the activity theory framework I present a theoretical foundation for dealing with relevant aspects of human work, making it possible to understand design and use as interlinked. The Chapter ends with a discussion of how this theoretical foundation relates to mobile work and mobile technology, particularly the concept of 'web-of-technology'.

Research method Placing myself within the action-oriented research tradition gives rise to questions in relation what constitutes 'research' in a discipline that is characterised by being interdisciplinary and design-oriented. I discuss the questions of interdisciplinarity and design orientation by relating them to existing research within $\mathrm{HCI}$ and $\mathrm{CSCW}$ and to my theoretical basis.

Developing usability practice in the BIDI-project Moving from questions of research to the practicalities of design, this Chapter discusses the design process and how the relationship between my three elements should be reflected in the techniques we choose. Different design and usability strategies are discussed with respect to their contribution to the goals of the BIDI project. The Chapter concludes with 
a number of concrete examples of how usability and design techniques were developed and used in the BIDI project.

Mobile work in a process environment Presents the primary case study (the CIS case) and the general characteristics of process work. This empirical material forms the basis of a number of analyses of mobile process work (comparing process plants to control rooms, seeing process plants as learning environments and analysing process work by means of different definitions of mobility). Related empirical studies of mobile work conclude the Chapter.

Mobile technology and design Gives a brief overview of the design challenges we face in relation design of mobile technology. I focus on the lack of design principles for mobile technology and issues concerning information visualisation and interaction paradigms. Themes from the discussions are exemplified in two design prototypes from the CIS project.

Conclusion This Chapter summarises my results so far and sets the direction for future work.

The SmartWindows project Describes the SmartWindows project.

The Vision2000 project Describes the Vision2000 project.

\subsection{Papers}

The core part of this dissertation consists of the following papers, included with the dissertation:

1. Bødker, S., Nielsen, C. and Graves Petersen, M.: Creativity, cooperation and interactive design. In Proceedings of the Third Conference on Designing Interactive Systems, DIS 2000, D. Boyarski \& W Kellogg (Eds.), ACM, 2000, New York, NY., pp. 252-261. In the text referred to as: [Bødker et al., 2000] and then marked with [P1]

This paper focuses on ways and means of supporting design in multidisciplinary design groups involving designers, engineers, software developers, users and usability people as explore in the BIDI-project. We have been particularly interested in tools used in design to get ideas for a new interactive application and its use. With a focus on history, multivoicedness, contrasting perspectives, and using theory as an inspiration for creating practical tools for design, we present a number of empirical examples of such tools and discuss their strengths and weaknesses as creative 'spring-boards' in collaborative design efforts.

2. Nielsen, C.: "Testing in the Field", In Proceedings of the Third Asia Pacific Computer Human Interaction Conference, APCHI 98, Shonan Village Centre, Japan, July 15-17 1998, pp. 285-289. In the text referred to as:[Nielsen, 1998] and then marked with [P2]

This paper discusses how field studies and lab testing may mutually inform each other. Aspects from the field have long been used in lab testing, e.g. through the development of realistic work scenarios or multiple user sessions. Even more progressive approaches involve actively setting the stage for use with workshops and using video to make the workplace present. However, the main contribution 
of this paper is that it documents how techniques traditionally used in usability testing in a lab may be successfully deployed in field studies. Based on field studies from projects at Kommunedata and Bang \& Olufsen, the paper reports on concrete examples of methods that have long been used for usability testing in labs and which were successfully used in the field.

3. Bertelsen, O. and Nielsen, C.: "Dynamics in wastewater treatment: A framework for understanding formal constructs in complex technical settings. In Proceedings of the Sixth European Conference on Computer Supported Cooperative Work, (ECSCW'99), København 12 - 16 Sept. 1999, Bødker, S., Kyng, M., Schmidt, K. (Eds.) Kluwer Academic Publishers, Dordrecht, 1999, pp. 277290. In the text referred to as: [Bertelsen and Nielsen, 1999] and then marked with [P3]

This paper investigates into the limits of formalisation in a process environment. Based on the wastewater treatment study and focusing on the complex technical setting, we identify five levels of dynamics to characterise the process of wastewater treatment, both internally in the organisation and in collaboration with other, external parties. Through it, we identify two distinctly different modes of work: maintenance and optimisation work, and discuss the tensions between them in relation to their possible disruption of collaborative activities.

4. Nielsen, C and Søndergaard, A: Designing for mobility: an integration approach supporting multiple technologies. In Proceedings of the First Nordic Conference on Human-Computer Interaction (NordiCHI) (CD-ROM) In the text referred to as: [Nielsen and Søndergaard, 2000] and then marked with [P4]

Based on the case study at a large, Danish wastewater treatment plant, we present a prototype for a shared PC- and Palm-based system to support the distributed, mobile work by means of providing integration and overview. The prototype is built on the understanding that support for mobile work is realised through a combination of mobile devices and desktop systems, which enables users to adapt and reconfigure themselves in response to the changing demands of use situations. Furthermore, the study shows that most tasks performed in this environment are context dependent and site specific which challenges the notion of being able to access all information from anywhere.

5. Bertelsen, O.W. and Nielsen, C., Augmented Reality as a Metaphor in Mobile Computing. In Proceedings of the Third Conference on Designing Interactive Systems, DIS 2000, New York, USA, pp. 17-19 August 2000. In the text referred to as: [Bertelsen and Nielsen, 2000] and then marked with [P5]

This paper challenges the predominant paradigm for interaction with mobile devices - pen based direct manipulation - by using the technical classification of augmented reality as a creative design tool to develop ideas for interaction with mobile devices. By juxtaposing the three levels of augmentation with real use situations, we develop four future scenarios with prototypes, which focuses on the physical interaction with objects of work. The prototypes show the potential of augmented reality as an inspiration for new ways of interacting with or through a mobile device.

Paper 1 and 2 deal with the design challenges in general as they emerged during the BIDI-project. 
Paper 3 analyses mobile work as it exists in a wastewater treatment setting.

Paper 4 and 5 present concrete design prototypes for supporting wastewater treatment work, i.e. mobile work in a process setting, using both mobile and stationary technology.

\subsection{Acknowledgements}

This Ph.D. project would never have existed without the help and support of a number of people.

First of all, I want to thank my supervisor, Susanne Bødker, for her unyielding moral support and brave efforts to keep me on track. She has been a constant inspiration and an always guiding force in my work.

Thanks also goes to all the participants in the BIDI project, which formed the basis for my work and through which my interest in mobile technology and mobile work was initially sparked. In particular, I want to thank Jakob, Ingrid, Thomas, Eva, Kirsten, Pi, Shin, Nina, Troels, Andrew and Mette for making those countless visits to Als thoroughly enjoyable and interesting. I also owe a big 'thank you' to the BIDI group here in Aarhus-Susanne, Kim, Pernille, Thea and Marianne-for making the working environment so stimulating and for always taking time to discuss a wild idea. And to the Danish National Center for IT Research (CIT) for funding the BIDI project and making my Ph.D. project possible.

The CIS project helped me mature my ideas into the concepts and prototypes presented in this dissertation. I owe thanks to the participating waste water treatment plants and the workers who, with great patience, helped me to broaden my understanding of mobile work. Also thanks to the research teams involved, particularly Susanne, Olav, Astrid, Christian, Wendy and Michel: working with you made waste water treatment an engrossing experience.

Finally, my dissertation would look very different if not for the following people:

Niels Olof Bouvin, for tirelessly proof-reading several versions of the dissertation and providing essential LTEX-support when I was about to despair.

Olav Bertelsen, for his 'tough-love'-approach to constructive criticism and for his annoying habit of being right regardless.

Marianne Graves Petersen, for suffering my rantings patiently as my work developed, and for the countless deeply engaging discussions about usability, activity theory and marginal technologies.

Astrid Søndergård, for making user interface design and writing about it such a treat. Anders Torp Brodersen, for keeping me sane and for caring enough to bear with me. 


\section{Chapter 2}

\section{Danish Abstract}

Som titlen antyder har jeg har i min Ph.D. overordnet beskæftiget mig med hvordan man designer mobil teknologi til at understøtte mobilt arbejde. Mere specifikt har jeg arbejdet med følgende tre stærkt sammenhængende komponenter: design (både som process og som værktøj), mobilt arbejde (på processanlæg), og teknologi (mobil og stationær-og sammenhængen mellem dem). Samspillet mellem de tre komponenter defineres med udgangspunkt i min uddannelses- og forskningsmæssige udvikling, der er et produkt af den aktions-orienterede tilgang til systemudvikling, også kendt som den Skandinaviske tradition for systemudvikling. Samarbejde, brugerinvolvering og eksperimentel metodeudvikling har været kendetegnende for denne forskningstradition og det er den tradition jeg fører videre i en mobil arbejdssammenhæng. En anden indvirkende faktor på min tilgang til det mobile arbejdsdomæne er den teknologiske udvikling: af det samlede antal af mikrochips, der produceres årligt bliver kun 3-5\% placeret i PC'er — resten bruges i mobil og embedded teknologi. Denne udvikling bevirker vi står overfor nye typer af teknologi, muligheder og begrænsninger, der skaber helt nye udfordringer for brugergrænsefladedesign.

Følgende gør sig på den baggrund gældende i forhold til design af teknologiunderstøttelse af mobilt procesarbejde: design processen, og de brugbarhedsmetoder vi inddrager i den, skaber en forståelse for den arbejdspraksis og de arbejdssammenhænge, vi forsøger at understøtte med ny teknologi. Arbejdssammenhængen sætter rammerne for hvad det er, vi understøtter og hvordan vi griber det an, og specielt i en mobil arbejdskontekst er det vigtigt at forstå heterogeniteten i arbejdet: arbejdsopgaverne og de tilgængelige ressourcer ændrer sig i forhold til, hvor man befinder sig (hjemme på kontoret, ude hos en kunde, ude blandt maskiner på værket, etc.) og brugerens behov for teknologiunderstøttelse og tilgang til information ændrer sig tilsvarende. Disse relationer skal afspejles i de teknologi-løsninger, vi udvikler, og det er derfor ofte mere $\emptyset n s k v æ r d i g t$ for en mobil arbejdskontekst at skabe et udvalg af forskellige redskaber brugerne kan vælge imellem som deres behov ændrer sig, end at erstatte en teknologisk tilgang med en anden. Dette er specielt vigtigt i forhold til mobil teknologi idet det håndholdte værktøj ofte understøtter mobiliteten i arbejdet på bekostning af f.eks. overskueligheden idet de fysisk små skærme ikke er i stand til at skabe overblik på samme måde som en stor PC monitor.

Derfor er sammenhængen mellem de tre elementer en vigtig del af min Ph.D. Jeg behandler hvordan mobilt arbejde stiller nye krav til de teknologiske redskaber, vi de- 
signer for at understøtte det, deriblandt mobil teknologi. Jeg behandler også at mobile redskaber stiller krav til nytænkning i forhold til brugergrænsefladedesign og funktionalitet, fordi vi har med en ny type teknologi at gøre, ikke bare en lille PC med en begrænset skærm. Endelig behandler jeg hvordan dette nye område indenfor HCIforskning stiller nye krav til de brugbarhedsmetoder vi bruger; til det omfang vi inddrager brugere og andre faggrupper og bruger arbejdskonteksten aktivt i designprocessen.

Som et samlende koncept for udvikling af mobil teknologi til underst $\varnothing$ ttelse af mobilt arbejde introducerer jeg begrebet 'web-of-technology', der fordrer at man skaber en forståelse for hvilken rolle det nye redskab skal spille $\mathrm{i}$ forhold til den allerede eksisterende teknologi i den konkrete arbejdssammenhæng. Ved at placere den nye teknologi i det eksisterende 'web-of-technology' tvinges man til at analysere, hvilke relationer det mobile reskab bør have til de andre teknologiske redskaber i arbejdskonteksten, og om det mobile artefakt skal være stærkt-, svagt- eller slet ikke integreret med den anden teknologi. Graden af integration mellem teknologier påvirker design af både funktionalitet og brugergrænseflader; stærkt integrerede redskaber kræver stor visuel og funktionel konsistens på tværs af redskaberne. Det er derfor vigtigt, at vi får afklaret disse spørgsmål omkring forholdet mellem den teknologi der er og den der kommer tidligt i udviklingsprocessen, som en naturlig del af at undersøge, hvordan arbejdspraksis påvirker designprocessen. 


\section{Chapter 3}

\section{Introduction}

"I think it's time to come to the era of products for the everyday person, products much more like the appliances in the kitchen, or for that matter the furniture in your house, that are meant to fit your lifestyle and meant to give you value and convenience, not to complicate your life. This requires, therefore, a very different approach to the design of our products [compared to the approach taken by the consumer electronics industry and the computer industry]. It requires an approach in which you observe the way that people live their lives, and you try to make products that fit naturally and seamlessly into people's lives. It requires a human-centred design approach where designers of all sorts-industrial design, graphics design, and interaction design — are working as a team from the very beginning of the concept of the product."

Don Norman on the future of technology design in [Bergman, 2000]

As a student and later a researcher in the area of human-computer interaction, specifically design of information technology and user interfaces, I can but agree with Don Norman's perspective on design of technology. One of the reasons being that I am fortunate enough to belong to a research community that has been working with design as an open, explorative, multidisciplinary user-centred process since the late 1970's. In reply to the quote, I have to note that it does not suffice to observe the user domain and then bring together the different kinds of design professionals; design of computer artifacts is informed by the input from several sources such as software architects, architects, engineers, and the future users of the artifact. Inspiration for good design can come from the most unlikely sources and is often spawned from the tension between different points of view or work practices. However, Don Norman has a very valid point when he remarks that we need to design products that fit our lifestyle and does not complicate our life. It becomes even more important that, when we look at the development of technology in the last decade, seriously introducing palm-size devices and wall-size screens into the marketplace, we need to re-evaluate design methodology as well as user interface design which have been based on the development of the desktop computer, to accommodate the new types of technology and be able to re-evaluate the relationships or networks they are put into.

Most noticeably in this period, the development in the area of microcomputers has literally exploded which has had a tremendous impact on mobile and wearable computing; the overwhelming success of mobile phones, at least in numbers sold if not in 
the services provided, the establishment of the palmtop organiser as a household item, and the distribution of in-car computers just to mention a few. Combined with the emergence of pervasive or ubiquitous devices, computer chips embedded in everyday products, we are dealing with an entirely new range of technology, possibilities and limitations, and consequently new user interface challenges. One of the problems with the current use of/design for these 'babyface'-devices, a term coined by Kari Kuttii to describe small devices without the usual large screen, keyboard and mouse peripherals, is that the established design paradigms which were developed for the PC, using the desktop metaphor and windows, icons, mouse and pointers (WIMP) interfaces to support a sense of direct manipulation with the virtual objects, are used indiscriminately for the physically and computationally much smaller units. As designers of mobile technology, we do not only have to understand that design must originate from use situations rather than the technological artifact itself, but that we are dealing with a new medium and device new ways of interacting with and presenting information on the devices. Furthermore, we need to go beyond the ordinary workplace studies and look specifically at the relations between the existing technology and the mobile device being introduced, because it is vital to understand which role the mobile device should play in this 'web-of-technology' and the degree of integration between the different technological artifacts to be able to design systems or services that takes advantage of the different elements it consists of.

The need for a constant evolution of design methods to reflect a general need for being better at designing information technology to support people in their work and everyday lives has been one of the driving forces behind my work so far. Combined with an avid interest in the development of new technology, particularly the hand-held or wearable kind, a dose of scepticism in relation to what we try to do with these new devices and why, and the great challenge of designing mobile technology sufficiently well enough for people to actually wanting to use it, this has guided my work and is here presented as my dissertation, which I have entitled: designing to support mobile work with mobile devices.

I see my work consisting roughly of three parts that mutually influence and inform each other:

Design or the design process and the usability methods used in this, which provides us with an understanding of the work domain we are designing for and which informs the practical design of computer artifacts for the

Work environment (mobile, distributed work), which we are aiming to support with

Technology (mobile and stationary), the design of which draws upon the understanding of the work domain, utilises the design methods and feeds back into the design process with guidelines and design principles, and which changes and is changed by the work praxis.

Looking at the contribution of my dissertation it, too, has a triadic structure. It deals with how mobile work makes new demands on the technological devices we design to support it, thereof mobile technology. It also deals with how the mobile artifacts demand new thinking in relation to the user interface design and functionality because we are dealing with a new type of technology, not just a very small PC with limited screen and next to no peripherals. Finally, it deals with how this new area of research (and the development of HCI and usability in general) sets new demands for the usability methods, how and to what degree we involve users and other professionals 
in design, how we take advantage of the use environment and utilise the use context actively in the design process.

These three constituents can not be considered meaningfully in isolation or even the two without the third without some distortion. Developments in usability practise and design of technology with no consideration for the use environment yields a technology-centric approach that is unable to deal with the changes and demands of the work practise. Conversely, developing the usability practise and use setting without looking at the (technological) artifacts that support the work will provide studies of work without any comprehension of how technology shapes and is shaped by the work it is introduced into.

In my work, and in my mind, design of technology is intrinsically connected to the usability methods or techniques used in the design process as well as the use domain we are designing for. This builds on an understanding that usability is an integral part of a design process and not merely a tool for evaluating and verifying a finished design. Development of one aspect of this 'trinity' have implications for the other two and therefore I would be negligent if I did not concern myself with developing all three aspects as they have mutually influenced each other in my work. The main contribution of this dissertation is thus one of usability issues concerning design of mobile technology to support mobile work, in this particular case, process work.

In the following I will briefly introduce each part and relate them to my papers and to the overall goal of the dissertation.

\subsection{Designing to support..}

I see design as a learning process through which, of course, different products, prototypes and user interfaces are designed, but also, and equally important, through which an understanding of the work domain is gained and experiment with future use of technology for that work setting are tried out. Through design of new technology or work artifacts in general, visions of future work are created. To do this satisfactorily, we need to take into account all aspects of the context of design, not only include software engineers and a test panel of users, but go beyond the traditional view of the inputs we need for designing to support a work practice. This requires knowledge of the technical possibilities, the practical use situations, aesthetics and design, just to mention a few, and the methods and techniques used in design and usability work must reflect the interdisciplinary field that it is.

The methods I describe in this dissertation build upon the cooperative design tradition, with roots in what is known as 'the Scandinavian school' (as opposed to the cognitive psychology-based participatory design approach), which emphasises cooperative prototyping and using flexible mock-ups, functional prototypes and other representations of work artifacts to support e.g. hands-on experience when designing [Greenbaum and Kyng, 1991]. Many of the usability experiences I present in this dissertation originated from the BIDI-project, a 3-year research project with participation from Danfoss, Bang \& Olufsen and Kommunedata who were some of the first to form usability groups within Danish industry. The overall focus of this research effort was to move the boundaries for how usability work is performed; from being user-centred to supporting active user involvement in design, moving out of the lab and into the field, and creating dynamic, creative design spaces for multidisciplinary groups. The outcome of the BIDI-project as such has been compiled and synthesised in [Buur and Bødker, 2000], which deals with the emergent usability is- 
sues in depth. The authors have given the approach the name "the design collaboratorium" to emphasise the effort to move usability from evaluation to collaborative design. See also [Bødker et al., 2000, Nielsen, 1998, Bertelsen and Nielsen, 2000, Bødker and Halskov Madsen, 1998] [P1,P2,P5] for more detailed accounts of projects and approaches taken in the BIDI project. The specific methodology presented has been chosen both because it offers excellent means to meet the goals in the BIDIproject in e.g. supporting collaboration in an open and exploratory manner, but also because it compliments the view of purposeful human work as a socially and historically defined, collective activity as found in the activity theory framework. Design in an activity theory context is seen as a change agent by means of which we can explore future work and technology, using as well as provoking the current work practice, existing artifacts and the organisational culture. Understanding the relationship between different technological devices has a great impact on our efforts in designing better and more integrated support, and even more so because we strive to take advantage of the different types of technology which are to work together in a larger system. My purpose in emphasising this is, naturally, not to invalidate the focus on e.g. the work practise, but to add an understanding of other relevant relations, in this case those that exist between technological devices. Similar relationships between non-technological artifacts as well as between technology and non-technological artifacts might take us even further in that direction, but this is outside the scope of my work. In relation to the three cases I have been working on and which I will present in the following paragraph, I shall look only at computer artifacts and the relations between them, particularly the design aspects of this relationship but also to some degree the technical and functional relations as these cannot, and should not, be separated - they are deeply interconnected. I have chosen the name 'web-of-technology' to emphasise the boundaries of this approach.

\section{2 mobile work...}

Mobility as part of a work practise, particularly with focus on distributed work, supporting cooperation and awareness between physically separated collaborating partners has been the subject of research for decades. One example of this is the Portholes project, started at the Xerox PARC labs, which allows physically distributed users to obtain a general and peripheral awareness of their co-workers [Dourish and Bly, 1992]. Another is the development of an event notification service, Elvin, running on a graphical one-line application called Tickertape which supports information availability and awareness at a distance within an office environment without demanding constant attention (see: [Parsowith et al., 1998, Fitzpatrick et al., 1999]). The adoption and success of this service within the organisation it was introduced into is an excellent example of the need for mobility within a local space, what [Bellotti and Bly, 1996] has denoted 'local mobility'. It notes that even though people share a working environment, they need to move away from their desk and office for reasons such as supporting coordination, awareness and using shared resources or expertise.

The focus on mobile work has increased within the HCI and CSCW communities in recent years. Critical voices, particularly within the CSCW community have attacked the lack of CSCW support that treats mobility as a vital and integral part of collaboration in a distributed environment [Luff and Heath, 1998, Bellotti and Bly, 1996, Fagrell et al., 1999]. Most systems designed to support cooperative, distributed work are 'workstation-centric' i.e. largely concerned with providing still more complex sup- 
port tied to a personal computer, which makes them ill suited for supporting the mobile aspects of work.

The empirical basis for my $\mathrm{PhD}$ project consists of three case studies of mobile, distributed work in process environments: the SmartWindows project, the Vision2000 project and the CIS-project. The CIS-project, however, has received my primary work effort and has become the focal point of my research efforts while the SmartWindows and Vision2000 projects have served as excellent learning experiences and have yielded important research results that I have been able to perpetuate and refine in the CISproject. Consequently, I have chosen to base this report on the work done in relation to the CIS project and bring in examples from SmartWindows and Vision2000 to exemplify or clarify findings where necessary. In the following, I will give a brief presentation of each.

\subsubsection{The SmartWindows Project}

The SmartWindows project aimed to support the work of process operators at a combined heating and power plant. Though our field study we realised that the lack of information locally at the plant made it necessary for the process operators to work in pair, one situated at the control room with access to the system information while the other moved around on the plant doing maintenance work.

\subsubsection{The Vision2000 Project}

The overall aim of the Vision2000 project was to develop a shared software platform for refrigeration components for the European and American market. One of the subgoals of the project, however, was to develop a new user interface strategy for both old and new products and thus to look into the needs of users working in or with refrigeration components for large supermarkets. In this context, we focused on the work of refrigeration engineers who are in charge of setting up, maintaining and optimising the large refrigeration systems in supermarkets.

\subsubsection{The CIS Project}

The CIS project was part of a long-term research cooperation in the areas of HCI and CSCW involving researchers from Danfoss, the Computer Science Department at Aarhus University and the Art, Culture and Communication department at Malmö University College, and four wastewater treatment plants in Denmark and Sweden. The overall focus for the Århus research effort was to look at common information spaces -how information is saved, shared and accessed at a technical process plant.

Common to the projects is that they are dealing with work in a process environment where the work is characterised by being highly distributed and mobile, centred on interaction with the physical components in the area. This, however, is juxtaposed by the high degree of central control and lack of access to information locally at the plant, which is typical for process environments. A vital element in supporting mobile work in a process environment thus becomes making information stored centrally available locally while still maintaining an overview of the status of the process itself. Detailed accounts of different aspects of the wastewater treatment work can be found in [Bertelsen and Nielsen, 1999, Nielsen and Søndergaard, 2000, Bertelsen and Nielsen, 2000][P3,P4,P5] 
The three projects in more ways than the obvious, chronological one, map out my progression into and through the field of mobile work; SmartWindows being my first project in which a hand-held device was introduced to support the mobility inherent in the work routines, followed by the study of refrigeration engineers in the Vision2000 project and culminating in the CIS-project, dealing with supporting the wastewater operators as they traverse the wastewater plant. The learning process I went through in dealing with mobile work during the course of one project is reflected in many of the steps taken in the preceding project(s). In the following, I shall give a much more detailed description of the CIS project whereas the SmartWindows project and the Vision2000 project, their goals, the methods used and the outcome of our efforts are described in Appendix 1 and 2.

\section{3 with mobile devices}

With the development in recent years in the field of mobile technology, a host of new devices most of which will fit in your palm have been introduced, and these new technological possibilities open new avenues for computer-based support for mobile work. This brings about a need for investigating into how new technology will affect the work practise as well as getting an understanding of how we design with and for this new medium. However, because the technology is new and still in rapid development, it has yet to establish a solid basis as an area of research.

At a workshop at the $21^{\text {st }}$ Information Systems Research Seminar in Scandinavia (IRIS'21), a reference model for mobile informatics was presented as part of an attempt to

www.viktoria.informatik.gu. se/groups/mi3/

daniel-pc.informatik.umu sel

research.dh.umu.se/idl/ www.ifi.uio.no/ johe/ ...establish an applied research field concerned with new applications for mobile settings. The objective is to explore, design and evaluate innovative ways of using IT in mobile work and leisure activities, thus not only focusing on the technical aspects. [Kristoffersen and Ljungberg, 1999b]

The Mobile Informatics approach, developed at the Viktoria Institute in Goteborg, and similar research initiatives e.g. at the University of Umeå, also in Sweden and the University of Oslo in Norway seek to develop an open, explorative base for mobile technology.

Of course, every self-respecting company who designs mobile technology and/or services have design guidelines they work from and refer to. However, with the exception of the research group at Nokia who has been responsible for the design of the user interfaces for their mobile phones and communicators, the mobile technology industry, be that manufacturers of personal organisers, GameBoys or mobile phones, are concerned with design of the device itself rather than with the design of the device in a use context and this is reflected in their design 'principles'.

The Nokia group, however, have adopted the contextual inquiry method developed by [Beyer and Holtzblatt, 1998] to gain

insights of users' activities and needs in their "real life".

While the method may be subject to discussion, the intention cannot. See [Väänänen-Vainio-Mattila and Ruuska, 1998, Väänänen-Vainio-Mattila and Ruuska, 2000] for a more detailed account of this approach and their conceptual background as such. And this is the crux: when it comes to design of mobile technology, the problem is conceptual rather than technological. Today's mobile devices and services have to a 
staggering degree failed to match the users' needs. One of the most recent examples is the introduction of WAP telephones and the lack of impact they have had on both the marketplace and people's lives. In an online article from ComputerWeekly, about widespread problems with WAP sites, it is reported that

"Tests by mobile technology provider Argogroup showed 89\% of the 1,596 sites examined failed usability, reliability or interoperability tests".

Of course, there is no simple explanation to this phenomenon but the way the WAP telephones and mobile devices in general are being advertised today is a big part of the problem. Consider the recent Nokia Communicator advertisement where the businessman draws a crowd in the train to work because he is using is mobile device for making coloured graphs and looking at video. The message of the commercial is that this device allows him to finish his work even before he gets to the office. This picture demonstrates some serious misunderstandings made by the advertisers when dealing with mobile technology in work situations, namely that work is something you do alone in front of your computer and thus the new, mobile device enables you to 'take care of business' anywhere outside the office. The two most serious miscomprehensions embodied in this vision are the following. First, anybody who have done studies of work will know that work is highly situated and cooperative in nature and often tied to one or more specific places and points in time. Second, giving the impression that a handheld device is exactly like a PC, only somewhat smaller is not only ridiculous but is seriously misguiding the user's expectations of what the handheld device can be used for. Granted, in advertising emphasising features to make a point is an often used strategy, but they nonetheless leave the prospective users with the notion that connectivity, data transfer speed, access to well-known applications, overview of the information and interactive abilities will be identical to their use of the PC counterparts. The way we interact with handheld devices and the tasks we use them for are radically different than working with a PC.

In general, mobile devices are better suited for specific rather than general tasks, e.g. WAP telephones are very badly suited for browsing but can very well be employed to find a recipe including chicken in a recipe database when you're in the supermarket and see there's a sale on that particular type of meat. Mobile devices need to fulfil at least one of the following demands to be successful:

1. Expand on an already existing service or system by giving them mobility and makes it possible to solve a set of specific tasks in specific contexts (and therefore not necessarily be a full copy of the original system). This requires that we clarify the need for integration between the different service- or system elements

2. Offer a solution to a well-defined, targeted task, i.e. provide here-and-now related information, by either working better and faster than other available devices or bridging a gap for which no appropriate device exist.

In this sense, the mobile devices I have been working with relate well to Norman's "information appliances" described in [Norman, 1999, Bergman, 2000] which he created as a reaction to the problems he sees with use of the more complex, general purpose PC.

Looking specifically at the usability issues in relation to the general difficulties with using mobile technology, I see this relationship: focus on the technology rather than the use situation, a lack of design principles specifically developed for mobile 
devices, a lack of understanding of how the mobile devices should relate to other types of technology in the use setting are all factors that may help us explain why so many mobile services and devices fail.

With this dissertation, I present my approach to designing support for mobile settings which addresses these factors and possible solutions to them.

Developing an understanding of the use environment and the work practice of the user groups does not automatically provide us with a clear-cut, laid-out design for technological support of it. Here, the experiences from the BIDI-project in developing usability practice and devising new techniques for supporting design based on empirical work become vital constituents in transforming knowledge about a work practice into concrete examples of mobile technology to support the distributed, mobile work. Through designing prototypes for mobile support of the work in the individual case studies we discovered several issues relating to support of mobile, distributed work that has a more general character and which should be explored further to better understand the implications for design of mobile devices. These issues deal with designing for large and small screens, integration versus stand-alone devices, and mobile devices and the myth of doing anything from anywhere at any time.

Because we are dealing with design for technology with physical and functional limitations compared to the PC, we need to put some serious effort into understanding what this means in terms of devising new interaction paradigms and information visualisation-develop new design principles in general. This, however, is outside of the scope of this dissertation but I will give some pointers towards what these design principles should encompass in relation to the role of the mobile device in the specific work environment, i.e. process work. The concrete design prototypes from the CIS project embody different aspects of the discussion presented here, see: [Nielsen and Søndergaard, 2000, Bertelsen and Nielsen, 2000][P4,P5].

\subsection{My contribution in the scope of things}

With this framing, I see my work contributing to the existing body of work in the following ways.

Firstly, that much work relies on a certain degree of mobility is not a new insight and studies of mobile work has been done, particularly within the field of CSCW, in many years. What is new is the rapid development of mobile technology which gives us the choice between many new alternatives for mobile computer support for mobile work and which, most importantly enables us to move away from the desktop computer in doing so. What has been missing in the research efforts in this area of mobile technology so far is a focus on how the different technological artifacts should relate to each other. Most mobile devices are designed and treated as stand-alone devices which seriously cripples any effort to see them in a larger context because it makes it impossible to gain any insights in which role they should play in relation to already existing technology when introduced into our work or life. In his provocative book "The Invisible Computer"'[Norman, 1999], Don Norman declares the personal computer dead because it has become too complex for anyone to use satisfactorily. Instead he proposes that "information appliances", i.e. task-specific, easy-to-use devices like ordinary household appliances will save the day and us. These devices should apart from being dedicated to a specific activity have the ability to "share information amongst 
themselves" [Norman, 1999], and thus work seamlessly amongst and to some degree with each other in a large, pervasive network not unlike what Mark Weiser envisioned in 1991 [Weiser, 1991]. Critical voices have attacked this vision with comical pictures of e.g. a man explaining a car accident to a police officer with a story of how the coffee pot at home had tried to tell his PDA that to buy some more coffee and the car overheard the message and took it as a command to turn for the grocery store there and then. However, I think they're missing the point of what "sharing information amongst themselves" means because it does not call for full control of the decision process to be transferred to the information appliances as the exaggerated comic strip implies, it opens the possibilities for the devices to transfer and receive relevant information at the bidding of the user. This discussion is essentially one of control and who has it, a topic we have met many times before, e.g. reflected in the debate of the 'push' versus the 'pull' approach when dealing with information retrieval. I am not arguing that Norman's vision will be easily implemented —it is problem-ridden on several levels on top of the obvious technical—nor do I even agree with Norman when he declares a general purpose tool as the PC for impossible to use, but I do applaud that he in his vision has made room for the fact that we will need to be able to relate these devices to each other and that they will change role depending on which use context they are put into. With this dissertation, I bring focus back on the need for relating the computer-based artifacts present in a work environment to the technology we wish to introduce as a natural part of the systems development process in order to be able to create design that takes full advantage of the different, often very heterogeneous technologies. I have chosen to refer to this relationship as the 'web-of-technology' and because this is a central concept in my dissertation, I will discuss it in relation to several different aspects of my work. First, I relate it to my theoretical basis in Section 4.2, second, I use it as a tool of analysis of the process work in the CIS project in Section 7.1.3, and finally, I discuss it as a means of guiding design of mobile technology to support mobile work, both in relation to a concrete example in Section 8.2.1 and as a more general concept in Section 8.3

Secondly, the field that encompasses mobile technology is still in its infancy and developing rapidly so we have not yet seen a stabilisation of devices that allows us to draw up design principles in general for this group of devices. Whether in fact it will be possible to create a 'desktop metaphor' for the mobile devices, is too early to tell, especially with the current development of embedded software whether we call it 'information appliances', 'ubiquitous computing' or 'pervasive computing' where the nature of the user interface changes completely. There is a need, however, for investigating into interaction paradigms as well as interface design, particularly information visualisation principles in relation to these palm-size (or smaller) devices, like electronic organisers, communicators and mobile phones in general, both simply because a systematic analysis of these areas have not been undertaken yet and because design still, to a large degree, is done ad-hoc and though it often is related to a specific work situation, the design is developed as if the device should be treated as a stand-alone unit regardless of the existing technological support for the tasks. While developing design guidelines for interaction and user interface design is outside of the scope of this dissertation, I present an overview of the current work in these fields in Section 8.1 and show how we have used these insights in our own efforts in designing mobile support for wastewater treatment in Section 8.2.

Finally, a touchstone in the usability work practise presented in this Chapter is the understanding that usability practise itself must continuously develop and improve to 
strive for creating increasingly better conceptual tools for design as the nature of work (and life) changes in our culture, the development of new technological support gives us new possibilities and limitations to work by and with, and we grow as a community. The overall goal of the BIDI project has been to facilitate changes in usability practise, both for us as a research community and for our partners in industrial design. With this dissertation, I present some of the most important outcomes of this effort, dealing with cooperation in highly heterogeneous groups, active user involvement in the design process, using the work environment as a resource in design and showing how the field and the lab can mutually inform each other. Chapter 6 gives a general discussion of the development of usability practise grounded by the concrete experiences from the BIDI project. 


\section{Chapter 4}

\section{Theoretical basis}

Even though theory and practise have often been presented as each other's opposite, I have always treated them as mutually dependent. Theory is a vehicle to reflect and develop on the principles and procedures that constitute our common knowledge base as a group or community of practise. The role of practise is to thoughtfully use this knowledge toward the solution of problems and the creation of better support for our everyday tasks and through this process produce new insights to be entered into the theoretical foundation.

Our theoretical foundation and practical work will always mutually influence each other. Even when we are focusing on 'doing', e.g. studying or designing, the theory reclines as an invisible backdrop, subtly guiding or influencing us. It is the platform under our feet or the glasses we look at the world through and it cannot but affect our vision and actions. Similarly, the things we produce change our understanding of the world as they change the work practise they are introduced into. 'Things we produce' can in this context be new methods for designing or doing usability, developing visions for future use, or creating prototypes or designs. This ever-alternating dialogue between what we think and what we do can be compared to the view of learning as described by Schön in [Schön, 1983], namely as providing both opportunities to "learn by doing" in concrete instances, and being able to "learn by reflecting", that is, articulate the practical, tacit knowledge when immersed in a situation and use this as basis for improvisation or re-adjustment.

I will try to explore this relationship throughout the next three Chapters. In this Chapter, I will continue the discussion of the relationship between theory and practise by introducing concepts from the activity theory framework which has formed the theoretical foundation for most of my work since (and including) my Master's Thesis [Bouvin et al., 1996]. I will end this Chapter with a discussion of how this theoretical foundation relates to mobile work and mobile technology, particularly the concept of 'web-of-technology'. Chapter 5 will give a presentation and discussion of my research considerations when engaging in action-oriented research and thus focusing on research 'in practice' and 'of practice'. Finally, Chapter 6 will discuss different techniques for usability practise to serve as change agents in other work practises and 
present concrete examples from the BIDI project.

First, I will give a brief presentation of some of the key elements in the activity theory framework which makes it possible to develop an understanding of how design and use are interlinked. I will base my presentation on both older and more recent research efforts that exemplify this relationship and will for this purpose assume the reader has a basic knowledge of the terms and concepts belonging to the Activity Theory framework as described in e.g. [Bardram, 1998, Bertelsen, 1998, Bødker, 1991, Engeström, 1990, Engeström and Middleton, 1996, Nardi, 1996]

\subsection{A foundation for analysing meaningful human work}

Vygotsky describes human activity, the fundamental unit of analysis in the Activity Theoretical framework, through three basic characteristics:

- it is directed towards a material or ideal object which distinguishes one activity from another

- it is mediated by artifacts (tools, language, etc.)

- it is social within a culture.

In this way, computer artifacts, like all other artifacts, mediate human activity within a practice. We, as human beings, gain knowledge about the world through dialectic reflections of the activities which in turn form our expectations of the world. This describes the basic dialectical relationship between the human being and the world, the subject and the object.

An Activity Theoretical analysis of human work provides an understanding of both the details of the structure of human activity and the socio-historical context within which the activity takes place. The historical perspective is necessary to understand how a workplace culture has developed-its values and beliefs have grown out of experience which are traceable through the artifacts, division of labour and rules and language that embody the work practise. The social perspective is necessary to describe the socially constituted practices and communities we are part of or wish to gain access to, and to understand the division of labour, rules and language belonging to a specific work practise.

\subsubsection{Mediation, transparency and breakdowns}

A key concept in understanding human work is, as stated above, mediation: the subject is mediated by tools, both physical tools like hammers and psychological tools like language, culturally determined rules and division of labour, aiding the subject in achieving or working on the real object of work. Tools can be seen as crystallisation of past work practise, shaped and re-shaped to evolve with the work tasks (object of work) as e.g. better materials for tools are made available or the conditions of work changes.

[Bødker, 1991] emphasises that tools are not intended to be the object of work itself and can only meaningfully be discussed in relation to the use situation and the object of use.

To the users, artifacts are what they are meant for. [Bødker, 1991, p. 34] 
This relationship is also described in [Mogensen, 1994] where Mogensen uses the distinction defined in [Heidegger, 1996] to distinguish between artifacts or "equipment" encountered in purposeful and involved engagement, being ready-to-hand (zuhanden) and equipment encountered in detached reflection, being present-at-hand (vorhanden). For equipment to contribute in the work it must withdraw itself from our focus. When we use equipment in purposeful and involved engagement, what we are concerned about is not the equipment itself, but the work to be done through it. The equipment is, so to speak, subordinated to an "in order to...", a purpose; the equipment is ready-to-hand. A very similar account of the same issues was voiced in [Winograd and Flores, 1993], being amongst the first to use Heidegger's ideas as a foundation for a new understanding of design. This relationship furthermore echoes the idea in Activity Theory of transparency in the interaction, which is the ability to work through the artifact rather than with it, letting the user focus on the real object of work as effortlessly as when using a hammer to drive in a nail.

Breakdowns in interaction are thus seen as shifts from artifacts being ready-tohand to being present-at-hand. [Bødker, 1991] distinguishes between breakdowns and focus shifts where breakdowns are forced by the artifact and focus shifts are conscious shift of focus by the user from working through the artifact to focusing on the artifact. Furthermore, to understand the nature of the breakdown it is necessary to identify at which level of the hierarchical structure of activity the breakdown or focus shift occurs: from the level of operation to that of action or from the level of action to that of activity.

When we design computer support for a given work practise we strive for it to become "ready-at-hand", allowing it to be used unconsciously as a means for obtaining another objective. However, we also need to support the ability to recover from breakdowns and this should according to [Ehn, 1988] be done partially by using breakdowns as a valuable resource in understanding the work practise. The breakdowns can be seen as discrepancies between the intended design of the artifact and the situated practise and used as tools for learning.

"The ability to deal with this contradiction between understanding of the ready-to-hand and detached reflection of the present-at-hand is fundamental to design. I shall later refer to this as "the dialectics of tradition and transcendence in design”. [Ehn, 1988, p. 66]

Thus, as designers of computer-based artifacts we strive to avoid breakdowns, and when they do happen, support recovery from them. However, we also need to take into account the development of the computer-based artifact when put in use. Just as the artifact will affect and change the work practise, the user will actively adapt the artifact for their own purposes, a relationship which is key to Activity Theory and which has been dealt with in other branches of research, e.g. by Mackay who in [Mackay, 1990] who argues that people and technology is in this sense co-adaptive. So how do we support the learnability and flexibility of the artifacts we design to extend to the actual use environment?

[Bardram and Bertelsen, 1995] presents a framework for looking at transparent interaction as it is developed by the user during the use activity. Their approach puts focus on the importance for creating the right conditions for achieving transparency in the design of artifacts by rejecting the notion that transparency is a property of the interface itself, but is reached only when specific operations are triggered by e.g. the material or physical conditions in the use situation. They formulate the following three conditions to be present when designing for transparency, namely supporting develop- 
ment in use, ensure an initial familiarity with the artifacts and the use situation, and set conditions for the formation of new operations.

Learning in use is also the focus of [Bødker and Graves Petersen, 2000], which uses the activity theoretical framework to provide a methodology to support the design of learnable artifacts.

\subsubsection{The social aspects of work}

"It is necessary to deal not only with the relation between the human being and the computer, but also with the surrounding conditions of work" [Bødker, 1991]

To understand a work practise in order to design for it or otherwise be a change agent in it, we have to consider that work is done within a culture and is highly situated and consider how this shapes our world view. Mogensen presents a Heideggerian notion of time to describe this relationship:

"First and foremost we are directed towards the future; in this directedness we are bound to the historical context in which we are situated (the past); in this mutual constituency between the future and the past, we are present in our purposeful engagement." [Mogensen, 1994, pp. 147-148]

This dialectic relationship has different consequences for how we act. First, it implies that we never approach a new field as a blank slate but with our past experiences as conceptual 'luggage'. Second, that the constraints and possibilities we perceive in a particular situation are historically determined. Third, that when we analyse a practise or design for it, we are in the world and not detached from it and thus our actions cannot but be influenced by the practise as it changes as will our design change the practice. But above all, our practise, our actions and our visions of the future should be approached with a respectful understanding what has been. Mogensen argues that we need a dialectic relationship between our directedness towards the future and our existence as historical being and that the Activity Theory approach to design of new technology is in constant fear of being stigmatised by the past. I, however, see no such discrepancy between the definition quoted above about the relationship between what has been and what is to become and the understanding of human activity as historically grounded but directed towards the future described by the Activity Theory framework. When a new product is introduced to a user activity system, it affects the different components of the system. An activity theoretical analysis of the different types of problems, contradictions and opportunities in the context of use as described e.g. in [Engeström, 1987] helps to show not only the existing needs and opportunities but also the impact of the new product to the everyday life of the user. Activity theory offers tools to analyse the problems and possibilities of technology. The developmental work research branch of Activity Theory has, based on the notion of expansive learning, for years worked on developing methodologies and techniques for transforming work practise through an interventionist approach aimed at helping practitioners analyse and redesign their activity systems.

The notion that work is inherently a social activity and therefore can only be understood fully when looking at the social, organisational, technical and historical context a person is part of when working is pivotal in the activity theory framework but it is an understanding which also resonates in the sociological and ethnographic spheres when 
it comes to developing a theory of human work.

In her critique of efforts in cognitive psychology to produce formal, step-wise descriptions of work, Suchman introduced the idea of plans as communication where the plan is not an all-encompassing description of action, but situated, i.e. sensitive to, and interactive with, the current circumstances so as to orient action, not dictate action in detail.

"The coherence of situated action is tied in essential ways not to individual predispositions or conventional rules but to local interactions contingent on the actor's particular circumstances.'[Suchman, 1987, p. 27]

I.e. human actions are not always guided by clearly defined plans, but are based on actions within specific situations-when the situation and available resources change, we need to be able to reconfigure ourselves to meet these new demands in a way that formalised plans cannot encompass.

Being able to reconfigure oneself is not only a matter of having the right tools available, but understanding which efforts are necessary for dealing with the new circumstances. In this, learning is a key concept.

Vygotsky describes learning as a collaborative and socially mediated relation, which he denotes 'zone of proximal development'. More specifically, the zone of proximal development describes:

"the distance between the actual developmental level as determined by independent problem solving and the level of potential development as determined through problem solving under adult guidance or in collaboration with more capable peers" [Vygotsky, 1978, p. 86]

e.g. the difference between what a child is able to do on her own compared to what she can do with guidance. Thus collaboration helps individuals to make progress through their zone of proximal development by the joint activity in which they are engaged.

In [Lave and Wenger, 1991] learning through apprenticeship is very visible. Learning is defined as a process of participation in communities of practice and is thus social in nature. Learning occurs as newcomers gradually increase their participation in communities of practice and gain access to a wide range of ongoing activities and resources in the form of interactions with masters, other newcomers, information, and opportunities for participation. Situated learning is often incidental rather than deliberate as the beginner moves from the periphery of this community to its centre.

Also inspired by Vygotsky (amongst others) is Engeström's notion of expansive learning [Engeström, 1987]. However, Engetröm focuses on the conflicts and different levels of contradictions inherent in an activity system and between the basic activity and other, connected activity systems, which is not present in Vygotsky's work. Using e.g. Bateson's hierarchical levels of learning [Bateson, 1972] and Wartofsky's hierarchy of primary, secondary and tertiary artifacts [Wartofsky, 1979], learning, in Engeström's terms is a process of identifying and analysing the contradictions in the activity system to traverse the zone of proximal development. 


\subsection{Activity theory and mobile work}

Supporting mobile work is not a matter of choosing one technology or system over another, but to provide a whole range of devices or tools to meet the changing needs of the user as he is exposed to a number of different work environments. Working at the home office is radically different than working out on a plant or at a customer's site, and so are the resources you have available as well as the nature of the tasks you perform in the particular environment. To deal, not only with design but design of potentially heterogeneous devices demands an analysis of more than the work practise and work environment; we also have to take the relationship between the different types of (possible) technologies, their possibilities and constraints, into account when designing for a mobile work setting, and thus I re-introduce the web-of-technology concept.

The web-of-technology concept is weakly supported in the activity theory frameworkwhat is emphasised in the model is the relationship between the subject and the object mediated in a social context (the subject and the world). When we look at human activity as the smallest unit of analysis we lack the means of clarifying relationships between different mediating artifacts within this structure, which makes it very difficult to utilise the web-of-technology concept as a supplementary tool for analysing the work practise as an integrated, natural part of an activity theory based analysis. However, this is a question of granularity rather than inapplicability. The web-of-technology concept does not belong as a core constituent in the definition of human activity; it is a means of analysing a technical relationship which may feed into the primary activity system. Thus, introducing a web-of-technology analysis is perfectly compatible with the Activity Theory concept which takes into account both shifts in work setting and resources as described above. I see the use of the web-of-technology concept in line with other tools for analysis derived from the Activity Theory framework such as focus shift analysis. 


\section{Chapter 5}

\section{Research method}

I belong to the action-oriented research tradition that has grown out of the Scandinavian cooperative design tradition which I will sketch the development of in Section 6.1. However, working within an action- and work-oriented [Ehn, 1988] tradition poses some questions in relation to how research is done and indeed what constitutes research in a field oriented towards design of (particularly) computer support for aspects of a work practise. As stated in [Bertelsen, 2000]:

"Information systems development, human-computer interaction, computer supported cooperative work and other fields related to the design and use of computer artifacts, build on a broad range of disciplines from cultural analysis through programming and hardware construction. Because computer artifacts eventually are to be used in the real world, research in these fields tends to emphasise relevance over scientific rigour. Our field is a hodgepodge, where it is hard to say that one result of research is better than another one; it easily becomes a matter of taste."

Does this mean we should give up any notion of doing research within the actionoriented tradition, because research results in an area which is design oriented and interdisciplinary are more or less a matter of opinion? Of course not. However, it does mean we have to deal with a more nuanced picture and our research agenda must reflect the diversity and complexity of the different voices in play. Star in [Star, 1996] describes this shift in research as:

"We know that, in spite of the failure of rationalism, the world does not fall apart. We've begun to understand that the absence of a monolithic voice does not mean chaos or babble, but pluralism, and that requiring translation. Having walked away from several important dichotomies (including organism/environment, individual/collectivity, mind/body, formal learning/everyday practice), we've learned not to replace them with mysticism, but with an analysis of novelty as it arises in communities and other collectivities." (p. 313)

I will focus on the research problems we may encounter in relation to the area we work within being interdisciplinary and design oriented

Furthermore, I will look at the research challenges that emerge when introducing aspects of mobile work in action-oriented research when there is no established practise or community of research. 
In the following, I will discuss these issues by relating them to existing voices in the $\mathrm{HCI}$ and CSCW research communities, specifically the work of Bertelsen [Bertelsen, 2000], Bødker [Bødker, 1999], Ehn [Ehn, 1988], Engestrom and Middleton [Engeström and Middleton, 1996], Mackay [Mackay and Fayard, 1997, Mackay, 1998b] and Mogensen [Mogensen, 1994]. In this context I will draw upon the theoretical considerations presented in Chapter 4 to anchor the discussion to my theoretical basis.

\subsection{Interdisciplinarity and design orientation}

The action-oriented research platform with its roots in the Scandinavian research community has evolved as the HCI and CSCW communities have grown and gained importance in information systems development and development of computer-based support for human work in general.

The emphasis on interdisciplinarity and a strong focus on design of technological support of a given work practice and thereby on change as an important factor (as opposed to "just" gaining an understanding of the practice) reflects two basic presuppositions in this approach (taken in the opposite order): first, that we as researchers and usability professionals engage in a project with a user organisation because there is a need in the user organisation to improve, develop or change aspects of the practice. This may be due to technical developments, competition, organisational re-arrangement or other internally or externally determined factors. Second, that the development of e.g. computer-based artifacts to aid this change process must include all the stake-holders in the project, ensuring a democratic and informed process that draws upon all the different groups of expertise available to us to ensure the best possible result. This is also the case if the changes we are seeking are of a more methodological nature, e.g. in the sense of organisational changes to aid knowledge building within the organisation.

However, when we introduce the notion of crossdisciplinarity in research, we also face questions of research validity as pointed to by the quote from [Bertelsen, 2000]. [Mackay and Fayard, 1997] describes the dilemma we face as:

"How do we decide among the multitude of paradigms to us? Unlike researchers or designers working within a single academic discipline, with well-established procedures for conducting their work, we find ourselves constantly borrowing, inventing and re-inventing techniques as we go. We draw from both science and design and must be able to converse with researchers and designers completely immersed in their individual disciplines. We work at both applied and theoretical levels [...] Because we create working prototypes, we select the methods that seem most appropriate for the problem at hand. At the same time, we must conduct our work in a way that is fundamentally sound at the level of each discipline we draw from and viewed as legitimate by our academic colleagues." (p. 223)

Mackay and Fayard argue that HCI neither can be seen as purely a science nor a design discipline because the focus is on the interaction between humans and artifacts. HCI presents an integration between the two disciplines, a new research direction in which they see triangulation, i.e. the use of different methods to address the same problem, as key. However, the question remains, can the results we produce using methods and theories borrowed from other research disciplines and re-applied in a new setting be considered to be valid? As argued by [Mackay and Fayard, 1997], the key 
point in this debate is not whether a particular study is "scientific" enough but a matter of determining the borrowed techniques relate to each other and

"understand enough about each approach and the corresponding assumptions to be able to choose which is most appropriate for addressing a particular design problem" (p. 225)

Because theories or techniques are not static entities, unchangeable and eternal, but evolve as our understanding of the work domain and circumstances change, we should be considered less with the 'truth' of them and more with how usable they are in the new context. When a theory, technique or design method is integrated into a new field, we have to consider that it may very well serve purposes that are different from the original intended and undergo adaption when applied in the new field. Thus we have to re-evaluate the results of the adopted theory or technique based on this understanding. The real test of the theory or technique thus becomes whether it is applicable in use, a position also taken in [Bødker, 1991].

The quote from [Mackay and Fayard, 1997] points towards another challenges posed by a design-oriented and interdisciplinary approach other than keeping a balance between the practically relevant and the theoretically sound, namely being able to communicate properly with participants "completely immersed in their individual disciplines".

The aspect of communication in cross-disciplinary project relates to what [Star, 1996] referred to as "pluralism needing translation", requiring the establishment of a common understanding between the participants in a cross-disciplinary project. This refers to the oft quoted declaration by Wittgenstein:

"If a lion could talk, we could not understand him" [Wittgenstein, 1958, p. 233]

which points out that the meaning of our words are inseparably connected to our use of then-our practise and culture. Mogensen deals with this discrepancy or potential pitfall his PhD dissertation [Mogensen, 1994]

"We know the artifacts or words from our own practises, but their meanings seem to be different because they are used in another practise for different purposes." (p. 84)

He uses this insight to stress that when researchers (or 'analysts', to use his term) enter a new practise and attempt to understand the artifacts and concepts that are utilised there we have to do this through addressing the specific usages. Thus in a cross-disciplinary research context we need means for bridging this gap in terminology and build a common understanding of the domain we are currently engaged in. How this may be achieved, I shall discuss later in this Chapter.

First, however, I will return to the focus on design in action-oriented research.

[Ljungberg, 1997] identifies a number of problems relating to what he denotes as 'the interdisciplinary transfer of theories', that is, the use of theories in an interdisciplinary research area which has originated from a contributor research area. The most interesting problem he mentions in this context is that most 'imported theories' do not look at the design aspects of information systems research 
"Unlike the humanities and social sciences with their interests of understanding what has taken place, we are interested in what is to come." (p. 49)

However, I think the point is that we need both; we need to understand what has taken place to anticipate what is to come. The Activity Theory framework enable us to look at both the historical development and the social structures of work in its real context as integral and natural parts of design of e.g. computer-based artifacts. We need to be able to take these aspects into consideration because, as stated in [Ehn, 1988], design of artifacts is more than designing the physical "thing"; we also design conditions for human use. We design the social as well as the technical aspects of an artifact. Design and use has to be interlinked to achieve this relationship, as does theory and practise, or in Ehn's words:

"As I see it, work oriented design of computer artifacts has to be not only theory but also practise for social and technical change." (p. 6)

Seeing design and use as interrelated naturally calls for new developments in the methodological 'tool-kit' to draw the two close together. When we stop seeing the design process as something that can be informed by but otherwise isolated from the use setting, we start looking towards techniques that allow us to take advantage of the use setting throughout the design process and allow future users to participate more actively in the design process. Ehn emphasises the need for new methods that involves future users as key resources in design

"I also claim the importance of rethinking the use of descriptions in design, and of developing new design methods that enable users of new or changed computer artifacts to anticipate their future use situations, and to express all their practical competence in designing their future. The dialectics of tradition and transcendence - that is what design is all about" (p. 7)

This development has been key in my work, both on a theoretical and a practical level; theoretically, through the stronger focus on use as part of design in Activity Theory, a development sketched in [Bertelsen and Bødker, 2002](in print) and practically, as a specific goal in the development of usability practise in the BIDI project, which I will describe in Chapter 6.

A fundamental question in design in action-oriented research thus becomes to get access to the 'ready-at-hand' information about artifacts and the unarticulated and culturally or socially embedded properties of a given work practise- the 'taken for granted'. Mogensen describes this problem in [Mogensen, 1994] as:

"In a situation of analysis for change on the contrary, it is a necessity to draw attention to our everyday handling of our means as well to question and challenge our reasons for doing so. [...] these questions cannot be addressed by observation alone (this yields the what and perhaps the how but not the why), nor by asking only individuals, we have to 'ask' the practise" (p. 110)

Drawing together some of the aspects of a interdisciplinary and design-oriented research discipline I have tried to sketch, Bertelsen [Bertelsen, 2000] presents the concept of design artifacts as the first step in developing a design-oriented epistemology. 
This approach is capable of dealing with issues of heteropraxiality and heterogeneity in design, issues of construction versus representation and issues of prescribed practice versus real use. Design artifacts mediate across three dimensions of design, based on Wartofsky's classification of primary, secondary and tertiary artifacts[Wartofsky, 1979]:

- Construction - the productive relation between the designing subject and the object of design

- Cooperation - the representational relation between subjects involved in design

- Conception - the dialectic relation between the designing subjects and the historically developing activity

In addition to dealing specifically with the three issues described above, Bertelsen argues theories, being the natural outcome of research, are also design artifacts and thus mediators of design, a view supported by [Bødker, 1999], stating that the most useful place for theoretical concerns is as sparring partners in reflection. Understanding theories as design artifacts makes the issues of interdisciplinarity and design-orientation in research easier to handle because they become balanced against the concern for practical relevance voiced earlier.

"Design artifacts mediate across the heterogeneous rooms of use, design and research, and across the multiple dimensions of design. The concept of design artifacts contributes to an understanding of the mechanisms underlying the intertwinement of different groups and professions in the networks of use, design and research activities, by maintaining focus on material mediation. The concept of boundary objects has been extended to denote mediation across situations, and not only across heterogeneous groups. Crystallisation and design as transformation of artifacts are mechanisms build on this extended meaning of boundary objectness across historical generations of the same practise. Understanding how design artifacts are extended boundary objects may be a resource in the understanding how knowledge can be transferred, or transformed, from research to practise and vice versa." [Bertelsen, 2000, p. 25]

The importance of tracing continuity and change within a work practise as well as between work practises, and the reflexive relationship between research method and practice voiced in [Engeström and Middleton, 1996] are clearly addressed with Bertelsen's design artifacts. In terms of needing an approach which enable us to understand enough about the different disciplines to be able to utilise their methodology in addressing a particular research (or design) problem and maintain a design-orientation without compromising the integrity of the research discipline as such, I see Bertelsen's Activity Theory based approach as a very promising step in the right direction.

Standing as a researcher in an interdisciplinary space between design and use, research and practice thus may seem somewhat of a balance between hopeless complexity and useless blandness of mixed disciplines. As a research community, actionoriented research is still developing its boundaries, 'rules' and orientation. Maintaining the balance between the theoretically sound and the practically applicable is a challenge, but one which has been met with enthusiasm from the participating disciplines. The combination of e.g. activity theory and situated action, seems to yield interesting insights for this community as do other combinations, such as the 'marriage' of activity theory, interactionism and informations-systems research as proposed by [Star, 1996]. 


\subsection{Mobile work research}

To complicate matters further, I have moved into the area of mobile work for which no well-defined research practice exist. This is partly due to the rapid development in mobile technology and the fact that there is a general lack of systematic analyses of the existing theoretical frameworks in relation to mobile technology. Will the conceptual models we build of the world, based on our theoretical understanding and practical experience, hold true when we move away from a stable work environment and have to relate it to mobile technology as a mediating artifact for supporting mobile work? Will the conceptual model be able to encompass the different and often highly heterogeneous technologies used in the same work context depending on the work task for the changing work environment, and be able to describe the relationship between these technological devices? Mobile work, as stated earlier, is characterised by changes in the available resources depending on where you are and what your focus is - the only thing we know for certain is that the user is not always at his desk in front of his PC. Thus, we need to consider how mobile work and mobile technology affect how we describe and model that work and if these models are able to describe the complexity in the work to a degree where we can use it for design of the technological devices needed to support it. A systematic analysis of e.g. activity theory in this respect is, however, outside of the scope of this dissertation. 


\title{
Chapter 6
}

\section{Developing usability practice in the BIDI-project}

\author{
"Let's return to my suggestion that we replace the word "user" with \\ the word "actor". I like the word actor because although actors have a high \\ degree of self-determination in what they do, they do their thing among an \\ amazing variety of other specialists doing theirs. There's the writer of the \\ screenplay, for example. The screenplay holds a film together. Without a \\ screenplay, no film would ever get made. A movie also has an amazing ar- \\ ray of specialised skills and specialisms - craft experts-such as the light- \\ ing and sound guys_-and all those "best boys" and "gaffers" and "chief \\ grips"-who know whatever it is that they do!" \\ John Thackara on seeing the participants in a design process as a movie \\ crew
}

This quote from John Thakara's keynote speech from 'CHI 2000-The Future is Here' in the Hague touches upon a central theme in my work, namely that design is a cooperative, iterative process which crosses boundaries between work practices and which must involve active participation from a wide range of contributors e.g. users, designers, usability people, engineers and architects.

Consequently, the techniques for supporting design in interdisciplinary groups must support this "multi-voicedness" [Engeström, 1987] by creating an open and dynamic design space for all stake holders. The concern for the necessary heterogeneity in design and usability work has been voiced earlier, e.g. in [Robinson and Bannon, 1991] . However, though they make a good case against seeing models as a sufficient basis for CSCW design, they only provide vague pointers to what might be done instead. I sympathise with [Kapor, 1996], which calls for making "software design" a profession in it own right where the practitioners work as "champions of the user experience", but I think it is the wrong way to go. I believe that a conceptual segregation from 'design practise' and 'use practise' will only cause the process to appear even more fragmented; what we need is a more integrated approach where skilled people from the design domain, the use domain, the usability domain and every other relevant domain come together much in the way Thackara describes a movie crew. In the usability work I have been engaged in e.g. within the BIDI-project and in the wastewater treatment project, I and my colleagues have sought to engage users actively, making them equal partners in the design process on the same terms as other stake holders in the design 
process.

The BIDI project presents a unique meeting between Danish HCI research within the academic world and Danish industrial usability practitioners. It was the first project in Denmark to specifically target usability methodology as it is being practised in different companies and to use shared experiences and the different backgrounds to develop design and usability practice. Based on the action-research approach, several projects over the three year period that BIDI spanned were planned, executed and shared. The degree of coordination between the participating groups varied from design workshops with participation across the different communities in cooperation with users, software designers and marketing people from the specific project domain to coordinated field studies where experiences were shared through a series of workshops with e.g. guest researchers, presenting different usability methodologies.

To support the triadic structure of my work as presented in Chapter 3, the process must reflect the relationship between the constituents in the techniques we choose. Thus it requires an empirical base to understand the mobile work environment, and an experimental approach to both the (introduction) of new technology and to the usability methods we apply in the design process. More precisely, it sets the following demands on the techniques used:

- they support work 'in context' in the 'real world', i.e. they let us look at and work with real work settings, realistic work scenarios and real users. As argued in [Mogensen, 1994]:

"We cannot observe the ready-at-hand aspects of equipment, so in order to understand an artifact we have to understand its actual uses for specific aims (the 'in order to...')—-we cannot understand it through its 'outward' characteristics." (p. 223)

This can be supported by a qualitative research approach which allow us to build an understanding of the actors and the actions within the project.

- they have to handle mobile work, not just work in an office setting with a stationary PC. This can only be supported by working in the field, through observation of use, participatory workshops and by designing from real work situations in a cooperative setting.

- they must make available concrete implications for design and reflect these in the prototypes built, and thus provide 'proof of concept' for the design ideas developed in the project.

Before I present how these demands have shaped my work with usability and design, I will give a brief account of the shaping of the cross-disciplinary field of cooperative design and human-computer interaction, which is 'the Scandinavian school of systems development', the research community with which I associate myself the most.

\subsection{The Scandinavian approach-from the $70 \mathrm{~s}$ to the present}

"As early as 1970, Kristen Nygaard had a vision about a new kind of co-operation between researchers, system developers and trade unions. 
This was a time when the social use of computers was not seriously questioned. If treated at all, the question of computers in relation to democracy at work was shoved to the side and taken up in so called "wild sessions" at conferences.

Nygaard had the ideas and energy to change this."

Dedication to Kristen Nygaard in the Preface of [Bjerknes et al., 1987, p. ix]

Democracy, user participation and an understanding that human-computer interaction encompass more than looking at the relationship between the human information processing unit as it sends input and receives output from a similar, logical construction in the computer are core constituents in the approach we have come to know as 'The Scandinavian school for systems development'. The name itself refers to the first generation of projects dealing with these issues in Denmark, Norway and Sweden in the late seventies and early eighties. However, it describes a meeting of worlds and broadening of understanding rather than a narrow, geographically defined relationship.

The first generation of projects were the so-called 'trade union projects' which started with the NJMF project in Norway, where the key project was a collaboration with the Norwegian Iron and Metal Worker's Union [Nygaard, 1979]. Building on the experiences from the NJMF project, the DEMOS project in Sweden and the DUE project in Denmark developed as 'twin projects'. The DEMOS and the DUE project looked at very similar work environments, i.e.they both did studies of office work within a large department store and work at large industrial plants as well as collaborate with parts of the trade unions movement in Sweden and Denmark. As such, these two projects were quite similar both in research topic, methodology and with regards to the research goals.

If we are to look at the three projects as the first generation of cooperative design they share the following, basic characteristics: They were amongst the first to question the development of computer support from a managerial perspective as being in conflict with the needs of the end users. They strove for a democratic research and development process in which they saw researchers as having the duty to support those with less power and resources. They also claimed that, when not reflecting on their role, researchers often support those in power. Thus these projects were an effort to gain more influence on the development of technology brought into the workplace for the actual users of the technology. [Kyng and Mathiassen, 1982, Ehn, 1993]

This perspective was further developed in the second generation of projects of which I will mention two. The UTOPIA project, which was a collaborative design effort with newspaper production staff with the purpose of designing integrated computerbased text and image processing systems for newspaper production, and the MARS project, which dealt with systems development projects in an effort to rethink the systems development process, introducing different techniques for supporting e.g. the relationship between product-oriented and process-oriented aspects of the development process. The UTOPIA project took the cooperative design ideas and used them as the basis for concrete design techniques, using future workshops to envision the future use of technology, mock-ups and prototypes to provide hands-on experience with the technology in development, user scenarios to ground the design in the concrete work practise and organisational games to gain a shared understanding of the work between users and system designers, just to mention a few. See [Bødker et al., 1987] for more detailed accounts of the project. The MARS project with its focus on managing the 
development process produced tools for analysing the organisational structure in order to deal with the forces inside and outside the project group and organisation that affect the development process.

The ground breaking book "Design at Work" from 1991 collects accounts of the experiences from these first two generations of projects which deal with treating design of computer-based technology as an open, innovative, user-involved, generally crossdisciplinary and thus multi-perspective cooperative process aimed at creating tools and systems to support work activities as they exist in their multi-faceted use context. I shall look closer at some of the previously mentioned techniques in relation to mobile work and the continuous development of usability methods in Section 6.3.

More recent research projects that build on this tradition are:

- The AT project (1990-1993) [Bødker et al., 1993a, Bødker et al., 1993b]

- The EuroCODE project (1992-1995) [Bouvin et al., 1996] ${ }^{1}$

- The Roskilde Festival project (1994-1995) [Bertelsen, 1996b, Bertelsen, 1996a]

- The BIDI project (1997-1999)[Buur and Bødker, 2000, Bødker and Halskov Madsen, 1998, Bødker et al., 2000, Nielsen, 1998] [P1,P2].

These we may collectively consider as belonging to 'the third generation and beyond' though the focus of the five projects are quite different.

This movement has formed the basis for a branch of research that still emphasises and develops the basic concepts for cooperative design to produce better technological support for everyday work, particularly within the research community I am part of at the computer science department at Aarhus University, but also on an international scale. The Participatory Design conference is one example of a research forum that is based on these principles of democracy and multidisciplinarity in the design process, design and use in context and social aspects of use and design. Built on this foundation is thus an impressive body of research, to which I hope to add this dissertation. Of these, I see my work most closely related to [Bardram, 1998, Bertelsen, 1998, Bødker, 1991, Grønbæk, 1991, Mogensen, 1994]

I will now turn from the past and look at how this design-oriented research tradition has been perpetuated by presenting our work in and relating to the BIDI project. I will in particular focus on the methods used in the design projects dealing with the design of mobile technology for process environments, though I will mention any relevant methods I have worked with during my time in the BIDI project. I see these as concrete examples of "springboards" in design [Engeström, 1987] or "triggering artifacts" [Mogensen and Robinson, 1995].

See [Bødker et al., 2000, Bertelsen and Nielsen, 2000] [P1,P5] for a more thorough presentation and discussion of the examples.

\subsection{Ethnographically inspired field studies}

Designing for supporting a work practice means we have to gain an understanding of the work practice and the use situations within which the technology we design is to be

\footnotetext{
${ }^{1}$ The evaluation of the High Road Demonstrator in the EuroCODE project formed the empirical base for my Master's thesis [Bouvin et al., 1996]
} 
entered into. In this, techniques from ethnography and sociology, such as field studies, using open-ended interviews, and videotaping and observing work, which have not traditionally been a part of the computer science 'tool-kit', have been an invaluable help in providing the essential insights into the environment for which we design.

Studying mobile work makes it even more important to take the development process into the field, because the work place itself is not fixed but spread throughout the work area at the different components and machines. We need to utilise the field not only in the early stages to explore the work setting and work practise but throughout the entire process. Using the field as an active resource in design e.g. doing workshops or setting up prototypes for evaluation enable us to see the effect the prototype has on the environment and what tools and other resources are necessary in specific work tasks. Furthermore, because we are studying mobile work in a process environment it becomes crucial to move away from the traditional office and control room studies e.g. [Mackay et al., 1998, Heath and Luff, 1996, Suchman, 1996] and find new techniques for studying and designing in a mobile context. The work we have been studying is characterised by being extremely distributed and mobile; for many of the wastewater operators their daily tasks kept them on the move, traversing the plant and taking occasional trips to the control room to verify or check status for a subprocess. Thus we are no longer able to set up two or three cameras with the expectation that they will be able to cover where the action is. As one of my colleagues so aptly put it:

Wherever you choose to put up a camera you will get the impression that things are happening somewhere else.

This has two implications for how we structure our field studies. First, it puts emphasis on being in the environment and experimenting with different 'shadowing' strategies such as following different workers, following a part of the process, following a document, etc. Second, it puts focus on the need for engaging the operators actively in the design process because they have the overview of the complexity of the work processes.

\subsection{Design and usability methods}

Design within the Scandinavian tradition is an open, explorative process using prototypes and mock-ups to provide hands-on experience with the object of design, metaphors and caricatures to inspire design and scenarios and work descriptions to anchor the design. Cooperative design or design within the Scandinavian school for systems development has always emphasised the need for user participation [Greenbaum and Kyng, 1991] as they are the experts in the work practise-better than anyone they understand the practical problems of the work we are trying to support. However, we need to move past the limited approach of collaboration between the designer, the usability workers and the users. The success of design, particularly of computer-based artifacts, is dependent on the ability to bring together all actors with valuable competencies related to the design process and the area of design, and support their voice in the design process, be that technical, aesthetic or sociological.

\subsubsection{Prototypes and mock-ups}

Prototypes and mock-ups are valuable resources in design, enabling the participants in the design process to express ideas and visions as tangible,physical objects. Physical 
objects have the advantage of being easily contextualised and used as a clear point of reference e.g. in comparison with other objects. There's a remarkable difference between saying 'it should be small' compared to 'it should not be any bigger than this'. Using mock-ups can help trigger work operations based on tacit, non-explicit knowledge which is otherwise impossible to access. Furthermore, prototypes and mock-ups from different stages of a projects provides a unique look into the development process and thus play an important part in the 'accumulation of design knowledge' in the construction and use of a design collaboratorium as described in [Bødker et al., 2001]. Similarly, prototypes and mock-ups from other projects can be introduced as a source of inspiration. An excellent example of the multiple roles of prototypes in design is described in [Petersen and Halskov, 1999, Bødker et al., 2000] [P1]. It presents a collaborative design workshop with participation from three different groups of participants: designers, usability workers and software designers. The participants in the design workshop had brought different prototypes of the products they work with to establish a common understanding of what different groups of participants were engaged in. During the design discussions, the different prototypes were used as resources in design, as objects of discussion and inspiration, to exemplify typical object of work, or as props for enacting use situations. Furthermore, different types of prototypes can accomplish different goals. Low-level mock-ups like simple Styrofoam blocks may be successfully used as basis for projecting a vision of piece of future technology by users by carrying it around in the work environment and describing a future work scenario. Blocks of wood or plastic wrapped in different materials without any computational function may be used to assess questions of shape, ergonomics and weight of the technological artifact. Higher-level software or hardware prototypes are needed later in the design process for specifying whether the information visualisation principles used are sound, whether the right information is made available and whether the information structure is correct and usable in the work context when we are dealing with the user interface aspects of design. In the CIS project we used several different kinds of prototypes, e.g. testing different visualisation strategies on paper. Later in the project we made software prototypes, implementing the chosen visualisation strategy on two different technological platforms and evaluating them with other researchers, designers and users at a workshop on the wastewater treatment plant. The concreteness of the software prototypes gave us useful feedback on the display layout and the relevance of information at a very detailed level. Details concerning the design process and the resulting prototypes can be found in [Nielsen and Søndergaard, 2000] [P4].

\subsubsection{Metaphors and caricatures}

Finding inspiration for design and introducing elements of creativity and innovation into the design process are highly attractive yet elusive and non-formalisable aspects of doing design. Using metaphors and caricatures to juxtapose apparently conflicting concepts and twist the familiar can aid us in unearthing new views of the design object and bring new inspiration into the design process. We have worked both with metaphors and caricatures built on a theoretical foundation as means of confronting the familiar and pushing design ideas beyond focusing rigidly on the work tasks they should support and allowing the participants in design to create a shared design space from which to proceed. The details of these efforts in relation to the BIDI project will be covered in Section 6.5 and for now I will look at the work forming our basis for using metaphors and caricatures, and work relating to our approach. 
Metaphors are extremely powerful tools for conveying meaning and intention into particularly graphical constituents of a user interface. Using existing artifacts as basis for a metaphor or building on existing metaphors are very direct ways of taking advantage of users' experience with a task or object and lift it into a new context. Furthermore, when we contrast different metaphors or use apparently unrelated and sometimes contradictory metaphors for a design object, like using a bowling alley as a creative metaphor in design of a CD rack, or look at a library as a meeting place and contrast this context with looking at it as a storage facility, metaphors become a source of inspiration rather than mere receptacles of previously defined meaning. I want to emphasise the work of [Madsen, 1994, Erickson, 1991, Laurel, 1986], which deal with these issues and others in relation to the creation and use of metaphors in the user interface.

Caricatures or extremes that take a feature or characteristic and exaggerates it to over-emphasise it and thereby makes it more visible are also excellent sources for inspiration in the design process. By exaggerating elements of the design or the use situation, like the plus- and minus- scenarios described in [Bødker, 1998] which emphasises and exaggerates the positive aspects of future technology and the negative, respectively, we provoke and confront different views on a problem and thus provide a strong focus on the consequences of a design or change in the work practise and avoid the bland middle-ground of indistinction. In particular, I find the use of caricatures which are based on theoretical structures particularly interesting as a source of inspiration and creativity in the design process because they allow us to reflect back on the theoretical assumptions as well as provide different perspectives to design through. Furthermore, theoretically founded caricatures provide a well-defined structure within which to work and provide a high degree of control in choosing what we wish to examine and thus map a design space rather than just trying out random characters. As described in Section 6.5.2, we have experience with using four theoretical perspectives of human-computer interaction described in [Kammersgaard, 1988] as starting point for four character-based interaction perspectives. These characters were used to emphasise different aspects of interaction in a setting based on real work descriptions and provided new views of what role technology could play when introduced into the work setting. Our efforts produced a creative design space which was negotiated and created by all the participants rather than actual, usable design prototypes for implementation. The details of this use of caricatures is presented in [Bødker et al., 2000] [P1]. These caricatures were later used in forming the interaction styles described in [Øritsland and Buur, 2000] which were utilised to inspire design of a handheld device for wastewater treatment. Using a theoretical structure as a metaphor in design can also inspire design as we realised when experimenting with using the three augmentation principles defined by [Mackay, 1998a]. Exaggerating the three distinctly different perspectives and relating them to interaction with physical objects using a PDA, we discovered new possibilities in interacting with a handheld device other than using a stylus and the screen. The details of this experiment is presented in [Bertelsen and Nielsen, 2000] [P5].

Others have worked with metaphors and caricatures in the design process and of these I would like to point out two new and interesting examples. The first is [Djajadiningrat et al., 2000] which describes how extreme characters and interaction relabelling can be used in the design process to produce new and quite radical ways of interaction with an everyday object. In considering how interaction with a gun could be 
transferred to the designing a new calendar the relabelling triggers new ways of thinking about interaction in general. The second is [Iacucci et al., 2000] which describes how role-play may be used in design of mobile technology.

\subsubsection{Scenarios and work descriptions}

Whether we refer to them as "work descriptions" and "future scenarios" [Kyng, 1999], "instances" [Christensen et al., 1998], "critical and typical situations" [Carroll et al., 1991] they all cover the concept of scenarios as examples of present or future work situations describing different elements of a work practise for different purposes.

Scenarios can play many roles in the design and development process, depending on the particular circumstances, phase of the project and goals. In the early stages, scenarios can e.g. be used to create visions of future work using new technology and serve as tools for creativity and inspiration, throughout the project, they can be used to identify and analyse problems and provide possible solutions by e.g. 'playing out' the examples, and in later stages they can e.g. be used to structure prototype evaluation sessions; highly detailed and controlled scenarios can guide the user through exactly the parts of the prototype we wish to be focused on while the more general scenarios leaves the user free to explore the prototype and how the different parts relate to each other and to his or her understanding of the work in general. Most importantly, and common to scenarios regardless of their purpose and shape, is the underlying link to the real work settings which helps us anchor our design efforts to the work practise we are engaged in designing for. The role of scenarios in design has been discussed e.g. in [Bødker and Christiansen, 1997, Bødker, 1998, Kyng, 1999], showing scenarios as valuable, dynamic resources in user-centred design to illustrate needs for technological support as well as to reflect on how the future work situation may change the work practice. As described in Section 6.3.2 we used caricatures in the BIDI project based on a set of theoretical perspectives of human-computer interaction combined with science-fiction characters and used these in a workshop where a design assignment was to choose one of these interaction perspectives and create a future scenario based on a video scenario from the combined heating and power plant. Just as the caricatures served the purpose of inspiring and provoking the way we look at work in a wastewater treatment plant, the work descriptions or video scenarios were necessary anchors into the concrete work environment. Another example of the use of scenarios as mentioned in the beginning of this section, namely as a means of creating visions about future work can be found in [Bertelsen and Nielsen, 2000] [P5] where the use of the augmented reality principles as metaphors resulted in four future scenarios that described work with a mobile device.

\subsection{Taking usability methodology even further}

[Grønbæk et al., 1997] introduces a conceptual framework for large-scale systems development, and notes that the participatory design approach and the cooperative design approach sometimes neglect to take existing systems and standards into account when designing and relying only on users' ideas and current work practise.

I have to agree with this critique, both in general but particularly when we look at projects dealing with mobility. Most studies of mobile, distributed work mainly consider the implications of the work practice for design to be developed, and disregard or overlook the role of the new artifact in the existing 'web-of-technology'. If we look 
at some of the most elaborate empirical research that has been done on mobile work, [Bellotti and Bly, 1996, Fagrell et al., 1999, Luff and Heath, 1998] they are somewhat vague about the concrete implications for design, particularly in the relationship between the proposed prototypes and other technological artifacts. It is of vital importance to explore how the (computer based) mediating artifacts may relate to each other because without knowledge of these relationships it is impossible for the design to take advantage of the possibilities of the different technologies.

This lack of seeing technology in a larger technological web is even more exaggerated when we look at mobile technology for the consumer market. WAP services are advertised in a manner which lead the user to assume they will be able to access and do much the same things on their minuscule mobile telephone that they can on their PC, but when the WAP services and portals are examined, they bear very little resemblance to the medium they relate themselves to. We need to move away from an approach where every mobile phone or palmtop device is designed as if it is to be a stand-alone device giving the user access to everything from everywhere, completely independent of all other existing technology. Instead, combining a clear understanding of the use practice and use environment with placing the mobile 'communication device' in the already existing 'web-of-technology' could give a much clearer picture of where it would provide an actual improvement of existing services and where it was trying do what other technologies already can, only slower and more cumbersome. This approach is well within the boundaries of the usability methodology I have been describing here.

\subsection{Concrete examples of use in the BIDI project}

In the following I will give more concrete examples of how we have used different, experimental usability techniques in the BIDI project.

\subsubsection{Interrelations between field and lab}

One technique for supporting the voice of the user and bringing aspect of the field into the lab is to organise a workshop area to (closely) resemble real work setting and use real artifacts from the workplace as resources in design. Complementary, staging action and playing out scenarios in the actual field environment adds a richness and detail to the situations impossible to duplicate in a 'lab' environment. Using the real work context provides us with access to the multitude of actors and artifacts present in real work and lets us investigate into the relationship between these and future technology. Techniques for letting the field and the lab mutually inform and support each other are described further in [Nielsen, 1998] [P2] which also gives other examples of how aspects from the field can be brought into 'the lab' and vice versa, and how this may inform design. Furthermore, organising the physical space has been explored as means of supporting collaboration in workshops, both within the BIDI-project and by other research groups within the HCI area. [Petersen and Halskov, 1999] summarises the experiences with setting up collaborative design workshops through a set of generally applicable guidelines. Another and equally interesting use of physical space in relation to design is as a vehicle to externalise design decisions and to illustrate the ongoing development of a design project as described in [Buur and Bødker, 2000, Covi et al., 1998, Karat and Bennett, 1991, Moran et al., 1999, Streitz et al., 1998]. The following examples have been chosen to illustrate some of these considerations and what might be 
gained from them.

A field experience in the lab-a Vision2000 example In our efforts to design new, technological support for refrigeration engineers, we engaged in a design workshop with refrigeration engineers from different companies in Denmark. We set up a range of products used by refrigeration engineers in the workshop area and made some mock-up refrigeration crates which were used with scenarios of set-up, maintenance and problem solving situations based on interviews with supermarket employees, the technical staff, managers and refrigeration engineers from our field study. The use of props and mock-ups has been explored and recommended by e.g. [Ehn and Kyng, 1991, Kyng, 1999] as valuable tools in (explorative) design. We presented the scenarios to the participating refrigeration engineers and asked them to comment on whether they found the situations to be realistic pictures of work situations. Furthermore, we asked the refrigeration engineers to act out the scenarios, as they would handle the problem presented, using the available technology and pretending we were in a supermarket. The discussions raised by these enactments both pointed out differences in work practices and served as a vehicle in identifying problem areas in relation to the available technology and the work practice. Following this, the refrigeration engineers were asked to describe how they wanted the technology to better support the work situation, and we engaged in a cooperative effort to create future scenarios with descriptions of future technology with the aid of hand-held prototypes and foam mock-ups.

Simulating use in the field-a CIS-project example At one of the CIS-project workshops involving participation from all the involved research groups and several wastewater treatment plants we set up different prototypes at the plant and asked participants in groups to evaluate the prototypes after receiving a demonstration of them. Their comments were, not surprisingly, related to the interface design, visualisation principles and the structure of information. Afterwards, we presented the participants with a work scenario where an alarm had been triggered on the inlet and asked them to play through the scenario with us, using the prototypes to demonstrate how they would handle the situation and discuss what was there and what was needed. Using the real use setting allowed us to relate the intended functionality with the actual context, to draw upon the information available in the area to support our choices of places and events in the future scenario. This type of staging use is more typical to usability studies in the lab where users are asked to perform typical use tasks with e.g. new software, but it works equally well in a real use environment, illustrating specific aspects of use or effects of new technological devices. During the CIS-project, each of the research groups ran a workshop at one of the wastewater treatment plants for the purpose of design or evaluation.

\subsubsection{Using theoretical constructs to inform design}

Interaction perspectives in the SmartWindows project In the SmartWindows project we investigated ways of challenging design of mobile devices by using four theoretical interaction perspectives (tool, media, system and dialogue partner) [Kammersgaard, 1988] as basis for defining four 'design perspectives' to illustrate different ways of interacting with artifacts. Each interaction perspective was developed into a two-page poster with the original, abstract description of the interaction perspective on the right-hand side and a character description to the left-hand side, focusing on his or her use of technol- 
ogy, which served as an exemplification of the perspective. These design perspectives were used at an inspiration workshop where a group of interaction designers, industrial designers, $\mathrm{HCI}$ researchers, usability engineers and psychologists from Danfoss, Kommunedata, Bang \& Olufsen and Aarhus University were gathered to work with the first version of the design perspectives in relation to work at the combined heating and power plant. Using work situation descriptions and video clips from the field study they were asked to explore design possibilities for a portable piece of equipment from the point of view of the four design perspectives, one perspective in each of four groups. The groups created scenarios based on the work situation description to situate their thinking about possible ways of interaction in this setting-where would the media perspective, emphasising communication between people in the plant, head? Or, with the tool perspective, which tools would be needed, and for what purposes? To present these considerations, the groups acted out their resulting future work situation with mock-ups of future technology. We found that the restrictions inherent in working with one specific work situation description and one specific design perspective actually helped define the boundaries and create a common ground on which the participants could use their individual experiences and backgrounds in the negotiation of the design. This 'boundary zone' [Bertelsen, 1998] was first defined through the negotiation between the participants of how the assignment should be understood and affronted. Later it served as a collaborative design space as the participants started sketching design ideas for the future scenario on paper and with simple props like pipe cleaners and plastic cups, elaborating on some and discarding others. The intended outcome of this workshop was not to generate specific design solutions but rather to inspire and aid the process of generating new ideas for regarding mobile support for work at a combined heating and power plant. We see the use of caricatures in the design perspectives as an important tool in achieving this goal. Because the design perspectives quite clearly did not provide realistic views of the world, it was also clear for all participants that their utilisation did not yield the solution to a design problem but rather the unfolding of a design space.

Augmented reality principles in the CIS project Similarly, we have used the theoretical classification of augmented reality principles [Mackay, 1998a] - augmenting the user, the object and the environment-as a tool for design in line with the use of metaphors in participatory design [Madsen, 1994], and the previously mentioned springboards in developmental work research [Engeström, 1987]. We used the augmented reality classification to inspire design of new ways of interacting with a mobile device to be used in a wastewater treatment environment, challenging the predominant 'direct-manipulation' interaction paradigm which proffers pen based interaction with the hand-held device. Based on four work situations from our empirical study at the wastewater treatment plant, we developed four horizontal prototypes where interaction with the mobile device reflected one of the three augmented reality principles. One had a gesture-like nature as if it was the extension of the user, another was based on the manipulation of other physical devices to which the mobile device could be attached, etc. Focusing on interaction with physical objects in the work setting provided us with specific boundaries to work within and thus became an effective guide in deciding what to include in each of the PDA applications. Thus, the concepts of augmented reality worked as a tool for handling the context problem. Most of the information and control made accessible with the suggested PDA applications is present in the existing process control system. The strong focus on interaction with physical objects around 
the plant, however, helped in specifying actual physical and situational context for the applications in the future scenarios.

\subsubsection{Design in multidisciplinary groups and mobile work}

The wide range of representations of work and artifacts made available at the workshops worked as sources of inspiration and promoted the different perspectives in the design work. The participants could use the artifacts as concrete anchors in more theoretical discussions by using them to refer to or interact with to exemplify a point they were making. Common to the methods presented is their anchor into real use situations. In a design context, realistic scenarios from empirical studies work as the frame within which new technology can be developed and experimented with without ever losing touch with reality and the use context.

In supporting mobile work, experimentation with design is particularly important. Support for mobile work must be found in the combination of e.g. desktop systems, hand-held devices and local displays in order to provide the best access to the information needed for workers to perform the daily tasks and to reconfigure themselves in response to changes in requirements and unplanned events [Luff and Heath, 1998]. To provide the best range of access points into the information we need to look at e.g. user interface design, interaction paradigms and information visualisation from many different angles. This can be accomplished through new, creative design techniques as the ones mentioned above, involving a wide range of practitioners and users, representing the stake-holders in design. 


\section{Chapter 7}

\section{Mobile work in a process environment}

Moving from techniques to change usability practices to a more specific area for application of the techniques, we turn to look at what constitutes work in a process environment. In the following, I will present the primary case study and pull forward key elements of work in a process environment, with emphasis on wastewater treatment, but also illustrated by examples from the two other case studies.

\subsection{The CIS case}

The CIS case study was part of a long-term research cooperation in the areas of HCI and CSCW involving Danfoss, the Computer Science Department at Aarhus University and the Art, Culture and Communication department at Malmö University College, and four wastewater treatment plants in Denmark and Sweden. Methodologically, the project was coordinated across research groups even though, thematically, the three research groups worked from different research goals or themes. Thus, field studies of three wastewater treatment plants were the basis for initial investigations and familiarisation with the wastewater treatment area for researchers from all three participating organisations. Later, feedback sessions and design and evaluation workshops with and without users were the primary way of sharing and comparing findings with the other research groups and users. For 'my' group, the purpose was to explore the theoretical notion and practical design of common information spaces, i.e. how information is collected, shared and accessed in a wastewater treatment environment.

We spent 40-50 hours within a five-month period doing participant observation at the site, following workers through their entire daily routine. Different researchers followed different workers, using hand-held video cameras or a digital camera to capture the events. We analysed the video with special emphasis on the daily work practice, use of artifacts, and how workers dealt with the disruptions, using the techniques described in [Bødker, 1996] and [Buur and Søndergaard, 2000]. Video clips were presented for the plant employees at three feedback sessions/user workshops at the plant. Furthermore, we compared the work practices at this site with data collected by other project researchers at the other wastewater treatment plants and held 3 project workshops emphasising design and evaluation with participation from all the cooperating parties. 


\subsubsection{The plant}

To establish the area of scrutiny to the reader, we shall briefly describe the specific type of wastewater plant we have visited, and look at how the work is organised. The wastewater treatment plant (MR) was one of the first larger plants in Denmark to implement automatic process optimisation for the removal of nitrogen. The automation has been possible due to the development of new technology, sensors, which has allowed for on-line measuring and control of the primary parameters of operation. Not surprisingly, the process optimisation has radically decreased the expense of e.g. the use of chemicals and in relation to the airing process. The plant has an estimated capacity of 220.000 Personal Units (PU) but is constantly running at 110-150\% because the plant has not been able to expand to match the increase in the city's production of wastewater. The purification process includes both mechanical, chemical and biological phases and the segmented sludge is first used to produce gas in putrefication tanks for running the plant before it is pressed and taken away to an incinerator plant.

\subsubsection{The work}

The studied wastewater treatment plant employs 8 people, 2 of which represent the management. The area of responsibility for the management is the plant in general whereas the workers are divided into sub-groups with more specific areas of responsibility, as we shall see in the following. Also, the management have goals and interests that may be in conflict with those of the workers. Among the workers we have the following divisions:

- 2 workers responsible for the lab, receiving the sludge-trucks, area of preliminary sorting and sand trap.

- 2 workers covering most of the outside areas of the plant as well as the putrefication tanks, sludge tanks, gas-turbine building and the control room

- 2 workers working in the building with the sludge press

The division of labour can be described as process-defined in the sense that the three groups of workers each are responsible for the tasks associated with a specific part of the treatment process. The division of labour is quite clearly defined and re-arranging of tasks only very rarely happen on a permanent basis but will occur temporarily e.g. in case of illness where the most pressing tasks are distributed among the rest of the work force. This organisation of work means that tasks cannot be interchanged between all workers but that each worker has a relatively strictly defined set of work tasks, with some overlapping. However, within these bounds each worker is able to 'juggle' the tasks as the situation demands. In general, the work day has a very dynamic structureprofound understanding for ones assignments and the plant in general makes it possible to e.g. place equipment in the area for later use, and to redefine the order of tasks in order to cope with the numerous events that cannot be anticipated. Furthermore, the workers give special attention to things that may later on obstruct the running of the plant (e.g. a motor sounding strange or leaking oil). To get a better understanding of the extend to which unplanned incidents occur, we might consider which events that may affect the work routines:

- Machine failure/alarms 
- Signs of problems

- Experiments on the plant

- Guests

The large number of alarms in one day alone makes it obvious that a great deal of flexibility is necessary in the daily routines to be able to keep the plant running smoothly. If the alarm is due to machine failure, it is often necessary for several of the workers to completely break off their daily routine and instead enter into a cooperative effort they are not usually part of. If the alarm is merely a warning of a breakdown, or if a worker sees signs of problems like a motor leaking oil or sounding strange, it is entirely up to the situation whether or not this calls for immediate action or can wait for days, whether the observant worker can handle the situation on his own or if other specialists need to be summoned. Noticing specific warning alarms and the physical signs of problems are highly prioritised in the everyday work as it naturally is much more desirable to prevent machinery breakdown than to recover from them. Furthermore, at this particular wastewater plant, many experiments to optimise the purification process in terms of cleaner water and decreased expenses are continuously running. Experimentation usually involves introducing new technology or work practices, and is as such a high disturbance factor as these often provoke unanticipated events or effects on everyday work. Finally, the wastewater treatment plant very often visited by outside guests, especially school outings, and even though these visits are carefully planned and executed, they nonetheless present a disturbance in the overall running of the plant. Considering what a multitude of unplanned events on several different levels these factors combined may cause makes it obvious that a high degree of flexibility in the work practices is crucial for the workers to maintain the continuous operation of the plant.

\subsubsection{The existing web-of-technology}

Looking at the current situation at the plant with regards to the technology they use, the predominant element is without doubt the central control system which maintains and controls the purification process and is accessed from the main control room or the manager's office. Certain changes to the lower levels of the control system can, however, only be done from a console in the central control room. Furthermore, access to parts of the control system or sub-systems is available through two computers in local control rooms at the plant, one in the preliminary sorting area and one in the building with the sludge press. Other technological artifacts used in the daily work in the lab are the spectrometer which analyses the contents of the water in the samples the lab technician collects on his daily round connected to a matrix printer which prints out the results. The lab worker brings this print-out to the manager's office or the central control room to enter the analysis results into the central control system because he does not have access to the central control system from the laboratory. While a computer in the lab is desirable for the lab worker, it is not considered important enough to be economically possible to the manager. This 'island' is vital to the control of the water purification process because the lab is the only part of the process where detailed information about the contents of the water can be given. However, direct connection to the control system would not alter the fact that the laboratory information provides an average picture of the state of the water over a 24-hour period prior to the analysis, which is the consequence of the method of sample gathering as it is done today. Finally, 
telephones and mobiles phones are used on the plant, but interestingly enough they are primarily used for communication with people outside of the plant or to call a coworker on the plant from a meeting or other activity outside of the plant. Between the workers on the plant, telephones are very rarely used; even the unplanned events are rarely time-critical so information is propagated through morning meetings or at lunch, or the wastewater operators 'visit' each other in their respective parts of the plant. Knowing each other's routines, the wastewater operators have a very keen sense of where to find each other during the day. A well-functioning social system like this would be difficult and even pointless to try to support through new technology whereas I see possibilities in connecting the 'island' to the rest of the system and generally provide a better connection to the components and the process outside of the control room.

\subsection{General characteristics of process work}

In the following, I have tried to synthesise the characterising elements in process work in general and wastewater treatment in specific.

\subsubsection{The complexity of the technical system}

Wastewater treatment is a hugely complex, technical process involving the control of thousands of components working together to ensure efficient and effective cleaning of the water. Similarly, the production of heat and electricity requires control by an incredibly complex technical system, and even small supermarkets need technically complex refrigeration systems to ensure their goods are handled safely from they enter the store till they leave it.

\subsubsection{Dynamics in process work}

Based on the activity theory perspective on human activity, particularly Raeithel's framework for understanding cooperative work (see: [Raeithel, 1996]),

[Bertelsen and Nielsen, 1999] [P3] presents an in-depth analysis of wastewater treatment work with respect to the dynamic nature of the process and the degree of formalisation that can be imposed upon it, identifying the following 5 levels of dynamics: "the technical process", "people moving around", "technical re-arrangement", "flexible routines" and "transformation of the domain".

"The technical process" describes the physical purification process where water runs through pipes and basins, through the different phases of mechanical, chemical and biological purification, entering the secondary processes like sludge treatment and gas production. "People moving around" describes the mobile aspects of wastewater treatment work from the wastewater operator's perspective. As described in the previous paragraph, wastewater treatment operators rarely spend more than 5 consecutive minutes in front of a computer; the rest of the time is spent walking around the plant, checking the physical components, collecting laboratory samples and generally keeping in touch with the state of the process. "The technical process" and "people moving around" can be seen as two sides of the same, operational aspects of wastewater treatment, structured by and reacting to the physical components and the environment. They relate to the co-operation level of Raeithel's framework. 
"Technical re-arrangement" describes the continuous development of the technical system in response to e.g. more restrictive demands on the purification process or to cut costs. Experimenting with a new type of sludge centrifuge to replace the sludge press changes the technical structure of the plant and requires the wastewater operators to adjust their daily work to incorporate the changes. Thus, "Flexible routines" describe the need for flexibility in the work practise enabling the wastewater operators to "juggle" tasks as the process changes and circumstances dictate. "Technical re-arrangement" and "flexible routines" are thus deeply interconnected. The "technical re-arrangement" is dependent on the existence of "flexible routines" to carry out the series of changes in the technical structure and conversely, the flexibility in everyday work is defined and developed because of the never ending changes and disturbances being introduced into the wastewater treatment process. These two levels of dynamics relate to the cooperation level of the framework where the goal is shared but the means of realising it is not, thus the need for continuous adaptation to e.g. other worker's actions or the feedback from the system.

Finally, 'transformation of the domain' describes more fundamental changes in the technical system and the work practise. Currently, wastewater treatment tests and reduces the levels of phosphor, ammonium and nitrogen in the water, but they might be asked to test for different types of hormones or heavy metals, too. Such legislative demands would require a series of changes of the process itself and, naturally, the control of the process. This level of dynamics corresponds to the co-construction level of the framework where neither goals nor means are known or shared between the actors.

Analysing the movements between these levels of dynamics and across the horizontal dimensions between the technical system and the work practise or between the mediating artifacts and the use situations provide us with an understanding of how the development of the physical environment affects the way work is carried out and vice versa.

\subsubsection{Central control versus distributed work}

Control of process environments is typically centralised, as is the case with the three case studies. A central computer receives the output from the many components and uses this information to control and regulate the processes, whether it is cleaning water, producing electricity or keeping your milk cold. Interaction with the components for regulation purposes is done though the central control system. However, this organisation of information does not correspond to the way we observed work being done in any of the case studies. Much of the tasks at the wastewater treatment plant, the combined heating and power plant and in supermarkets are dependent on having direct access to the local environments and the components. Specific sites provide workers with non-system information e.g. the look and smell of the water, the sound of motors running or seeing oil leaking from a valve. In the case of supermarket work, the system information might not even accurately represent the actual situation: the temperature in e.g. an open refrigerator may look fine in the system when in fact the products are too hot because the temperature sensors are placed near the cooler elements instead of on the shelves. We have seen countless examples from all three case studies where walking around in the environment contributed with valuable information some of which may not even be accessible through the system. Workers may be prompted into action by a leaking pipe or discoloured water, but often they need more than what is readily available on site. The following example is from the wastewater treatment study as 
described in [Nielsen and Søndergaard, 2000] [P4].

Dan, who works in the building next to the lab, calls Robert, who is doing the daily laboratory tests, over to tell him that the contents of the primary clarifier looks strange today: it foams and is almost as grey as cement. They briefly discuss what could cause this and decide that the best cause of immediate action is for Robert to pay extra attention to the laboratory test results today. In this situation, no immediate action is taken because even though the water looks odd, because this alone does not provide enough information to determine a course of action. Robert needs the results from the laboratory, too.

This point to an important aspect of work in this environment, namely that the information available in the area along with the information provided by the control system form the basis for how work is performed, and in most cases, any one source is not sufficient for deciding how to progress. However, at present the information obtained from walking around in the area is completely detached from the information from e.g. the sensors, which are only available in the control system. This makes the task of getting an overview of the 'state' of the process extremely complicated.

In general, the centralised organisation of information is in conflict with the actual use practice and the needs of the workers. The workers in the SmartWindows case were forced to work in pairs to have access to all the information they needed to perform their daily tasks. One remains in the control room with access to the control system while the other goes out, into the plant, carrying a walkie-talkie to contact the control room when needed. Similarly, the workers in the CIS-project spend most of their time out on the plant to perform their daily work and were rarely found sitting in front of the computer unless they needed information about the area they had just come from or were about to move into. For the refrigeration engineers in the Vision2000 project, the work is further complicated by the fact that part of maintaining a refrigeration system for a supermarket is done by monitoring the status of their clients' systems from their computer system 'at home'. However, they spend an equal or larger amount of time solving problems and doing repair work on site, i.e. at the individual supermarkets. Often, they have little or no access to the control system from he supermarket shop floor because the supermarket may not have their own control system terminal. In these cases they must bring a portable computer or use a hand-held one-line display device they can plug into the system bus and use to flip through the multitude of system parameters, one by one.

\subsection{Process plant environments versus control rooms}

Work environments like process plants where work is highly mobile and distributed is comparable with dynamics we see described in control-room studies like [Heath and Luff, 1996, Hutchins and Klausen, 1996, Suchman, 1996, Mackay et al., 1998] even though they cannot rely directly on co-located resources in constructing a common information space. Resources like peripheral awareness and broadcasting are only vaguely present and cannot be used as resources in creating and maintaining the common information spaces in the same manner as pilots [Hutchins and Klausen, 1996], air-flight controllers [Mackay et al., 1998, Suchman, 1996] or line-controllers at the London underground [Heath and Luff, 1996]. In circumstances like these where people cooperate in a shared, physical space and share artifacts, they can construct and use a common 
information space without a need for representing the use context because they are all part of it. However, other but similar resources are used instead, e.g. the workers have a remarkable good sense of where to find co-workers at a given point in time. Furthermore, phones, unplanned 'meetings', seeking each other out and breaks during the work day serve as resources to keep others up-to-date on what is happening at the different parts of the plant. Despite of the size of the plant and the presence of both mobile and stationary phones, most of this 'coordination-work' is done through faceto-face meetings. Contrary to the control rooms described in [Heath and Luff, 1996, Hutchins and Klausen, 1996, Suchman, 1996], the control rooms at the three case study sites are used as a place to tap into system information rather than a place where cooperation takes place. So even though the physical setting has the potential of making information available to multiple users and thus create a local and open information space to support collaborative efforts, they are not used as resources in this way. Most collaborative efforts in the process environment take place locally, at components, e.g. when a component or subsystem breaks down and needs repair. These places are not stable areas for cooperation but a temporary scene for a collaborative effort. Another contrast between the two domains is that in most control room studies it is noted that all the available information is accessible in or through the control room-there is no need or maybe rather possibility to compare the available information with the actual, physical circumstances to the same degree as it is possible on the process plant. The ability to reach outside the control room in those studies can at best be compared to the way the workers at the combined heating and power plant worked in pairs, namely by calling up someone from another work group (and work practice) who can be physically present at a given location and cooperate through the phone or walkie-talkie on solving the problem. In that sense, the physical part of the world that is represented in the control room is outside the reach of the people inside it. Working through phones, cameras and computer systems causes control room operators to work at least through one degree of separation from the world they are acting upon.

Finally, an important difference between air flight controllers, line controllers and personnel on a ship's bridge is that no lives will be lost if something goes wrong at the wastewater treatment plant, the combined heating and power plant or at a supermarket, so the work is not time-critical in the same manner.

The mobility is further contrasted with the centralisation of system information. Most component specific information is not available at the component but only though the central PC-control system. This creates information heavy and extremely local 'corners' of the common information space that resemble the control rooms described in [Heath and Luff, 1996, Hutchins and Klausen, 1996, Suchman, 1996] but which are not used in the same manner. As described in the presentation of the CIS-project above, workers spend very little time in the control room. When they do, it is mainly to get information about the area they are about to visit or to compare what they have experienced locally on the plant with system information relating to the area or one or more components. We therefore saw a need for expanding the common information space of the control system by providing access to it locally on the plant.

\subsection{Process plants as learning environments}

Navigating in a complex technical environment is by no means easy, a thing we as researchers and being foreign to the work and the work processes realised the first day we visited the plant. The multitude of components, sounds, visual cues and the barrage 
of input you are met with as you enter the plant is impossible to filter to the untrained eye. Creating a sense of the 'state of the process' is a learning process that takes years, the scope of which has been very aptly put by one of the workers at MR as:

"I have been working here for four years and am starting to 'know' the plant, but I think it will take another two years before I know it well enough - where all the machines are, etc. For example, we have pipes running through this building and they are normally working fine so you can basically work here for years without knowing there's a (throttle) valve up there [pointing]" (..) You never find out before something happens (..) We work with 50.000 components-you don't learn about them all on your first day".

In the following I will look at those issues that relate to seeing the process environment as a learning environment. I have chosen to look at learning from the activity theoretical perspective and use terms derived from Section 4.1 in my analysis of the work and the work environment because the notion of situatedness, peer learning or apprenticeship, mediation and transparency offer excellent means of describing what goes on at a wastewater treatment plant.

When we look at the structure of the work done at the wastewater plant, one of the most thought-provoking observations we did is that we can find no stable centre of control/learning. Despite the existence of control rooms, the decisions about how to control the process are taken on the plant more often than in front of the computer. This decision making process is mediated by the environment; developing the ability to know what to look for in which part of the plant depending on the situation is supported by the cues implicit in the technical environment. However, an more importantly, 'getting to know' the plant is also supported by the apprenticeship-like working arrangement where every wastewater operator is part of a two-man working team with responsibilities for a certain part of the plant or maybe more conceptually correct, a certain part of the process. This work structure thus not only ensures that a novice worker will always have a 'more knowledgeable peer' to support his or her learning process when commencing work at the plant but also that peer (or cooperative) learning is maintained as the plant and work practise changes over time. Because of the complexity of the technical system as described in the quote above and because of the highly dynamic and unpredictable nature of work as illustrated by the great number of unplanned events during an average day, this learning process can only be meaningfully undertaken on the site. I do not mean to suggest the workers need no formal training before taking a job as a wastewater operator, but as with learning how to drive a car, the initial tutoring or classes enables you to operate and maneuver a car but the real learning experience starts when you enter real traffic. Turning back to my initial statement that the learning process is mediated by the environment itself, this relates to the familiarisation with the technical system and the cues from the environment which play an important part in supporting the learning process. Because the wastewater operators have access to (and almost physical contact with) the different stages of the purification process and can look directly at and smell the water at different junctions, they have a sort of direct feedback from the process which can guide them in adjusting their understanding of the state of the process at any given point in time. Similarly, the direct contact with many of the technical components, such as gas turbines and preliminary sorting machines aid the building of the picture of the wastewater treatment process as an organic whole. Breakdowns in the technical system will affect the purification process so listening to 
the motors and looking for oil leaks are routine tasks in an effort to maintain the system and avoid potential problems. This feeling for the state of the process would be lost if the wastewater operators were confined to a control room, and made to control the process with the aid of e.g. cameras and online sensors or other ways of augmenting or 'bringing the process to the centre of control'. Consequently, the learning process would seriously be crippled if the wastewater operators were deprived of their direct contact with the purification process and our task as researchers should be to support and enhance this relationship rather than try to eliminate it by introducing technology that separates the users from the process.

\subsection{Definitions of mobility}

Clearly, wastewater treatment work is highly mobile and distributed but if we strive to support this kind of work our first task should be to pinpoint what exactly constitutes mobile, distributed work and what are the relevant aspects of that in relation to wastewater treatment work and process work in general. I find it particularly important to separate mobile work from mobile technology because they are easily confused. However, it is necessary to keep in mind that one describes the circumstances that define the work or modus operandi and the other is a mediating artifact which may be employed to support this.

Three definitions of mobility:

Local and long-distance mobility. [Bellotti and Bly, 1996] reports from a field study of distributed work at a design-consulting firm. They found that the members of the product design team rarely sit at their desks but move around in the local area to visit colleagues to keep up-to-date with the progression of projects, to use shared resources and to coordinate their work. They denote this kind of mobility local mobility: short-distance mobility in the local environment, such as walking between rooms or buildings. This stands in contrast to the better-known long-distance mobility that is usually in focus when supporting distributed work. That mobility doesn't necessarily involve travelling over long distances means that a lot of work settings that are considered non-mobile in fact depend on a high degree of mobility, which has a significant impact on how the work is coordinated and supported. More so because the existence of local mobility poses a threat to the way long-distance mobility is conducted and coordinated in that the distributed systems often rely on the telephone or email to support spatially distributed collaboration.

Micro-mobility, local mobility and remote mobility. [Luff and Heath, 1998] uses examples of mobile work from a doctor's consultation, a construction site and the London Underground to identify three types of distinctly different mobility. Micro-mobility denotes the mobility inherent in physical objects in that they may be moved about and be shared between people to support e.g. communication, such as a blueprint or a doctor's journal. Building on the work of [Bellotti and Bly, 1996], local mobility is in this context exemplified by the collaboration patterns of people working in the London Underground operations room with the teams of workers present at the different stations, i.e. confined to a local, physical location. Remote mobility again denotes the more conventional, long-distance mobility where people move about different, spatially distributed 
physical locations and communicate or interact with each other through technology. The interesting points this paper draws out when exploring how mobility affect and exists in collaborative settings is that different kinds of mobility need different kinds of technological support, and if we overlook mobility in collaboration we cannot possibly support collaborative work properly. "In considering mobility, we need to examine the activities in which people engage, with other, when they are 'mobile', and how various tools and artifacts, feature in those activities". Or, in other words: rather than pouring all efforts into building 'the system' for collaboration it is necessary to understand that different tools are needed in different situations and if we provide a range of tools to choose between, we are much better equipped to deal with the situations at hand as it changes or unfolds.

Travelling, visiting and wandering By identifying what they call 'typical instances of a type of mobility', [Kristoffersen and Ljungberg, 1999c] creates a classification with three distinct types of mobility which have different impacts on the types of technology brought into the setting to support it. Travelling denotes the kind of mobility where you move from one place to another using a vehicle, like commuters. Visiting denotes the type of mobility where you spend a temporary period of time at one physical location before going somewhere else, e.g. consultants or photocopy repairmen. Wandering denotes local mobility within a smaller area such as a building with very little time spent in any one place, e.g. the night watchman going on his round.

Whereas the first two classifications are dealing with the spatial properties of mobility (how far do you move), the third classification also integrates purpose or mode (how and in what sense are we mobile - for what). I will in the following take the liberty of combining the classification from [Bellotti and Bly, 1996] with the classification in [Luff and Heath, 1998] because they work within the same frame of mobility, and though it is not explicit in the text, the classification from [Luff and Heath, 1998] is clearly inspired by the one in [Bellotti and Bly, 1996]. Furthermore, these authors represent strong voices in a primarily CSCW-oriented perspective on work. Analysing the work done at the wastewater treatment plant through these two perspectives gives a multi-faceted view of the mobility inherent in their work and through that, hopefully, a clearer understanding of how to support it. This was done to some extend in [Nielsen and Søndergaard, 2000] [P4] but I would here like to expand on this analysis to give a more detailed view of the mobility aspects of wastewater treatment work.

Describing wastewater treatment work by means of the first classification-micro mobility, local mobility and remote mobility — reveals that work contains elements of all three, though the element of local mobility seems to be predominant. Most work is done in or in relation to objects or locations on the plant as opposed to in an office in front of the computer, so for most of the wastewater operators' local mobility is an important and ever present element in their work. Remote mobility is present but much less obvious or frequent, e.g. in communicating with external work resources like electricians and smithies when repair work is necessary, the union work done by the local union representative, workers undergoing additional training and management going to meetings with the local council, discussing the current state of wastewater treatment and the goals for the future. These are all tasks that describe important aspects of wastewater treatment work even though they are not all directly involving the purification process. They are currently not well supported by information technology but rely primarily on the use of phones and face-to-face meetings, and the question now 
becomes whether they should be. Most of these remote activities utilise and depend on the face-to-face interaction, which makes them very difficult to support through technology. Micro mobility is also present e.g. through the paper protocols in the lab and in the control room-in the lab the protocol stays on top of the table so anybody can come in, inspect it and us it as a resource in discussions about the state of the process. However, we never saw anyone use the protocol in this manner. Possibly, the division of labour and the reporting processes-entering all data present in the paper protocols into the computer system-and the subsequent multiple presence of information has weakened the use of the paper protocols as commonly used shared resources, but this does not mean that the paper protocols are obsolete and can be eliminated from the work process. The lab protocol serves as a valuable resource for the lab worker in providing him with a clear and quick overview of how the water has 'behaved' during the past month, even though the micro mobility inherent in it is not utilised. The analysis suggests that the conflict between long distance collaboration and local mobility is only weakly present so emphasis should be put on clarifying and supporting the local mobility present in the plant work.

If we now turn to the second classification-travelling, visiting and wanderingwe get a radically different picture of how mobility in wastewater treatment may be described by using a set of concepts that describe why people are mobile as well as how this may be supported. Again we find that wastewater treatment work contain elements of all three types of mobility, though wandering seems to be the most common. The wastewater treatment operators' daily round on and around the plant is characterised by predominantly moving around locally, on the plant, often varying the route in response to the things they encounter. The round is very focused and structured compared to another instance of wandering we find on the plant, namely when one worker who is in charge of one area of the plant seeks out other parts of the plant to alert other wastewater operators of a possible crisis or development in their area that might affect the entire plant or another specific area, or demand quick intervention from all workers at hand. Wandering in order to pass on information or coordinate efforts is never time critical so if the wandering worker is unable to find his colleagues, he might just as well wait till the next break and meet with the other wastewater operators in the lunch room. Visiting in relation to wastewater treatment work occurs when the workers or managers go to meetings or classes outside of the plant whereas travelling is done primarily in relation to these activities (and is, of course, also seen when the workers on the plant arrive for work in the morning and when they leave in the afternoon, but that does not describe mobility in relation to the work). Furthermore, as they on the wastewater treatment plant have no residing smithies or electricians, but a service contract with outside companies for the tasks of this nature, the smithies and electricians travel from their headquarter and visit the plant whenever a problem occurs. However, these two groups have not participated explicitly in this project but have only been present peripherally, thus we have made no efforts to support their needs for working at the plant in the process or though the prototypes. The outcome of this analysis must therefore be that the wastewater operators would benefit from some kind of mobile technology to provide them with the system information they otherwise only have access to in the control room to support their work on the plant, because both desktop and laptop systems are, according to this framework, ill suited for supporting particularly the wandering mode. 


\subsection{Other empirical studies of mobile work}

As stated in the introduction, studies of mobility and mobile work are by no means a novelty. Empirical studies of mobile work have formed the basis for much CSCW related research and I would be remiss if I did not dedicate some ink and space for pointing towards some of the most interesting and inspirational for my work.

[Fagrell et al., 1999] conducts a study of electricians' work. More specifically, they have studied local service stations belonging to a large electricity provider with the aim of examining how the existing knowledge management systems support the mobile groups and the implications for redesign and re-evaluation of the knowledge management concept. The local service stations are in charge of the customers in their local area, responsible for installation, maintenance and problem solving if a breakdown occurs. Electricians work in pairs to ensure both low voltage and high voltage expertise in the field. While the study itself offers interesting examples of mobile knowledge management (sharing, indexing, diagnosing and foreseeing) and a discussion of how this will affect the design of future systems for supporting knowledge management, it ends before actual implications for design can be proposed. This makes it difficult for the reader to use this paper as much more than a well-constructed example of a field study of mobile work.

In [Herstad and Thanh, 1999], a 'deconstruction' model is used to support communication and coordination for a bike delivery service; breaking down the 'terminal' technology into wearable, customisable units called 'basic components' can be assembled and re-assembled to form the kind of terminal that supports the bike messenger best under given circumstances - as the circumstances change, so can the assembly of basic components, allowing the bike messenger to adapt to changes without loss of control. This model resembles the view on information appliances and the future of technology given by Norman in [Bergman, 2000], where he states:

"You can assemble whatever combination best fits the way that you work. And I foresee that's how our appliances will be developed"

As such there are many parallels between this kind of work and the work done by the wastewater treatment operators: the nature of their work (the tasks), working within a limited geographical space, working in pairs, and working outside the office more often than not. More importantly, the work described in this literature all share the characteristic of containing a high degree of unforeseen events as part of the daily work and consequently juggling tasks as the circumstances change. In the extreme case for the bicycle delivery service the deliveries may literally be assigned from moment to moment. That means planning will serve only as a general guideline or structure for what needs to be done as described by [Suchman, 1987], e.g. a (mental) checklist to remind the wastewater treatment operator of the areas he needs to visit during his maintenance round. The progression through the points on the checklist, however, cannot be anticipated and should not be prescribed because it depends completely on the state of the process and the effect that has on the different local areas. If a wastewater treatment worker was forced to follow a formalised plan dictating his round independent of what was encountered on his round, the wastewater treatment process would most likely collapse in a matter of hours. Furthermore, these cases share a high emphasis on collaboration-working in pairs or needing to keep one self continuously updated on what other people are doing are key to the wastewater operators' routines just as it is important for the electricians to learn about the experiences of colleagues.. 


\section{Chapter 8}

\section{Mobile technology and design}

This Chapter examines design of mobile technology. More specifically, I will look at the challenges that arise when dealing with interface design, how to interact with the new technology and look at integration issues between the mobile technology and other technology. However, before I enter into these topics in depth, I will give a short presentation of the range of mobile technology I will be discussing in relation my primary areas of interest.

\subsection{Mobile technology-an overview}

In 1976, Alan Kay described a vision of a general computing tool powerful enough to support $80 \%$ of a single user's computing needs and lightweight enough to be carried everywhere. He named his vision 'the Dynabook' [Jones, 1983].

In 1991, Mark Weiser coined the phrase 'ubiquitous computing' to describe his vision of a computational environment where a hosts of small computers were hidden in everyday objects, providing users with an easily interactable and fully connected computational space no matter where they went. Personal documents and work could be accessed everywhere at your convenience [Weiser, 1991].

In 1995, Kari Kuutti coined the term 'babyfaces' to describe computational devices with small user interfaces, i.e. without the traditional large screen, mouse and keyboard. The development of particularly mobile devices that match this description has boomed within the last 5-10 years, especially within the field of telecommunication but also in the realm of e.g. mechatronics components like flow meters, frequency converters and motor valves.

In 1999, Don Norman stated that the PC is too complex to be useful to anybody and states that the future instead belongs to task-specific, easy-to-use, built-in gadgets, referred to as 'information appliances' [Norman, 1999].

Palmtop devices, mobile phones, mechatronics components with solid user interface (SUIs), GameBoys, wearable devices, embedded devices, tangible bits—only 3\% of the total number of chips produced today are put into personal computers. For the purpose of narrowing the scope for this dissertation I will limit my focus to dealing with hand-held devices. Specifically, when discussing mobile technology I will relate the discussion to palmtop devices and mobile phone devices because these are the types of technology I have had experience in using and working with myself.

[Kristoffersen and Ljungberg, 1999c] distinguish between five categories of mobile 
devices to describe what they perceive to be key types of mobile technology in respect to their purpose and their characteristics:

- The mobile phone

- The PDA

- The hybrid

- The mobile information appliance

- The wearable computer

In this context, I find it more meaningful to distinguish between task-specific and general-purpose devices, both in relation to PDA's and to cover the 'hybrids' presented in [Kristoffersen and Ljungberg, 1999c], and thus get the following classification:

- General purpose PDA's including "mixed communication devices"

- Task-specific PDA's and other mobile information appliances including standard mobile phones and most wearable computing devices

General purpose PDA's cover general communication devices like the Nokia Communicator which aims to be a mobile communication central, allowing the user to e.g. access web pages and write email in addition to using the ordinary phone connection. Task-specific PDA's cover devices like electronic calendars such as the 3Com PalmPilot and the Casio Cassiopeia, GameBoys and mobile phones. Since the first truly handheld mobile phones were introduced in 1986, mobile phones have developed into the most commonly used mobile communication device and the most generally available and best selling mobile device in general. At the end of 1999, almost 500 million mobile telephone units were sold globally. Within this categorisation scheme, mobile phones denote mobile devices with basic telephone capabilities. The categorisation describes two major trends I see emerging within the realm of information and communication technology: media convergence and specialisation. Media convergence describe (on a larger scale) the increase in the development of multimedia devices like PC/TV's where the convergence of the former independent devices provides the user with more functionality conveniently collected in one device (or, at least, that is the vision). Specialisation describes the movement towards creating devices that have one or a few specific areas of application like a corkscrew, a tape recorder or the popular computer gaming consoles. In [Norman, 1999], Don Norman uses the term 'information appliances' to describe task-specific computational devices (with the capability of sharing information amongst each other) and thus launches the attack against the personal computer which he claims has become so complex it is failing as a meaningful tool for supporting human work. While I do not agree that the personal computer has failed to support work in a variety of ways for numerous groups of professionals, I find the arguments hold true in relation to mobile devices because, as I shall argue in detail later, they are utterly unsuitable as general purpose devices.

\subsubsection{A general lack of design principles}

With the astonishing increase in the development of different types of mobile devices and services comes a demand for developing the user interface and interaction 
modes to support the interaction with the components. Common to all efforts, however, is an acknowledgement of lacking a set of principles or an appropriate conceptual framework to guide the interface design for babyface devices as emphasised by e.g. [Rodden et al., 1998]:

"Furthermore, more prosaic developments such as mobile phones, GPS and embedded in-car automation all point to a more mobile and embedded future for computation. This development of applications which exploit the potential offered by this technology brings together issues from distributed systems, HCI and CSCW. However, designers of these systems currently have few principles to guide their work"

While not solving the problems, an important issue resonated throughout the literature (e.g. [Dix and Beale, 1996, Rodden et al., 1998, Olsen, 1999, Johnson, 1999]) is, that the focus for designing for mobile devices needs to be shifted from the design of the device itself to designing for the context of use. However, it is a far cry from pointing to an approach as general as designing with the use context in mind rather than the technology, which I support wholeheartedly, to providing actual guidelines for design and none of the aforementioned papers offer much more than this, unfortunately.

[Rodden et al., 1998] presents a taxonomy of mobility within which to consider interaction with mobile devices and discusses the multiplicity of contexts as a starting point for design of interaction. The taxonomy emphasises the devices relationship with the technical infrastructure, the application domain, the socio-technical system in which it is situated, the location of its use and the physical nature of the devices as vital aspects of context, and distinguishes between different aspects of locality and mobility, e.g. fixed, mobile and autonomous with respect to the level of mobility, and free, embedded and pervasive with respect to the relation to other devices or the environment. As all taxonomies, however, it deals with the general rather than the specific, defining structures within which design of mobile technology may be understood and developed as the field matures. [Olsen, 1999] stresses that the rapid development in all computer-related areas presents us with the task of dealing with and designing for a highly heterogeneous collection of devices with different physical attributes, using different formats and providing different services. Olsen's notion of 'chaos' corresponds on a general level to the term 'wired wilderness', used by [Bertelsen and Nielsen, 1999] [P3] to describe a wastewater treatment plant as a complex but ever-changing, highly technical setting sustaining the process of cleaning the water. The wastewater treatment plant consists of a multitude of highly heterogeneous devices to monitor and control the process through which the workers have to interact using many different interaction forms. The development in mobile technology thus demands, as [Johnson, 1999] also argues, that human-computer interaction issues becomes more central to design of the new, mobile systems. He makes an important point in stressing that even though we can utilise frameworks that allows us to analyse and understand the social, organisational and historical context in which the artifacts will be a part, like the activity theory framework, this has not solved the design questions:

"The problem for design is not to understand or explain that behaviour, structure, or society, but design systems to work within it and improve upon it"

Thus we are now faced with the challenge of considering issues of e.g. diversity, inconsistency and integration, which our current frameworks of analysis and models for 
design may be unable to deal with. I do not aspire to solve these problems with this dissertation and provide a full-fledged framework for interface design for mobile devices, but I will provide some concrete examples of how to deal with aspects of design for integration between heterogeneous devices in Section 8.2.1.

\subsubsection{Interface design for mobile technology}

The often very limited screen space and processing power sets a new agenda for information visualisation. The latest generations of PDA's are getting closer to PC's with respect to the processors they pack, and the resolution is definitely getting better, but for mobile phones the differences between the amount and quality of information we can present is a far cry from your standard PC monitor. Common to both the PDA's and the mobile phones is the limitations in the physical size of the screen which presents interface design with some serious challenges, particularly with respect to information visualisation. In the following, I will present different approaches to dealing with these challenges before I present a solution created for the CIS project in Section 8.2.1.

[Björk et al., 1999] also deals with presentation of information of heterogeneous devices or more precisely the need for "automatic on-the-fly transformations of existing web content to mobile formats". They base their approach on focus+context techniques, an issue first identified in 1980 by Bob Spence and Mark Apperley who subsequently created the Bifocal Display as a solution for it [Spence and Apperley, 1982]. With this, they aim to provide a good overview and basis for navigation in large quantities of information on a small device without basing everything on the well-known WIMP-techniques. As such, it is an admirable effort to take a step away from menu based structuring of information in interface design for babyfaces. However, their choice of using the focus+context approach on the PDA seriously cripples the effort because the structuring principle inherent in this approach of showing the object in focus in a representation of its context demands a lot of space and as such is wholly inappropriate for devices with very limited screen space; in effect, they replace one information visualisation technique designed for the PC with another.

[Zellweger, 1998] presents a novel technique for enhancing hypertext links by attaching expandable glosses or margin remarks to the links, placing the information in context with the source material. Fluid links use fluid annotations to smooth the hypertext browsing experience and help reader to choose between links. They present different strategies for making space to display the glosses that have different advantages and disadvantages with respect to e.g. placement and trade-offs with the other text material. Having worked with eBooks, the screen space issues have definitely been present in their approach. Lately, however, the fluid link approach has been extended to look at fluid annotations on 'normal' web sites, e.g. in [Zellweger et al., 2001].

\subsubsection{New interaction paradigms for mobile devices}

The prevalent interaction paradigm for mobile devices, particularly the PDA-type devices, is direct manipulation based on the desktop metaphor, as we know it from the PC. The advantages of this interaction approach are that you interact more directly with objects or representations of objects through dragging them or pressing buttons, and you get immediate visual feedback on how your operations on them changes them, 
than through e.g. a complex command based interface. However, direct manipulation of often visually rich detailed objects require quite a lot of space and may force scrolling, even for the PC environment. This space problem becomes even more handicapping when we deal with a $160 \times 160$ pixel screen, which is the standard for several Palmtop devices. Many palmtop devices are designed as electronic calendars (hence the four standard hard-coded buttons for easy access to your calendar, address book, a notebook and a to-do list), i.e. a specific tool rather than a general-purpose tool like the PC. Text has been deemed the predominant input/output mode which is why the touchsensitive screen solution combined with a stylus and a graffiti language was chosen for the best interaction mode for the device as it pertains the look and feel of your regular calendar. Ironically, the stylus and graffiti language is much less suitable for text input compared to the keyboard because it gives the impression of being as natural as writing with a pen on paper but forces the user to adopt an artificial alphabet which is error prone in relation to the translation needed for the device to recognise the characters. The adoption of the desktop metaphor to the PDA devices is understandable in that it is the predominant interaction paradigm for computers (by this I mean, PC's) and many palmtop devices are presented as smaller versions of laptop computers, which are smaller versions of the desktop PC and as such a device that works as a stand-in for their PC when they are out of their office.

Taking up the design challenge on the interaction front, [Kristoffersen and Ljungberg, 1999a] present MOTILE, a technique and system for operating mobile that offer an interaction style based on design implications from two case studies: no or little visual attention, structured, tactile input and the use of audio feedback. Their case studies share similarities with [Bertelsen and Nielsen, 2000] [P5], where we push the boundaries for interaction with a handheld device by using the augmented reality principles as interaction styles, but where [Kristoffersen and Ljungberg, 1999a] focus on developing a general interaction technique for a handheld computer that moves beyond direct manipulation, we show the potential of interaction based on the physical object using specific work situations to frame and motivate the efforts.

In the following I will mention other examples of new ways of interacting with handheld devices, the ones I find particularly interesting, I will cover in more detail:

\section{Keyboards-real and virtual}

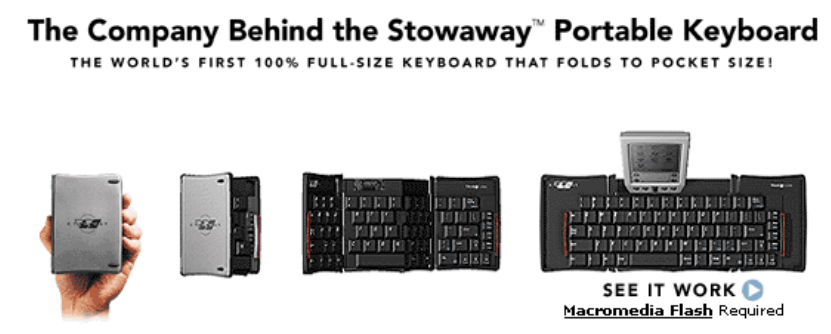

Figure 8.1: The foldable Palm keyboard

Text input is still by far the most important mode of interaction with any of the mobile devices in this context. For mobile phones, SMS or texting has become immensely 


\begin{tabular}{|c|c|c|c|c|c|}
\hline$\rightarrow 1$ & $\mathbf{q}$ & 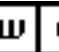 & $\mathbf{e}$ & $r$ & t \\
\hline$\hookleftarrow$ & a & $\mathbf{s}$ & d & f & g \\
\hline 仓 & 2 & 28 & c & \begin{tabular}{l|l}
$c$ & $\mathrm{v}$
\end{tabular} & 11 \\
\hline
\end{tabular}

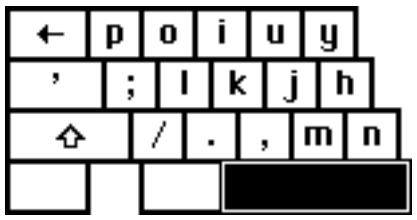

Figure 8.2: The Half-QWERTY keyboard layout

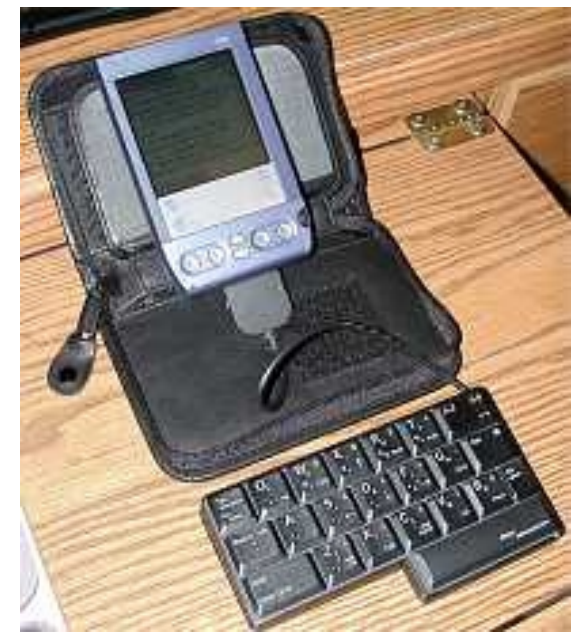

Figure 8.3: The Palm with the half-qwerty keyboard 
popular, especially amongst teenagers who use texting for everything from coordinating their activities with friends to voting for music videos on MTV. For Palmtop devices, we deal roughly with two categories: the specialised personal calendar/organiser (Palm, Cassiopeia, Visor) or the more general communication device (Nokia communicator). In both cases, however, writing is an integral part of interacting with the device; you write addresses and meeting notes in your calendar frequently just as you input text when you want to browse the web or send an email. Not surprisingly, keyboards still, in many respects, provide a fast and reliable text input superior to handwriting recognition or stylised languages like the graffiti-language used on the PalmPilot. Consequently, a lot of designing effort has gone into making keyboards that are both handy and mobile and which do not sacrifice the usability by e.g. making them so small they can only be used with extreme care and a pointy stylus, like the virtual keyboard present in any palmtop device. Some are pretty straightforward, like the foldable Palm-keyboard, but others have used a less traditional approach, like the wireless rings presented in [Fukumoto and Tonomura, 1997]

\section{Screen + stylus}

Alternatives to the graffiti languages and text recognition schemes are using movements or written gestures to input text. I have chosen two examples of ways that use the touch-screen and stylus but which do not use some kind of alphabet to write letters and numbers.
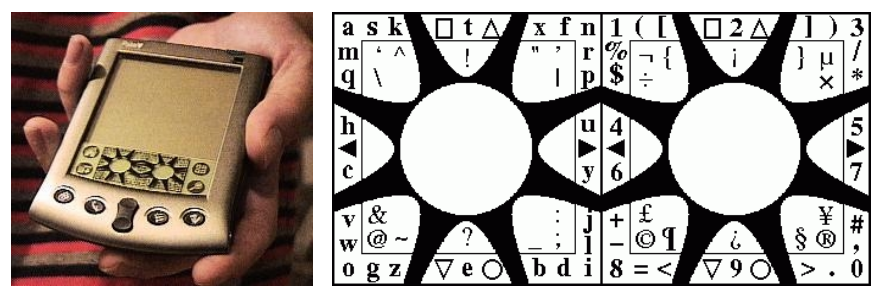

Figure 8.4: The Quickwriting layout for the PalmPilot device

Quickwriting - text input The idea behind Quickwriting [Perlin, 1998] is to use a pen movement from the centre of the figure and through the relevant letters, thus writing entire words or even sentences as one, continuous gesture. This mode of writing is supposedly many times faster than any ordinary graffiti-type text entry scheme. I use the word 'supposedly' because I have tested the emulator which is publicly available on the Quickwriting web site but have not been able to produce as much as one intelligible word using it. The layout itself demands a high degree of concentration from the user to be able to find the letters you want, and the density of the characters makes it impossible to differentiate between the individual letters and numbers with the pen strokes.

T-Cube-text input using marking menus The T-Cube [Venolia and Neiberg, 1994] allows each user to encode the characters as "flick gestures"; defined by a space of nine target cells and eight possible directions to move in a marking menu style structure as 


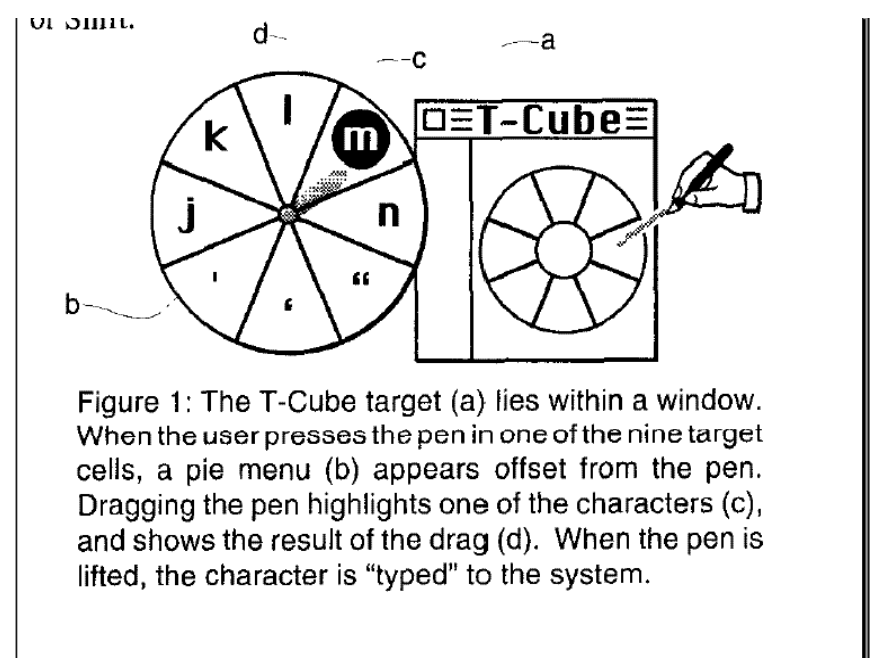

Figure 8.5: Using marking menus for text input-T-Cube

www.daimi.au.dk/CPnets/ CPN2000

www.ideogramic.com some disadvantages. First, even though the menu becomes visible when the pen is stationary for a few seconds, there is not much help in discovering the full structure-i.e. where the other letters are placed in relation to this menu. Second, marking menus may provide extremely fast interaction when you associate a function or letter with a direction or movement, but it quickly becomes cumbersome to remember forty-some distinctly different directions for the different letters, numbers and special characters. Marking menus show their strength when we are dealing with a very limited number of functions and are much less useful as a text-input scheme. Excellent examples of this can be found in the CPN2000 project, and the Knight project. Third, because no standardisation exists for marking menus, it is impossible to regulate or predict the placement of functions or letters from one application to another.

\section{Gesticulation-focus on natural interaction.}
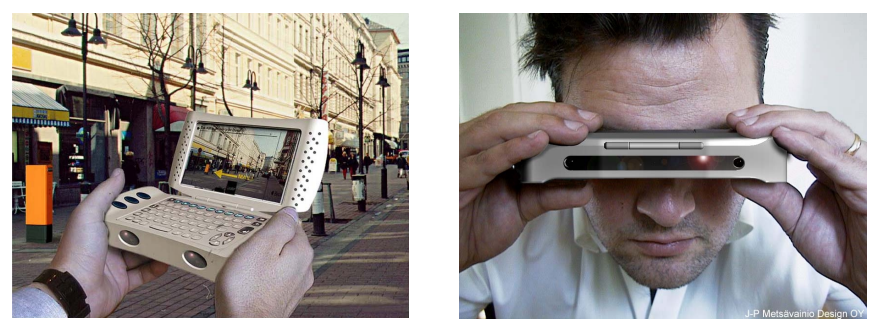

Figure 8.6: Two ways of interaction with the CyPhone

\section{CyPhone-gesticulation interface to location specific services}


"The goal of the CyPhone project is to develop augmented reality services and picocellular based network architecture for future mobile telecommunication services"

www.ee.oulu.fi/projects/ CyPhone/concept.html

This quote describes the concept behind the CyPhone device as described by the research team at Oulu University. The CyPhone device is conceived as a general purpose tool where the projection of an information layer upon the real world provides the user with and augmented reality to move within, enhancing and supporting e.g. travelling in a new area. Originally, the interaction with the device was to be based on a gesturelike 'pointing and beaming' strategy-you pointed a handheld unit at whatever you wanted to receive information about or interact with and the units in the environment responded. The prototype the project has built so far apparently uses a touch-pad input device positioned in the user's belt. Pictures of the prototype can be found on the project web site. Exactly how the current interaction strategies differ from the original is unclear but the original concept seemed focused on providing a natural interaction with the surroundings which, of course, introduce issues of precision in relation to direction (if you are in a highly wired environment and point to an object at a long distance, how will the units in the environment know which one you are trying to interact with?).

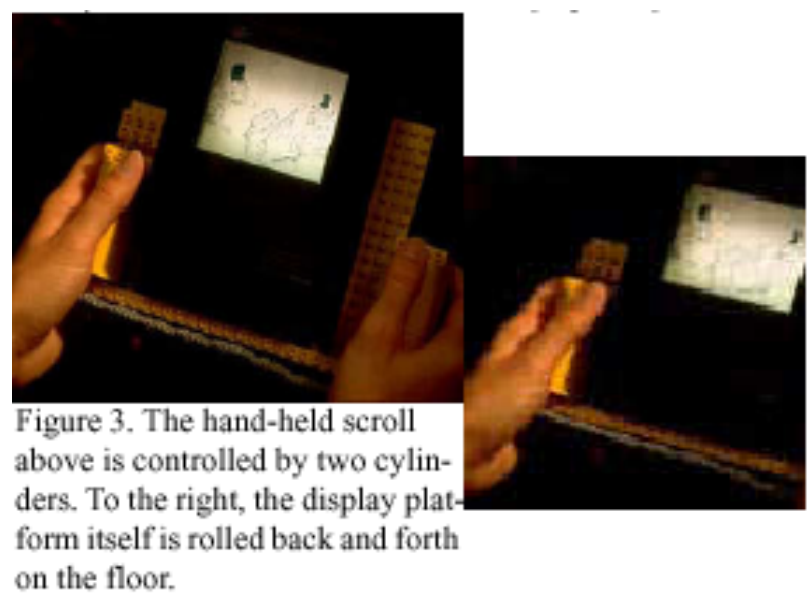

Figure 8.7: Scroll painting prototype

Spatially aware graspable interfaces The two prototypes presented in this paper [Small and Ishii, 1997] use movement in real, physical space to control navigation in the digital space, one being a scroll painting (see Figure 8.7 and the other a portable electronic newspaper. Using sensors to detect the acceleration and velocity of tilting plus cylinders or thumb 'clutches' to interact with the devices, they aim to "erase as much as possible the division between input (control) and output (feedback)"- an attempt to make interaction as direct as possible by acting directly upon the physical object and taking advantage of the device being aware of its location in relation to the user in the feedback.

www.ee.oulu.fi/projects/ CyPhone/prototype.html 
Other examples of 3D manipulation of virtual objects are the tilting interface presented in [Rekimoto, 1996] and [Harrison et al., 1998]

\section{Multi-modal interaction}

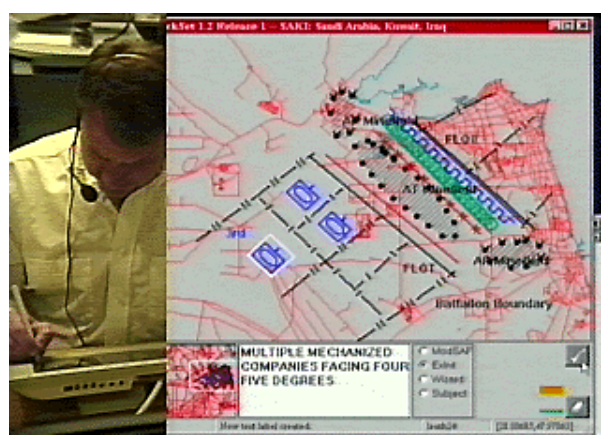

Figure 8.8: Quickset device layout

Quickset-interaction through a combination of audio commands and pen based interaction QuickSet is an agent-based, wireless, collaborative, multi-modal system that enables multiple users to create and control military simulations. The QuickSet prototype uses a multi-modal interaction scheme, combining speech and gesture to interact with e.g. maps. By pointing and using verbal commands (See Figure 8.8) it is thus possible to e.g. find the distance between two locations. Furthermore, QuickSet scales from wall-sized to hand-held units, enabling users to interact with a wall-size screen through a hand-held device as depicted in Figure 8.9. This bears some resemblance to the pick-and-drop concept presented in [Rekimoto, 1997, Rekimoto, 1998]. However, Rekimoto's approach treats the different technologies as different tools, e.g. a palette (PDA) and a canvas (whiteboard). The combination of different modalities in the interaction seems very promising, particularly when combining pointing to an object with using a closed set of verbal commands as is the case with the QuickSet system.

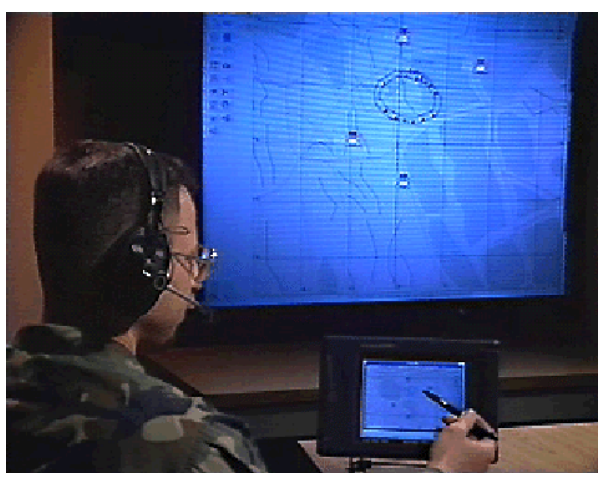

Figure 8.9: Quickset—using multiple technologies 


\subsection{Our prototypes}

In the following, I will discuss how the design considerations have been reflected in my work by presenting some of the prototypes I have made during the CIS-project.

\subsubsection{The integrated approach}
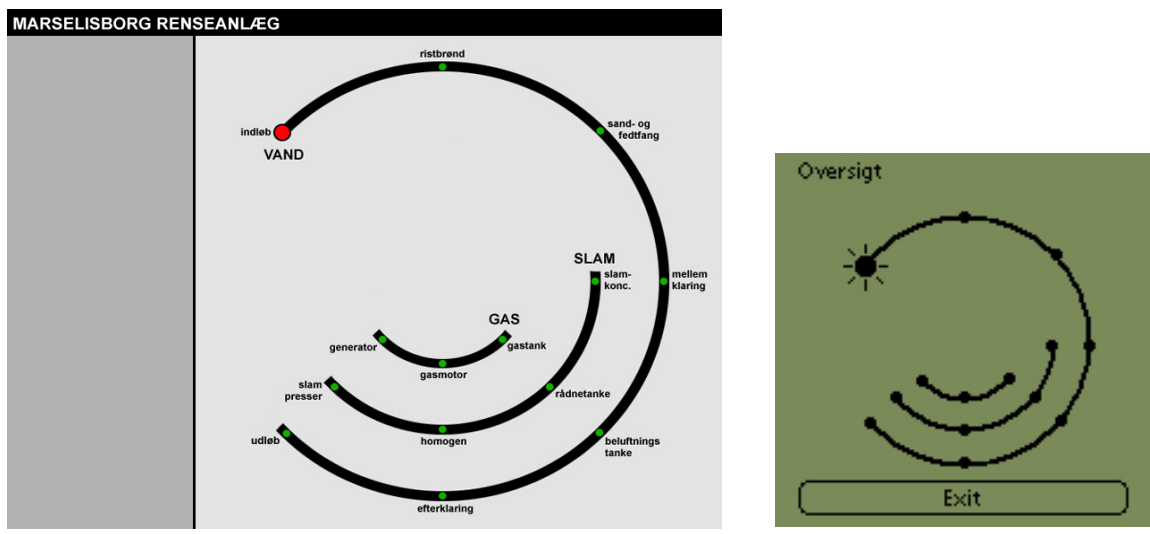

Figure 8.10: First view—PC and PDA plant overview
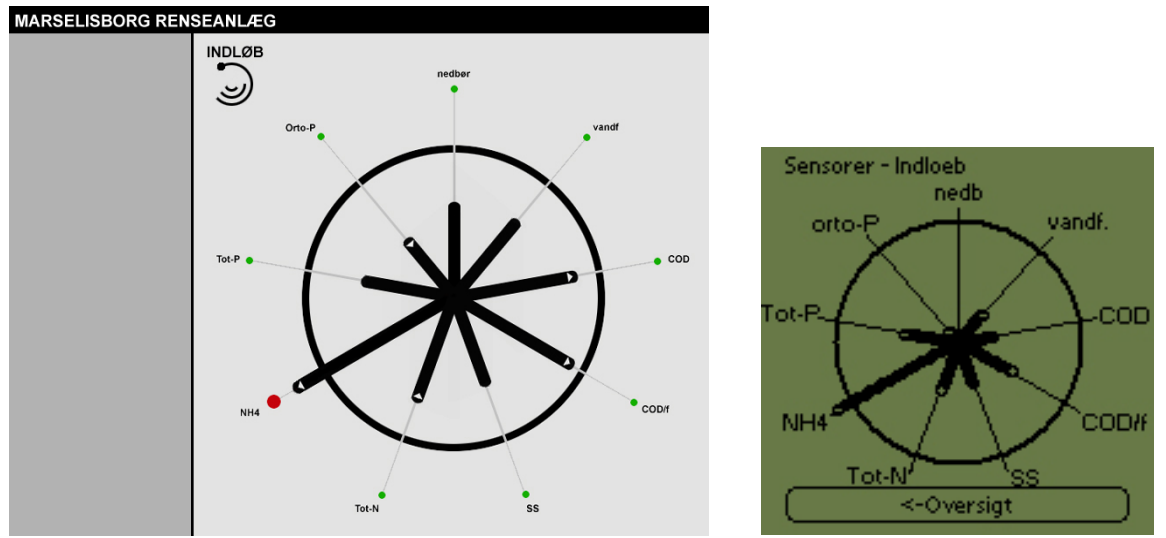

Figure 8.11: Second view-PC and PDA inlet water

My first example is an integrated prototype where we introduced a handheld device as an expansion of the existing control system, giving the system mobility by enabling the wastewater operators to access system information on the plant. The design builds upon the understanding that we are extending the larger, PC-based system with basic mobile viewing capacities, and not replacing it by moving the entire system to a mobile base. This is reflected in the user interface and the functionality. Our main goals with 


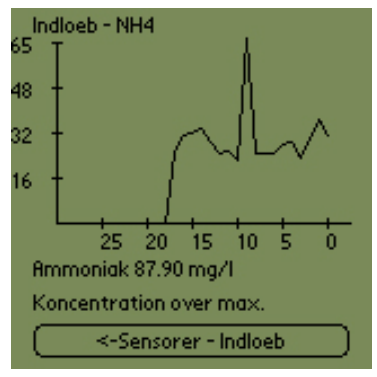

Figure 8.12: Third view—PDA single sensor information

the prototype was to support overview of the process and provide a sense of integration between the PDA-based and the PC-based constituent as well as provide access to otherwise inaccessible system information locally on the plant. We supported overview by choosing the circle shaped graphics, both because the circle shape is excellent at representing relations e.g. between the different processes (water, gas and sludge) on the overview screen (see Figure 8.10), but also because it let us fit the entire process onto one screen and thus provide an at-a-glance overview of the entire process. If a component reports an alarm, the associated sub-process on the overview screen will change graphically as is the case with the inlet in Figure 8.10. Thus, the wastewater operator can walk past his PC or pull out his PDA and instantly get a sense of the state of the process from the overview picture. The same argument can be made for the second level, i.e. the inlet (see Figure 8.11. Integration was supported by choosing a sufficiently simple graphical layout to be used on both devices. We wanted the design to show a clear link between the system on the PC and the mobile device and using the same graphical representation for a collection of devices is a direct way of denoting integration between them. The empty space at the left of the screen design for the PC indicates that here is room for buttons, alarm lists, etc. that would provide the user with access to other parts of the information in the central system or other applications relevant for the running of the plant. At the third level we find the component specific information which on the PDA provides a graph of the development of the sensor values in the last hour/last month, the current value from the sensor, a possible alarm message and a button for going back to the second level. At the evaluation workshop, however, the graph was rejected by the wastewater operators who stated they would use the PC if there needed to look at more detailed trends than the one given on the second level.

With this prototype we focused on issues of information visualisation on highly heterogeneous devices. In designing the screen layout, We wanted to steer clear of the pitfall of down-scaling the interface design from the PC to fit the PDA and thus propagate a much too complex interface structure for such a limited screen. Conversely, we wanted to avoid designing for the lowest common denominator, the PDA, up-scaling a much too simple interface design that was unable to take advantage of the PC's technical possibilities. The result was a total re-design of the existing interface to accommodate both types of technology without sacrificing the need for maintaining an overview and display a sense of integration between the devices. A possible enhancement of our 
design could be pursued by looking towards the fluid link strategy [Zellweger, 1998] presented in Section 8.1.2, utilising the space-economic fluid links to e.g. associate the current value for a component with its link on the second level, making component specific information available there at the user's request.

A more detailed account of the field study that the development of the prototype was based on and our design considerations can be found in [Nielsen and Søndergaard, 2000] [P4]

\subsubsection{Augmented Reality prototypes}

My second example deals with interaction principles for the PDA that transcends the use of a pen tapping on a screen. Using the concept of augmented reality [Mackay, 1998a] as a thinking tool for exploring interaction with a mobile device, we created four future scenarios and four corresponding horizontal prototypes that exemplified interaction principles where focus was on physical interaction with the PDA. These future scenarios were based on real work descriptions from our field study at the wastewater treatment plant and developed through the 'glasses' of each of the augmented reality principles, augmenting the user, augmenting the object and augmenting the environment. The resulting future scenarios and the prototypes should thus not be seen as actual design foundations but as a source of inspiration for new interaction paradigms for PDA's.

The first prototype (Figure 8.13), based on the 'augmenting the user' principle treats the PDA as a remote control for the different components, letting the user interact with e.g. motors in a gesture-like fashion.
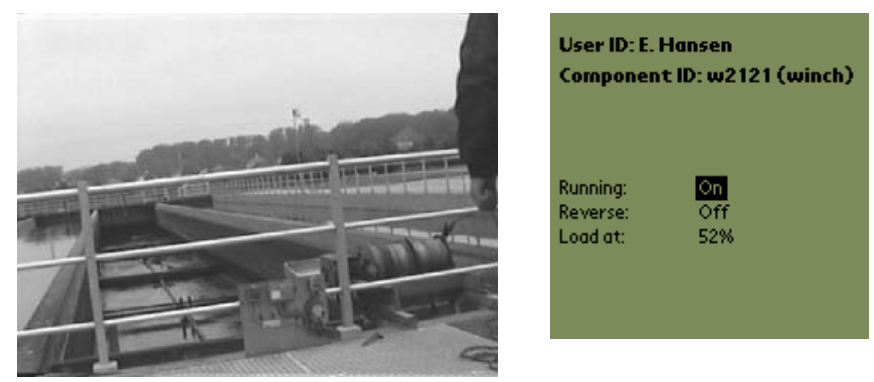

Figure 8.13: Prototype based on the augmenting the user strategy

The second prototype (Figure 8.14), based on the 'augmenting the object' principle, deals with local display and control. By placing the PDA on the component, control of the component is given locally, through the PDA.

The fourth prototype (Figure 8.16), based on the 'augmenting the environment' principle deals with access to online help. During repair of components, the PDA guides the user through the disassembly procedure as the user scans in bar codes placed on the parts he remove. When one part is scanned, the PDA's display changes to show the next step, highlighting the next part to be removed on a technical drawing. 

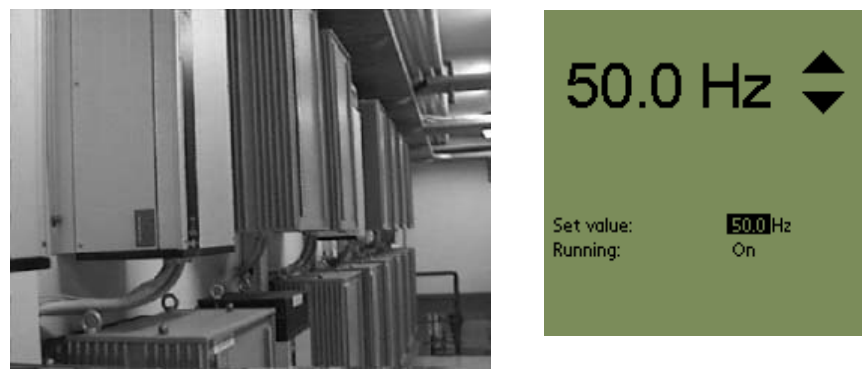

Figure 8.14: Prototype based on the augmenting the object strategy
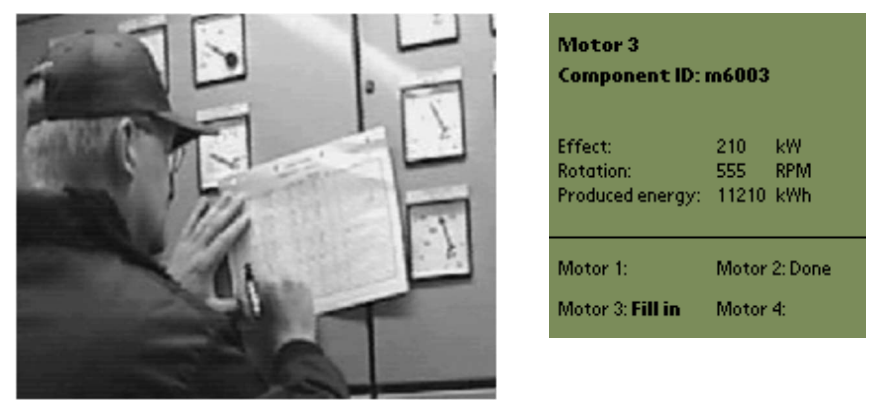

Figure 8.15: Second prototype based on augmenting the object
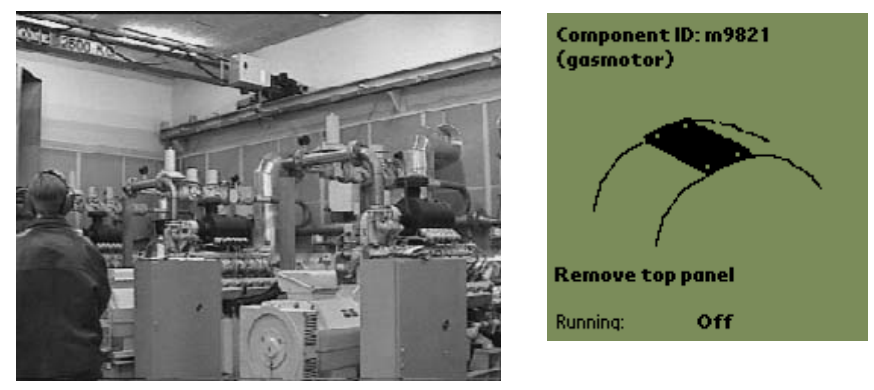

Figure 8.16: Prototype based on the augmenting the environment strategy 
The three different strategies of augmenting the user the object and the environment enabled us to transcend the image of interaction with a PDA as limited to scribbling on a four square inch pad. Through our future scenarios, a broader range of physical postures in interaction with a PDA emerged: hand waving, writing, walking around, etc. The original formulation of augmented reality was primarily a concept of interface technology, the way we have used it in this paper turns it into an interaction style concept. Thus, augmented reality may be abstracted into interaction concept independent of the concrete technical substrate of implementation.

\subsection{Mobile technology and integration}

When looking to support mobile, distributed work by means of introducing new technology, e.g. a mobile device, we need to consider how this new technological artifact should relate to the existing technology as well as to the work practice in general. If new technology is designed without regard to the other technological artifacts present in the work situation and treated as if it were to accommodate anybody doing anything from anywhere it poses a serious threat to the understanding that support for mobile work is realised through a combination of mobile devices and desktop systems, which enables users to adapt and reconfigure themselves in respond to the changing demands of use situations.

To transcend this 'interacting in chaos' [Olsen, 1999] and create a sense of coherence in the access to shared information through the employment of heterogeneous devices, it is therefore necessary to look at the devices in their 'web-of-technology', instead of merely considering it cooperation between independent devices. The 'webof-technology' concept looks at the introduction of new technology in relation to the existing technological artifacts in concrete use situations and thus provides a shift in focus from 'designing the user interface for a mobile device to support mobile work' to 'designing the user interface for a mobile device to support mobile work in relation to the existing technology'. In some settings close integration between the new and 'old' technology will be strong and in others, it will be weak. The important point, however, is that we are brought to consider the relationship between the different types of technology mediating the use activity as a natural part of design technological support for a use practice. Without it we are forced to design blindfolded with respect to understanding how the relevance of information in different situations and physical contexts affects the functionality of the different devices in the work context and consequently the design of the technology to support it.

Dealing with integration across devices is the focus of [Rist, 1999], which presents user interfaces for accessing the same virtual meeting place from heterogeneous communication devices, namely a PC, a Palm and a mobile phone. Their proposed user interfaces touch upon some important aspects of designing for a great variability in e.g. the physical output devices but still pertaining a sense of integration in the system, which is of vital importance in collaboration tasks. Their approach, however, is centred on the technical solutions for this type of collaboration, and works under the assumption that the presentation of information can be automated. I find this assumption highly questionable, particularly because the studies so far of design for babyfaces show that the less screen space you have to work with, the more innovative your approach to presenting information has to be. Furthermore, this approach does not 
question the relevance or necessity of accessing all information in the system regardless of which device and situation the user presently is in. My experience with the use of mobile devices so far, which has been gained through my participation in design projects and through teaching a class in mobile and wireless systems, leads me to findings that points to the exact opposite: the more limited the device you access information through is, the more context dependent the information you seek has to be because it is vitally important to economise the amount of information we put out there.

[Román, 1999] explores the challenges of integrating a PDA in a distributed environment. They argue the importance of using PDAs as 'enabling bridges' to services rather than treating the PDAs as isolated entities, which in phrasing seems quite similar to our view of integration. However, as their approach to integration is technical, the consistency in their system is supported by contents alone. Visual representation is an important element in maintaining a sense of integration across different devices and it is with this visual and contextual integration in mind the technical integration must be developed rather than treating the design aspects as independent from the technical aspects. My concern with integration thus extends from being a product of the process to being a vital part of the process; for technical, functional and design-wise integration to be present in a product, the design and development process must allow for an integration of the different, relevant fields of expertise as well as of the different aspects of development. Thus the process itself must be open, dynamic and be able to handle multi-disciplinary participation.

The discussion of integration on and across different dimensions has strong relations to information appliances and the way they are envisioned to be seamlessly incorporated into the environment. Norman's plug-and-play vision for the information appliances where everybody adds and removes components to fit one's needs demand a high degree of integration on several different levels. A huge technical infrastructure is needed to establish the expansive network for dealing with the different information appliances as they go on and off the network. This dilemma is described in [Odlyzko, 1999]:

"Careful design that is focused on human factors, and incorporates powerful processors and software, can provide information appliances that are a delight to use. The Palm Pilot and game consoles prove this. However, that does not mean that we will be delighted with the new electronic environments full of such gadgets, even if (and this is a big if) each is excellent in itself. Information appliances are not meant to be standalone devices."

Even if we get the environment wired and stable enough for the technical dimension to function satisfactorily, we are faced with another challenge, one of conceptual integration. How will the individual information appliance adapt to and provide the user with information about which other devices it is "plugged into"? How can we possibly design user interfaces for mobile or embedded devices that are flexible enough to cope with being part of a multitude of different relations that change dynamically? When the functionality of an information appliance changes in response to receiving more or less information from the surroundings, the user interface must change accordingly to reveal the associations. This either requires user interfaces to be generated completly dynamically or by allowing only a fixed set of other devices it can be connected to, to 
anticipate the possible changes. The former is impossible to realise and the latter is too restrictive for the plug-and-play vision because it presumes to know which configurations of information appliances will be used by everybody. The future might very possibly prove me wrong, but for now the vision of a wired world inhabited by millions of interconnected information appliances is just that: an interesting vision. However, work that may very well be useful in this context is being done in relation to supporting work on maritime bridges. Elastic interfaces and elastic systems [Bøgh, 2001] based on instrument semiotics [May and Bøgh, 2000]: a semantic analysis of maritime intstruments' interface elements into basic building blocks that may be use to reassemble and tailor interfaces to different tasks. Thus in a given situation, the user on the bridge may combine different instruments to better support the task he is engaged in. I find their efforts and results extremely interesting and highly relevant in a number of contexts where flexibility is an issue. 


\section{Chapter 9}

\section{Conclusion}

With this dissertation I have presented my approach to design of mobile technology to support work in a mobile process setting. Central to my work has been the concept of 'web-of-technology' as a starting point for design: focusing on the existing 'webs-of-technology' when analysing work helps us gain an understanding of how the new technology we are about to introduce into a work setting should relate to what is already there. This relationship is particularly important when we are dealing with mobile devices as the physical and computational limitations of the mobile technology often makes them unfit for some tasks, e.g. providing an overview of large amounts of information or showing relationships across applications. Even though palmtop devices are now equipped with impressive processors, the PC is still superiour with respect to internet connectivity and screen space. Furthermore, supporting work in a mobile context often entails working in different environments with different resources made available to you, just as your needs change with the tasks you are involved with. It is therefore necessary to provide different types of support depending on the context. So instead of replacing one technology with another, it is often much more useful to expand the technological tool-kit and enable users to better adapt to the changing situations and environments. Taking the view of enhancement rather than replacement, the relationship between the different tools then needs to be clarified becuase the degree of integration between the different devices has an impact on how we design for them. Strongly integrated devices require a higher degree of consistency in the user interface across devices than weakly integrated, and often the user interface for the existing technology is unsuited for an integrated design as was the case with the control system interface in the CIS project [Nielsen and Søndergaard, 2000] [P4].

In the following, I will sum up the results my work has yielded, starting by relating the 'web-of-technology' concept to each of the three constituents I am dealing with: the design process, the work environment and the technology

\subsection{Designing to support...}

What does the 'web-of-technology' concept offer the design process? It provides a focus on the technological artefacts in the work environment as a natural part of workplace studies alongside observing use, which can only strenghten our understanding of the work practice. It also provides means for analysing the relationship between new technology we wish to introduce into the work environment, and the technological 
artifacts already present.

Taking a broader view of an (activity theory based) action-oriented research perspectiv on the design process, my dissertation has examined and developed upon the following:

Use and design are becoming more closely related. This calls for a focus on active user involvement and participation in the design process from other groups than designers and usability workers and for getting out of the 'usability lab' and do design 'in the wild'. Chapter 6 and [Bødker et al., 2000, Nielsen, 1998] [P1,P2] describe our efforts to address these issues during the BIDI project. We have supported the latter by introducing new methods for bringing the field into the lab (e.g. by physically simulating the use environment in a workshop space) but also bringing the lab into the field (e.g. by playing through scenarios in the actual work environment) because the two realms have much to offer as complements to one another. We have approached the former particularly with the focus on active user involvement; providing the users with the opportunity to do design alongside designers and usability workers. This has been supported in part by taking design to the use environment as described above, but also: by introducing caricatures and metaphors to challenge and inspire design; by using realistic work descriptions as basis for developing visions for the future; and by using prototypes and mock-ups to make design discussions concrete for all participants and to express design ideas as tangible, physical objects. These efforts are furthermore broad enough to form the basis for a general support of interdisciplinarity in design, supporting contributions from aestetics and sociology as well as the technical realm.

\section{2 mobile work...}

As described in Chapter 7, working within a mobile process setting brings focus on the heterogenaeity of context-work is characterised by being site-specific and context dependent and to support it we must understand the dynamics in the scope of the work. In a specific situation where a worker at a process plant brings a small device into the environment, the information on the device and the contextual information in the environment will work together. This dynamic determines what kind of information it is needed to access where. This relationship has two implications. First, it questions (and rejects) the assumption that all information is relevant regardless of location and situation, which is the foundation of the "accessing anything at any time from anywhere" ideal often associated with the development of mobile technology. Second, it brings focus on providing a range of technology, enabling the user to choose the right tool for the right task.

With this dissertation I have presented means for addressing both issues. The first, through providing analyses of the dynamics in wastewater treatment work, both in [Bertelsen and Nielsen, 1999] [P3] and through the different analyses presented in Chapter 7. The second, by unfolding the existing 'web-of-technology' as proposed in Section 7.1.3 and use this and knowledge of the work practice to focus the development of technological support on the understanding that when we work, we are 'here, now', not 'anywhere, anytime'. 


\section{3 with mobile devices.}

The development of microprocessors, memory chips, integrated sensors, storage devices, and wireless communication systems gives us new possibilities for supporting mobile work. At the same time, design of mobile technology poses design challenges because no design guidelines have been defined. This is partly because we are dealing with a multitude of heterogeneous mobile and embedded devices with different interface properties but also because the above mentioned development of technology has not yet stabilised. With my dissertation, I have presented concrete examples of how some of the interface design challenges may be approached, both with respect to information visualisation [Nielsen and Søndergaard, 2000] [P4] and interaction paradigms [Bertelsen and Nielsen, 2000] [P5].

The design of mobile technology may be informed by placing the mobile device in the 'web-of-technology' associated with the work practice we are aiming to support. This allows us to see the mobile device in a larger context and consider how the site-specific and situation dependent tasks should influence the interface design and functionality of the different devices present. I have given a concrete example of this by presenting an integrated prototype for wastewater treatment operators that provides them with different opportunities for accessing system information depending on whether they work in the control room or are walking through the plant [Nielsen and Søndergaard, 2000] [P4].

With this dissertation, I have focused on introducing my 'web-of-technology' concept in relation to how it may be used to get a clearer understanding of mobile process work and how it may inform design of technological support for mobile process work. What has been left out of my discussion is how such an analysis relates to other strategies of understanding mobile work, e.g. the relationship between 'web-of-technology' and organisational analysis. Nor have I discussed the implications of having different views into the work in relation to creating the 'web-of-technology'; the relations and conflicts between the 'web-of-technology' for one individual worker and the 'web-oftechnology' for a group of workers or for the process plant itself. I find both elements to be highly important in and see them as part of a natural next step for re-evaluating and developing the 'web-of-technology' concept.

\subsection{Future work}

Even though I am at the end of my dissertation work, my work in relation to mobile technology has only just begun. Design issues concerning the different aspects of interface design for mobile technology are far from resolved. The technologial development shows no sign of slowing down and the pervasive computing focus becomes increasingly important as more and more computer chips become embedded in the surrounding environment. There are many different ways by which you could approach these issues of which I will mention only one, namely the way I have chosen in my further pursuit of research within the realm of mobile work and pervasive computing.

\subsubsection{Designing a mobile EPJ}

Hospitals in Denmark are currently engaging in projects to replace the paper-based patient journal with an electronic journal. However, most of these electronic patient 
journal (EPJ) systems are PC'based and thus stationary, forcing the user to come to the "seek out" the journal to get access to the patient's information, which does not support the work practise for neither nurses nor doctors. A one-year project with the purpose of enhancing such an electonic patient journal system with a mobile unit to better support the work tasks at a hospital started in October 2001, with participation from the Center for Pervasive Computing at Aarhus Universitet. Based on an empirical study of a surgical hospital ward using an EPJ, we aim to develop twohand-held prototypes for accessing patient data. The first prototype will illustrate how EPJ data can be accessed through a browser application on a hand-held PDA. The second will illustrate design of client applications, supporting specific work tasks, and we will with this prototype focus specifically on information visualisation aspects for the hand-held device as part of an effort to design generel user interface principles for 'babyfaces'.

\subsubsection{A Post-WIMP analysis of mobile technology interfaces}

Having argued that interface paradigms created for the PC (e.g. the direct manipulation paradigm and the desktop metaphor) are ill suited for applying to design of mobile technology interfaces in [Nielsen and Søndergaard, 2000, Bertelsen and Nielsen, 2000][P4,P5], it seems to be time to consider alternatives. A structured analysis of how Post-WIMP interface properties [Beaudouin-Lafon, 2000] may be used in relation to design of mobile technology could be an interesting starting point for discussing and suggesting general design principles for mobile technology. I see this work done in spirit with the systematic analysis and development of CPN/Tools for the CPN2000 project [Beaudouin-Lafon et al., 2001]

\subsubsection{Fluid links on mobile interfaces}

The use of fluid links and fluid structures in general [Zellweger, 1998] have been introduced in different contexts ranging from eBooks over spread-sheets to web pages with success. I find the approach in relation to mobile technology and particularly palm-top devices very promising because the fluid links provide a space-economic apprach to information visualisation, enabling the user to call forth information as it is needed without changing the current context of use. 


\section{Appendix A}

\section{The SmartWindows project}

The SmartWindows project was a six-month internally defined project for the User Centered Design group at Danfoss (UCD) involving seven people (Jacob, Thomas, Ingrid, Kirsten, Shin, Nina, Eva) from the group and two research assistants (Pernille \& I) from Aarhus University. Furthermore, other actors were involved in shorter or longer periods of the process; The project was part of a coordinated field study in the BIDI project and several workshops were held with participants from the BIDI partners, several one- or two-day workshops with external participants were used to inform the process, e.g. with guest lecturers Paul Dourish (situational computing workshop), Melissa Sefkin (interaction analysis workshop), and Jeanette Blomberg (ethnography workshop). Last, but not least, the project was very focused on engaging users in design, which is reflected in the ethnographically inspired fieldwork using video to capture the daily tasks of the process operators, and the unusual large number of feedback, design and evaluation workshops with the users in this six-month period. In summary, the process can be described as task-driven and highly open with participants from many different disciplines.

\section{A.1 Introducing the work setting and methods used}

The work setting studied was a combined heating and power plant in Sønderborg (SKV). The aim of the project was to support the work of process operators at the plant and in that to investigate into the needs for 'smart tools/windows' - hand-held devices. A group of eight researchers, armed with video cameras and working in pairs followed four of the process operators over the course of two weeks to get an understanding of the work done and the needs of the operators in performing this work. A set of scenarios exemplifying a (gennemgående) inability to access relevant/vital information outside of the control room was created from the field video tapes and based on these, we started to design a hand-held device the operators could take with them when they walked around on the plant that could function as a window into the system, hence the name "SmartWindows".

After the initial field study, some of the researchers went back to the combined heating and power plant with a selection of foam-block mock-ups and let the users create their own future scenarios with the 'hand-held device', describing in some detail in which situations they would use a hand-held device and what kind of information they would need. These future scenarios were enacted on site and captured on video. 
Rather than going into detail with all the workshops, I will try to provide an overview of the massive number of cooperative, user-involved sessions in this project with Table A.1.

The combined heating and power plant is highly distributed with thousands of components spread over a wide area but control is central as all component/sensor information is sent to a central control system in a central control room with the aim of providing sufficient overview to supervise the process. Though the field study we realised that lack of information locally at the plant made it necessary for the process operators to work in pair, one situated at the control room with access to the system information while the other moved around on the plant doing the maintenance work that requires access to the physical components and the information available in the area (temperature of pipes, sound of motors, etc.). Another guiding force in their work was the alarm list, which was monitored and filtered each shift by the person in the control room.

\section{A.2 Summary}

Strong focus on:

- the physical fashioning of the artefact

- the usability process - users as designers

- an open approach-using field studies to understand work practise

Weak focus on:

- the existing technology

- on detailed interface design-information visualisation 


\begin{tabular}{|c|c|c|}
\hline Time & Type of event & Participants \\
\hline June & Field study (3 weeks) & $\begin{array}{l}\text { UCD group, Pernille } \\
(\mathrm{AU}), \text { users from SKV }\end{array}$ \\
\hline June & Users create their own future scenarios & $\begin{array}{l}\text { UCD group and users } \\
\text { from SKV }\end{array}$ \\
\hline June & $\begin{array}{l}\text { Workshop with Melissa Sefkin on interaction analysis } \\
\text { of video }\end{array}$ & BIDI members \\
\hline July & First design workshop—users building prototypes. & $\begin{array}{l}\text { UCD group and users } \\
\text { from SKV }\end{array}$ \\
\hline July & $\begin{array}{l}\text { Workshop with Jeannette Blomberg on ethnographic } \\
\text { method }\end{array}$ & BIDI members \\
\hline July & "Museum Workshop" at Danfoss & $\begin{array}{l}\text { UCD group, Christina } \\
(A A U), \text { Trond }\end{array}$ \\
\hline August & $\begin{array}{l}\text { "Flash Gordon and friends"-workshop. Working with } \\
\text { interaction perspectives. UCD presented five differ- } \\
\text { ent designs for a handheld device with focus on shape } \\
\text { and placement on body ("gun", wrist watch, glasses, } \\
\text { augmented vest and traditional handheld) }\end{array}$ & BIDI members \\
\hline August & $\begin{array}{l}\text { Workshop with Paul Dourish on situational comput- } \\
\text { ing }\end{array}$ & BIDI members \\
\hline September & $\begin{array}{l}\text { Design weeks at Danfoss ( } 2 \text { weeks }) \text {-designing with } \\
\text { interaction styles. }\end{array}$ & $\begin{array}{l}\text { UCD group, Christina } \\
(A A U), \text { Trond }\end{array}$ \\
\hline September & $\begin{array}{l}\text { "Catwalk" to present the three distinct prototypes } \\
\text { from the design weeks }\end{array}$ & $\begin{array}{l}\text { UCD group, Christina } \\
(\mathrm{AAU}), \text { Trond, people } \\
\text { from other Danfoss divi- } \\
\text { sions }\end{array}$ \\
\hline Oktober & Prototyping with the Newton (4 weeks) & $\begin{array}{l}\text { Student programmers } \\
\& \text { Christina (AAU), } \\
\text { Thomas \& Troels (UCD) }\end{array}$ \\
\hline November & $\begin{array}{l}\text { Presentation of the project at the annual Danfoss ex- } \\
\text { hibit }\end{array}$ & $\begin{array}{l}\text { UCD group, people from } \\
\text { all Danfoss divisions }\end{array}$ \\
\hline December & Final Evaluation Workshop & $\begin{array}{l}\text { UCD group, Christina } \\
\text { (AAU), "future users" } \\
\text { from different compa- } \\
\text { nies, "Danfoss people", } \\
\text { primarily marketing and } \\
\text { development }\end{array}$ \\
\hline
\end{tabular}

Table A.1: Timeline of user-involved and cooperative sessions 


\section{Appendix B}

\section{The Vision2000 project}

The refrigeration electronics project "Vision 2000" was a cooperative effort between Danfoss' refrigeration electronics division on Als (AC), and an American daughter company in Baltimore (USAC) that also develops refrigeration electronics components. The first phase of the project, which was the part I took part in, ran from January 1998 till February 1999. The overall goal for the project was to develop a shared software platform for development of refrigeration electronics products in Denmark and USA. As it were, they two companies used basically the same components but different software, which made the refrigeration electronics products imcompatible. This presented bigger and bigger problems as they faced a development where more and more supermarket chains branched out intercontinentally: which of the two existing product lines should the supermarket choose and what is the extra overhead in transferring to the local standard. A second and more far reaching goal was a movement towards a common user interface for the refrigeration electronics components, which was why the UCD group from Danfoss had been involved in the project by AC.

Thus the goal for the first phase of the project was not to produce commercially available products but to develop the basis software for future products. Furthermore, as a basis is formed, UCD wanted to look into the need for new user interfaces in the refrigeration electronics "world" (i.e. in supermarkets, refrigeration engineers, etc.) for different user groups. In this context new challenges arose, such as: can the users' needs for supporting their work be supported by the software platform and can we define a task-specific distinction that can be reflected at software level? My work in this project was particularly oriented towards addressing these challenges. However, this position of showing a structural and closely knit relation between the user interfaces and software structure met with little understanding from the American partners: their position was that user interface issues are solely related to the individual applications which are build upon the software platform, and should not permeate the underlying levels. As it turned out, they weren't altogether wrong.

Another issue that shaped the project was the current discussions about "intelligent components". Questions this discussion raised were e.g.: "Do we want intelligent frontends or intelligent components?"; "In which contexts do we need intelligence in the individual component? Should refrigeration units be controlled by a master controller or would it be more advantageous having a distributed system of "intelligent fridges", possibly with a shared front end?"

Finally, Danfoss were at this point in time very interested in developing a "company look-and-feel" for their product lines and wanted in relation to this project to look into 
developing a new user interface strategy for both old and new products.

In this context, we- the User Centered Design group at Danfoss, a small group of people from AC and myself-looked into the needs of users working in or with refrigeration components for small to large supermarkets and sketched a number of new components for the different user groups. This was done through a new, evolutionary approach to using scenarios and video in field studies, described in more detail below. My work then focused on a hand held device to support the work of refrigeration engineers who are in charge of setting up, maintaining and optimising the large refrigeration systems in supermarkets.

In summary, the process can be described as experimental, highly user-oriented and seeking to push the notion of using video and scenarios as evolutionary design materials. Introducing the work setting and methods used

\section{B.1 Introducing the work setting and methods used}

Building and understanding of how users in a refrigeration electronics environment work and thus the need for new user interfaces was done through a series of field studies to the surrounding supermarkets and refrigeration consultants companies on Als. Through these initial field studies key problems relating to refrigeration components and work in supermarkets were defined, e.g.: "how should a coordinated defrost progress?" or "supermarkets get an amazing number of alarms in just one day-how should these be handled and by whom?" These key questions were then transformed into scenarios, presenting the problem.

The initial field studies also formed the basis for suggesting four new user interfacesshop front-end, technical front-end, local displays and service tool-which I will describe in more detail later in this chapter. The new tools are not to be seen as replacements for existing control systems, e.g. on the PC, but as an enhancement of the control.

A second round of field studies were then initiated. We visited different user groups, e.g. technicians, shop managers, service workers, etc. with the scenarios and foam models to represent the new refrigeration electronics devices. After presenting the different models, and stressing how they differed, the user was asked to do a walk-through of the work area and show which devices would be relevant in a given situation (the scenario), and where to place the mock-ups in the environment for him or her and the co-workers to benefit the most from using them. They were also asked to play through the scenario, showing how they would use the models and what kind of information would be needed. These field studies were videotaped and edited into a 10-minute film with the most interesting episodes from the field. The plan was then for the UCD group to present the scenarios, models and video in similar field studies in England and after that USA later in the project. The scenarios were to be modified or expanded as new key problems and new user groups were encountered, which was an evolutionary approach to using scenarios I hadn't seen used systematically before. However, I did not participate in the field studies abroad, and have therefore no information about the results of the experimentation with scenarios or whether it was carried out as planned.

The outcome in terms of prototypes were four suggestions for new devices for the refrigeration environment.

A wall-mounted touch screen display presenting a graphical overview of the refrig- 
eration installations in the supermarket (plus air-conditioning and lights). Aimed at the supermarket employees, the electrician and the manager (and possibly the technician) for providing a better overview of the state of the refrigeration in the different units. Possibility for printing information but not for changing settings (in the technical control system).

Locally mounted unit for adaption/optimation of the refrigeration installation. Primarily a tool for technicians.

7-segment displays or a slightly larger display with just enough room for displaying the primary data plus one or two lines of secondary information. E.g. displaying the temperature and information concerning the 'mode' the refrigeration unit is in, such as 'defrosting'.

Hand-held device resembling the SmartWindows model. Primarily a tool for technicians, used to access system information locally in e.g. set-up situations.

\section{B.2 Summary}

Strong focus on:

- technical integration-creating new, shared software platform

- design integration — creating company look-and-feel in the different cooling/heating products' shape and interface design

- an iterative/expansive use of scenarios (Denmark => England => USA) —redesign of scenarios

- separating products in relation to their functionality with respect to potential user groups (techtool, overview tool, servicetool...)

- building user interfaces to reflect the structure of specific tasks (maintenance, optimisation, problem solving...)

- an open approach—using field studies to understand work practise 


\section{Bibliography}

[Bardram, 1998] Bardram, J. (1998). Collaboration, Coordination, and Computer Support. PhD thesis, Computer Science Department, Aarhus University.

[Bardram and Bertelsen, 1995] Bardram, J. E. and Bertelsen, O. W. (1995). Supporting the development of transparent interaction. In Blumenthal, Gornostaev, and Unger, editors, Human-Computer Interaction. $4^{\text {th }}$ International Conference, EWHCI '94. Selected Papers., pages 79-90. Springer Verlag.

[Bateson, 1972] Bateson, G. (1972). Steps to an ecology of mind. New York: Ballantine Books.

[Beaudouin-Lafon, 2000] Beaudouin-Lafon, M. (2000). Instrumental interaction: an interaction model for designing post-WIMP user interfaces. In Proceedings of the 2000 ACM Conference on Human Factors in Computing Systems (CHI'2000), pages 446-453. ACM Press.

[Beaudouin-Lafon et al., 2001] Beaudouin-Lafon, M., Mackay, W., Andersen, P., Janecek, P., Jensen, M., Lassen, M., Lund, K., Mortensen, K., Munck, S., Ratzer, A., Ravn, K., Christensen, S., and Jensen, K. (2001). CPN/Tools: A Post-WIMP interface for editing and simulating coloured petri nets. In Proceedings of the $22^{n}$ dInternational Conference on Application and Theory of Petri Nets (ICATPN 2001).

[Bellotti and Bly, 1996] Bellotti, V. and Bly, S. (1996). Walking away from the desktop computer: Distributed collaboration and mobility in a product design team. In Ehrlich, K. and Schmandt, C., editors, Proceedings of ACM 1996 Conference on Computer Supported Cooperative Work., pages 209-218. ACM, ACM Press.

[Bergman, 2000] Bergman, E., editor (2000). Information Appliances and Beyond. Morgan Kaufmann Publishers.

[Bertelsen, 2000] Bertelsen, O. (2000). Design artefacts - towards a design-oriented epistemology. Scandinavian Journal of Information Systems, 12:15-17.

[Bertelsen and Nielsen, 1999] Bertelsen, O. and Nielsen, C. (1999). Dynamics in wastewater treatment: A framework for understanding formal constructs in complex techincal settings. In Bødker, S., Kyng, M., and Schmidt, K., editors, Proceedings of the $6^{\text {th }}$ European Conference on Computer Supported Cooperative Work., pages 277-290, Copenhagen. Kluwer Academic Publisheres, Dordrecht.

[Bertelsen and Nielsen, 2000] Bertelsen, O. and Nielsen, C. (2000). Augmented reality as metaphor in mobile computing. In Boyarski, D. and Kellogg, W., editors, 
Proceedings of the $3^{\text {rd }}$ Conference on Designing Interactive Systems, pages 185192, New York, NY. ACM, ACM.

[Bertelsen, 1996a] Bertelsen, O. W. (1996a). Contradictions in the festival project activity systems, obstacles and dynamic forces in design. In Dahlbom, B., Ljungberg, F., Nuldén, F., Simon, F., Sørensen, F., and Stage, F., editors, Proceedings of the 19th. Information systems Research seminar in Scandinavia, (IRIS 19), pages 597-612.

[Bertelsen, 1996b] Bertelsen, O. W. (1996b). The festival checklist: design as the transformation of artefacts. In Blomberg, J., Kensing, F., and Dykstra-Erickson, L., editors, PDC '96, Proceedings of the Participatory Design Conference, pages 93-101.

[Bertelsen, 1998] Bertelsen, O. W. (1998). Elements to a theory of design artefacts: a contribution to critical systems development research. $\mathrm{PhD}$ thesis, Computer Science Department, University of Aarhus.

[Bertelsen and Bødker, 2002] Bertelsen, O. W. and Bødker, S. (2002). Activity theory. In J. M. Carrol. Toward a multidisciplinary science of human-computer interaction.

[Beyer and Holtzblatt, 1998] Beyer, H. and Holtzblatt, K. (1998). Contextual Design: Defining Customer-Centered Systems. Morgan Kaufmann.

[Bjerknes et al., 1987] Bjerknes, G., Ehn, P., and Kyng, M., editors (1987). Computers and democracy: A Scandinavian challenge. Avebury, Aldershot.

[Björk et al., 1999] Björk, S., Holmquist, L. E., Redström, J., Bretan, I., Danielsson, R., Karlgren, J., , and Franzén, K. (1999). West: A web browser for small terminals. In Proceedings of the 12th annual ACM symposium on User interface software and technology, pages 187-195.

[Bouvin et al., 1996] Bouvin, N., Nielsen, C., and Sejersen, C. M. (1996). Spirits in a material world: An activity theory based evaluation of Ariel, a demonstrator in the EuroCODE CSCW project, aimed at supporting inspection work at the Great Belt bridge. Master's thesis, Department of Computer Science, University of Aarhus.

[Buur and Bødker, 2000] Buur, J. and Bødker, S. (2000). From usability lab to "design collaboratorium": Reframing usability practice. In Boyarski, D. and Kellogg, W., editors, Proceedings of the $3^{\text {rd }}$ Conference on Designing Interactive Systems, New York, NY. ACM, ACM.

[Buur and Søndergaard, 2000] Buur, J. and Søndergaard, A. (2000). Video card game: An augmented environment for user centered design discussions. In Mackay, W., editor, Proceedings of DARE 2000, pages 63-70. ACM.

[Bødker, 1991] Bødker, S. (1991). Through the Interface. A Human Activity Approach to User Interface Design. Lawrence Erlbaum Associates, Inc.

[Bødker, 1996] Bødker, S. (1996). Context and consciousness. Activity theory and human computer interaction, chapter Applying activity theory to video analysis: How to make sense of video data in HCI, pages 147-174. MIT Press. 
[Bødker, 1998] Bødker, S. (1998). Scenarios in user-centred design — setting the stage for reflection and action. In Proceedings of Hawaii International Conference on System Sciences 32. CD-ROM.

[Bødker, 1999] Bødker, S. (1999). Computer applications as mediators of design and use - a developmental perspective. Doctoral dissertation. DAIMI PB - 542. The Computer Science Department, Aarhus University.

[Bødker and Christiansen, 1997] Bødker, S. and Christiansen, E. (1997). Scenarios as springboards in design. In Bowker, G., Gasser, L., Star, L., and Turner, W., editors, Social science research, technical systems and cooperative work., pages 217-234. NJ: Erlbaum.

[Bødker et al., 1993a] Bødker, S., Christiansen, E., Ehn, P., Markussen, R., Mogensen, P., and Trigg, R. (1993a). The at-project: practical research in cooperative design. Technical report, DAIMI PB 454, Aarhus University.

[Bødker et al., 1987] Bødker, S., Ehn, P., Kammersgaard, J., Kyng, M., and Sundblad, Y. (1987). A utopian experience: On design of powerful computer-based tools for skilled graphical workers. In Computers and democracy: A Scandinavian challenge., pages 251-278. Avebury, Aldershot.

[Bødker and Graves Petersen, 2000] Bødker, S. and Graves Petersen, M. (2000). Design for learning in use. Scandinavian Journal of Information Systems, 12:61-80.

[Bødker et al., 1993b] Bødker, S., Grønbæk, K., and Kyng, M. (1993b). Cooperative design: Techniques and experiences from the scandinavian scene. In Schuler, D. and Namioka, A., editors, Participatory Design. Principles and Practices., pages 157-176. Lawrence Erlbaum Associates., Hillsdale, New Jersey.

[Bødker and Halskov Madsen, 1998] Bødker, S. and Halskov Madsen, K. (1998). Context - an active choice in usability work. Interactions, pages 17-25.

[Bødker et al., 2001] Bødker, S., Krogh, P., and Graves Petersen, M. (2001). The interactive design collaboratorium. In Proceedings of the EIGHTH IFIP TC.13 CONFERENCE ON HUMAN-COMPUTER INTERACTION - INTERACT'01.

[Bødker et al., 2000] Bødker, S., Nielsen, C., and Graves Petersen, M. (2000). Creativity, cooperation and interactive design. In Boyarski, D. and Kellogg, W., editors, Proceedings of the $3^{\text {rd }}$ Conference on Designing Interactive Systems, pages 252261, New York, NY. ACM, ACM.

[Bøgh, 2001] Bøgh, P. (2001). Elastic systems. In Proceedings of Human-Computer Interaction INTERACT'01.

[Carroll et al., 1991] Carroll, J. M., Kellogg, W. A., and Rosson, M. B. (1991). The task-artifact cycle. In Carroll, J. M., editor, Designing Interaction: Psychology at the Human-Computer Interface, pages 74-102. Cambridge University Press, New York.

[Christensen et al., 1998] Christensen, M., Crabtree, A., Damm, C., Hansen, K., Madsen, O., Marqvardsen, P., Mogensen, P., Sandvad, E., Sloth, L., and Thomsen, M. (1998). The m.a.d. experience: Multiperspective application development in evolutionary prototyping. In Proceedings of the 12th European Conference on ObjectOriented Programming (ECOOP'98), pages 13-40. 
[Covi et al., 1998] Covi, L. M., Olson, J. S., Rocco, E., Miller, W. J., and Allie, P. (1998). Cooperative Buildings: Integrating Information, Oragization, and Architecture, chapter A Room of Your Own: What Do We Learn about Support of Teamwork from Assessing Teams in Dedicated Project Rooms?, pages 53-65. Springer.

[Dix and Beale, 1996] Dix, A. and Beale, R. (1996). Remote Cooperation: CSCW Issues for Mobile and Teleworkers., chapter 9: Information Requirements of Distributed Workers., pages 113-144. Computer-Supported Cooperative Work. Springer-Verlag, London.

[Djajadiningrat et al., 2000] Djajadiningrat, J. P., Gaver, W. W., and Fres, J. W. (2000). Interaction relabelling and extreme characters: Methods for exploring aestetic interactions. In Boyarski, D. and Kellogg, W., editors, Proceedings of the $3^{\text {rd }}$ Conference on Designing Interactive Systems, pages 66-71. ACM.

[Dourish and Bly, 1992] Dourish, P. and Bly, S. (1992). Supporting awareness in a distributed work group. In Proceedings of the 1992 ACM Conference on Human Factors in Computing Systems, pages 541-547. ACM Press.

[Ehn, 1988] Ehn, P. (1988). Work-Oriented Design of Computer Artifacts. Arbetslivcentrum, Stockholm.

[Ehn, 1993] Ehn, P. (1993). Scandinavian design: On participation and skill. In Schuler, D. and Namioka, A., editors, Participatory Design: Principles and Practices, pages 41-77. Lawrence Erlbaum Associates., Hillsdale, New Jersey.

[Ehn and Kyng, 1991] Ehn, P. and Kyng, M. (1991). Cardboard computers: Mockingit-up or hands-on the future. In Greenbaum, J. and Kyng, M., editors, Design at Work: Cooperative Design of Computer Systems., pages 169-196. Lawrence Erlbaum Associates, Hillsdale, NJ.

[Engeström, 1987] Engeström, Y. (1987). Learning by expanding. Orienta-Konsultit, Helsinki.

[Engeström, 1990] Engeström, Y. (1990). Learning, Working and Imagining: Twelve Studies in Activity Theory. Orienta-Konsultit Oy, 00601 Helsinki.

[Engeström and Middleton, 1996] Engeström, Y. and Middleton, D., editors (1996). Cognition and Communication at Work. Cambridge University Press.

[Erickson, 1991] Erickson, T. (1991). Working with interface metaphors. In Laurel, B., editor, The Art of Human Computer Interface Design, pages 65-73. Addison Wesley.

[Fagrell et al., 1999] Fagrell, H., Kristoffersen, S., and Ljungberg, F. (1999). Exploring support for knowledge management in mobile work. In Bødker, S., Kyng, M., and Schmidt, K., editors, Proceedings of the $6^{\text {th }}$ European Conference on Computer Supported Cooperative Work., pages 277-290, Copenhagen. Kluwer Academic Publisheres, Dordrecht.

[Fitzpatrick et al., 1999] Fitzpatrick, G., Mansfield, T., Kaplan, S., Arnold, D., Phelps, T., and Segall, B. (1999). Augmenting the workaday world with elvin. In Bødker, S., Kyng, M., and Schmidt, K., editors, ESCSW99, pages 431-451. Kluwer Academic Publisheres, Dordrecht. 
[Fukumoto and Tonomura, 1997] Fukumoto, M. and Tonomura, Y. (1997). Body coupled fingering: Wireless wearable keyboard. In Proceedings of the 1997 ACM Conference on Human Factors in Computing Systems, pages 147-154, Atlanta. ACM.

[Greenbaum and Kyng, 1991] Greenbaum, J. and Kyng, M., editors (1991). Design at Work - Cooperative Design of Computer Systems. Lawrence Erlbaum Associates Publishers., Hillsdale, NJ.

[Grønbæk, 1991] Grønbæk, K. (1991). Prototyping and Active User Involvement in System Development: Towards a Cooperative Prototyping Approach. PhD thesis, Computer Science Department. University of Aarhus.

[Grønbæk et al., 1997] Grønbæk, K., Kyng, M., and Mogensen, P. (1997). Computers and Design in Context, chapter 8. Toward a Cooperative Experimental System Development Approach, pages 201-238. MIT Press.

[Harrison et al., 1998] Harrison, B. L., Fishkin, K., Gujar, A., Mochon, C., and Want, R. (1998). Squeeze me, hold me, tilt me! an exploration of manipulative user interfaces. In C. Karat, J. K. and Horrocks, I., editors, Proceedings of the 1998 Conference on Human Factors in Computing Systems, pages 17-24. Addison-Wesley Publisheing Group.

[Heath and Luff, 1996] Heath, C. and Luff, P. (1996). Cognition and Communication at Work., chapter Convergent activities: Line control and passenger information on the London Underground., pages 96-129. Cambridge University Press.

[Heidegger, 1996] Heidegger, M. (1996). BEING AND TIME. A Translation of Sein und Zeit. SUNY Series in Contemporary Continental Philosophy. State University of New York Press.

[Herstad and Thanh, 1999] Herstad, J. and Thanh, D. (1999). Tailor to fit it. In Käkölä, T. K., editor, Proceedings from the Twenty Second IRIS Conference (Information Systems Research Seminar In Scandinavia), volume 2, pages 67-78. Jyväskylä University Printing House.

[Hutchins and Klausen, 1996] Hutchins, E. and Klausen, T. (1996). Cognition and Communication at Work., chapter Distributed cognition in an airline cockpit., pages 15-34. Cambridge University Press.

[Iacucci et al., 2000] Iacucci, G., Kuutti, K., and Ranta, M. (2000). On the move with a magic thing: Role playing in concept design of mobile services and devices. In Boyarski, D. and Kellogg, W., editors, Proceedings of the $3^{\text {rd }}$ Conference on Designing Interactive Systems, pages 193-202. ACM.

[Johnson, 1999] Johnson, P. (1999). Usability and mobility; interactions on the move. In Proceedings of the $1^{\text {st }}$ Workshop on Human Computer Interaction with Mobile Devices, Edinburgh, Scotland.

[Jones, 1983] Jones, T. (1983). The grand old man - interview with alan kay. Psychology Today, pages 50-56.

[Kammersgaard, 1988] Kammersgaard, J. (1988). Four different perspectives on human-computer interaction. International Journal of Man-Machine Studies, (28):343-362. 
[Kapor, 1996] Kapor, M. (1996). Bringing Design to Software, chapter 1. A Software Design Manifesto., pages 1-9. Addison-Wesley.

[Karat and Bennett, 1991] Karat, J. and Bennett, J. L. (1991). Designing interaction: Psychology at the human-computer interface, chapter 14. Working within the Design Process: Suporting Effective and Efficient Design., pages 269-285. Cambridge University Press.

[Kristoffersen and Ljungberg, 1999a] Kristoffersen, S. and Ljungberg, F. (1999a). "Making Place" to make IT work: Empirical explorations of HCI for mobile CSCW. In Proceedings of the 1999 International Conference on Supporting Group Work, pages 276-285. ACM Press.

[Kristoffersen and Ljungberg, 1999b] Kristoffersen, S. and Ljungberg, F. (1999b). Mobile informatics: Innovation of it use in mobile settings. SIGCHI Bulletin, 31(1):29-34.

[Kristoffersen and Ljungberg, 1999c] Kristoffersen, S. and Ljungberg, F. (1999c). Mobile use of IT. In Käkölä, T. K., editor, Proceedings from the Twenty Second IRIS Conference (Information Systems Research Seminar In Scandinavia), volume 2, pages 271-284. Jyväskylä University Printing House. IRIS22.

[Kyng, 1999] Kyng, M. (1999). Making representations work. Communications of the ACM, 8(9):46-55.

[Kyng and Mathiassen, 1982] Kyng, M. and Mathiassen, L. (1982). Systems development and trade union activities. In Bjørn-Andersen, N., Earl, M., Holst, O., and Mumford, E., editors, Information Society: For Richer, For Poorer, pages 247-260. Amsterdam, North Holland.

[Laurel, 1986] Laurel, B. (1986). User Centered System Design: New Perspectives on Human-Computer Interaction, chapter Interface as mimesis, pages 67-85. Lawrence Erlbaum.

[Lave and Wenger, 1991] Lave, J. and Wenger, E. (1991). Situated Learning: Legitemate peripheral participation. Cambridge University Press., Cambridge, UK.

[Ljungberg, 1997] Ljungberg, J. (1997). From Workflow to Conversation. PhD thesis, Göteborg University, Department of Informatics.

[Luff and Heath, 1998] Luff, P. and Heath, C. (1998). Mobility in collaboration. In Poltrock, S. and Grudin, J., editors, Proceedings of ACM 1998 Conference on Computer Supported Cooperative Work, pages 305-314. ACM Press.

[Mackay, 1990] Mackay, W. (1990). Users and Customizable software: A CoAdaptive Phenomenon. Doctoral Dissertation. The Massachusetts Institute of Technology, Cambridge.

[Mackay, 1998a] Mackay, W. (1998a). Augmenting reality: Linking real and virtual worlds. a new paradigm for interacting with computers. In Proceedings of the ACM Conference on Advanced Visual Interfaces. ACM Press. 
[Mackay et al., 1998] Mackay, W., Fayard, A.-L., Frobert, L., and Médini, L. (1998). Reinventing the familiar: Exploring an augmented reality design space for air traffic control. In Proceedings of the 1998 ACM Conference on Human Factors in Computing Systems (CHI'98), pages 558-565. ACM Press.

[Mackay, 1998b] Mackay, W. E. (1998b). Triangulation within and across HCI disciplines. Human Computer Interaction, 13(3):310-315. Commentary on: Wayne Gray and Marilyn Salzman (1998) Damaged Mewrchandise? A review of experiments that compare usability evaluation methods.

[Mackay and Fayard, 1997] Mackay, W. E. and Fayard, A.-L. (1997). HCI, natural science and design: A framework for triangulation across disciplines. In Proceedings of the 1st Conference on Designing Interactive Systems, pages 223-234, Amsterdam, The Netherlands. ACM Press.

[Madsen, 1994] Madsen, K. (1994). A guide to metaphorical design. The Communications of the ACM, 36(12):57-62.

[May and Bøgh, 2000] May, M. and Bøgh, P. (2000). Organisational Semiotics, chapter Instrument Semiotics. Kluwer Academic Publishers.

[Mogensen, 1994] Mogensen, P. (1994). Challenging Practice: an Approach to Cooperative Analysis. PhD thesis, Computer Science Department. University of Aarhus.

[Mogensen and Robinson, 1995] Mogensen, P. and Robinson, M. (1995). Triggering artefacts. AI and Society, (9):373-388.

[Moran et al., 1999] Moran, T. P., Saund, E., Van Melle, W., Gujar, A. U., Fishkin, K., and Harrison, B. L. (1999). Design and techonology for collaborage: Collaborative collages of information on physical walls. In Proceedings of the 12th annual ACM symposium on User interface software and technology, pages 197-206.

[Nardi, 1996] Nardi, B., editor (1996). Context and Consciousness: Activity Theory and Human-Computer Interaction. MIT Press.

[Nielsen, 1998] Nielsen, C. (1998). Testing in the field. In Proceedings of the $3^{\text {rd }}$ Asia Pacific Computer Human Interaction Conference, pages 285-289, Shonan Village Centre, Japan. IEEE Press.

[Nielsen and Søndergaard, 2000] Nielsen, C. and Søndergaard, A. (2000). Designing for mobility: an integration approach supporting multiple technologies. In Proceedings of the $1^{\text {st }}$ Nordic Conference on Human-Computer Interaction (CD-ROM).

[Norman, 1999] Norman, D. (1999). The Invisible Computer. MIT Press.

[Nygaard, 1979] Nygaard, K. (1979). The iron and metal project: Trade union participation. In Sandberg, A., editor, Computers dividing man and Work, Swedish Center for Working Life, Demos Project Report no 13, pages 94-107. Utbildningsproduktion, Malmö.

[Odlyzko, 1999] Odlyzko, A. (1999). The visible problems of the invisible computer: A skeptical look at information appliances. First Monday, 4(9).

[Olsen, 1999] Olsen, D. (1999). Interacting in chaos. Interactions, 6(5):42-54. 
[Parsowith et al., 1998] Parsowith, S., Fitzpatrick, G., Kaplan, S., Segall, B., and Boot, J. (1998). Tickertape: Notification and communication in a single line. In Proceedings of the $3^{\text {rd }}$ Asia Pacific Computer Human Interaction Conference, pages 139-144. IEEE Press.

[Perlin, 1998] Perlin, K. (1998). Quickwriting: Continuous stylus-based text entry. In Proceedings of the 11th annual ACM symposium on User interface software and technology.

[Petersen and Halskov, 1999] Petersen, M. G. and Halskov, M. K. (1999). Supporting collaboration in multimedia design. In Brewster, S., Cawsey, A., and Cockton, G., editors, Proceedings of Human-Computer Interaction INTERACT'99, volume II, pages $185-190$.

[Raeithel, 1996] Raeithel, A. (1996). From coordinatedness to coordination via cooperation and co-construction. Presented at the Workshop on Work and Learning in Transition.

[Rekimoto, 1996] Rekimoto, J. (1996). Tilting operations for small screen interfaces. In Proceedings of the Tenth Annual Symposium on User Interface Software and Technology (UIST'96).

[Rekimoto, 1997] Rekimoto, J. (1997). Pick-and-drop: A direct manipulation technique for multiple computer environments. In Proceedings of the Eleventh Annual Symposium on User Interface Software and Technology (UIST'97), pages 31-39.

[Rekimoto, 1998] Rekimoto, J. (1998). A multiple device approach for supporting whiteboard-based interactions. In Proceedings of the 1998 ACM Conference on Human Factors in Computing Systems (CHI'98).

[Rist, 1999] Rist, T. (1999). Using mobile communication devices to access virtual meeting places. In Proceedings of the $2^{\text {nd }}$ Workshop on Human Computer Interaction with Mobile Devices, pages 81-86, Edinburgh, Scotland.

[Robinson and Bannon, 1991] Robinson, M. and Bannon, L. (1991). Questioning representations. In Bannon, L., Robinson, M., and Schmidt, K., editors, Proceedings of the Second European Conference On Computer Supported Cooperative Work, pages 219-233. Kluwer Academic Publishers.

[Rodden et al., 1998] Rodden, T., Cheverst, K., Davies, N., and Dix, A. (1998). Exploiting context in HCI design for mobile systems. In Proceedings of the $1^{\text {st }}$ Workshop on Human Computer Interaction with Mobile Devices.

[Román, 1999] Román, M. e. a. (1999). Integrating PDAs into distributed systems:2k and PalmORB. In Gellersen, H., editor, Handheld and Ubiquitous Computing. Proceedings of First International Symposium, pages 137-149. Springer.

[Schön, 1983] Schön, D. (1983). The Reflective Practitioner: How professionals think in action. Basic Books.

[Schuler and Namioka, 1993] Schuler, D. and Namioka, A. (1993). Participatory Design. Principles and Practices. Lawrence Erlbaum Associates., Hillsdale, New Jersey. 
[Small and Ishii, 1997] Small, D. and Ishii, H. (1997). Design of spatially aware graspable interfaces. In Extended Abstracts of CHI'97. ACM Press,.

[Spence and Apperley, 1982] Spence, R. and Apperley, M. (1982). Data-base navigation: an office environment for the professional. Behaviour and Information Technology, 1(1):43-54.

[Star, 1996] Star, S. L. (1996). Cognition and Communication at Work, chapter 13. Working together: Symbolic interactionism, activity theory, and information systems, pages 296-318. Cambridge University Press.

[Streitz et al., 1998] Streitz, N. A., Geiler, J., and Holmer, T. (1998). Roomware for cooperative buildings: Integreated design of architectureal spaces and information spaces. In N. Streitz, S. Konomi, H. B., editor, Cooperative Buildings: Integrating Information, Organization, and Architecture, pages 4-21. Springer.

[Suchman, 1987] Suchman, L. (1987). Plans and Situated Actions.The problem of human-machine communication. Cambridge University Press.

[Suchman, 1996] Suchman, L. (1996). Cognition and Communication at Work, chapter 3, pages 35-60. Cambridge University Press.

[Venolia and Neiberg, 1994] Venolia, D. and Neiberg, F. (1994). T-cube: A fast, selfdisclosing pen-based alphabet. In Adelson, B., Dumais, S., and Olson, J., editors, Proceedings of Human Factors in Computing Systems (CHI '94), pages 265-270. ACM Press.

[Väänänen-Vainio-Mattila and Ruuska, 1998] Väänänen-Vainio-Mattila, K. and Ruuska, S. (1998). User needs for mobile communication devices: Requirements gathering and analysis through contextual inquiry. In Proceedings of the $1^{\text {st }}$ Workshop on Human Computer Interaction with Mobile Devices.

[Väänänen-Vainio-Mattila and Ruuska, 2000] Väänänen-Vainio-Mattila, K. and Ruuska, S. (2000). Information Appliances and Beyond, chapter 7. Designing Mobile Phones and Communicators for Consumer's Needs at Nokia, pages 169-204. The Morgan Kaufmann Series in Interactive Technologies. Morgan Kaufmann Publishers, Academic Press.

[Vygotsky, 1978] Vygotsky, L. (1978). Mind in society: The development of higher psychological processes. Harvard University Press.

[Wartofsky, 1979] Wartofsky, M. (1979). Models: Representation and scientific understanding. Dordrecht: Reidel.

[Weiser, 1991] Weiser, M. (1991). The computer for the 21st century. Scientific American, pages 933-940.

[Winograd and Flores, 1993] Winograd, T. and Flores, F. (1993). Understanding Computers and Cognition. A New Foundation for Design. Addison-Wesley Publishing Company.

[Wittgenstein, 1958] Wittgenstein, L. (1958). Philosophical Investigations. Oxford, UK: Basil Blackwell. 
[Zellweger, 1998] Zellweger, P. e. a. (1998). Fluid links for informed and incremental link transitions. In Proceedings the Ninth ACM Conference on Hypertext and Hypermedia (Hypertext'98), pages 50-57. ACM.

[Zellweger et al., 2001] Zellweger, P. T., Bouvin, N. O., Jehøj, H., and Mackinlay, J. D. (2001). Fluid annotations in an open world. In Proceedings of The Twelfth ACM Conference on Hypertext and Hypermedia (Hypertext 2001), pages 9-18.

[Øritsland and Buur, 2000] Øritsland, T. A. and Buur, J. (2000). Taking the best from a company history - designing with interaction styles. In Boyarski, D. and Kellogg, W., editors, Proceedings of the $3^{\text {rd }}$ Conference on Designing Interactive Systems, pages 27-38. ACM. 


\title{
Creativity, Cooperation and Interactive Design
}

\author{
Susanne Bødker, Christina Nielsen, Marianne Graves Petersen \\ Department of Computer Science \\ University of Aarhus \\ +4589425630 \\ bodker, sorsha,mgraves@intermedia.au.dk
}

\begin{abstract}
This paper focuses on ways and means of stimulating idea generation in collaborative situations involving designers, engineers, software developers, users and usability people. Particularly, we investigate tools of design, i.e. tools used in design to get ideas for a new interactive application and its use.

Based on different studies from a research project that we have been involved with over the past three years, we present specific examples of such tools and discuss how they inform design. We frame this discussion through the following (theoretical) considerations: a concern for the past and the present in informing design, for using theory as a source of inspiration in design and for making extremes and multiple voices play a role in innovation.

These considerations are used to structure and discuss the examples, illustrating how it is important for such tools to be concrete, tangible and even caricatured.
\end{abstract}

\section{Keywords}

Tools for idea generation, cooperative, iterative design

\section{INTRODUCTION}

Many design methods suggest that something new, i.e. the new computer application, arises from a stepwise process describing first e.g. the existing physical system then the existing logical one followed by the changed logical one and ending with the changed physical one [15]. A first reaction to this is that it is difficult to imagine that something creatively new should come out of a stepwise derivation process from the existing. At the same time we do not subscribe to the idea that creative design is a matter of the individual designer's genius nor a strike of lightening, a characterization that seems predominant e.g. in industrial design and architecture of today. Instead, this paper will focus on the systematic and deliberate attempts to create a new design that transcends the current practice of the users, at the same time as it is based on this practice, as well as on the knowledge and skills of designers, engineers, software developers and usability people.

\footnotetext{
Permission to make digital or hard copies of all or part of this work for personal or classroom use is granted without fee provided that copies are not made or distributed for profit or commercial advantage and that copies bear this notice and the full citation on the first page. To copy otherwise, or republish, to post on servers or to redistribute to lists, requires prior specific permission and/or a fee.

DIS '00, Brooklyn, New York.

Copyright 2000 ACM 1-58113-219-0/00/0008 ...\$5.00.
}

Our experiences stem from the design of a wide range of products: from software to industrial components and TVsets (see also [4]). Some of these experiences date to earlier projects (e.g. [9]) whereas the examples that we are discussing stem from a project that we have been involved with for the past three years regarding the development of usability design. While the methods presented have been developed and used through several activities in the project, we have chosen to present only one such situation for each.

In [4] Bødker \& Buur coin the term design collaboratorium to talk about the overall methodological results from this project. The design collaboratorium is a design approach that creates an open physical and organizational space where designers, engineers, users and usability professionals meet and work alongside each other. At the same time the design collaboratorium makes use of event-driven ways of working known from participatory design [8]. This paper focuses on ways and means of stimulating idea generation in the design collaboratorium or similar collaborative design situations.

In our way of thinking, design, be this of computer systems or other sorts of appliances, is an iterative process involving the active participation of users and of professional designers, engineers and usability people. Hence, design is co-operative. We have earlier discussed how it is of vital importance for designers to understand use so as to build artifacts to support and develop use $[6,7]$, and how it is essential for users to get hands-on experiences with mockups and prototypes to participate actively in design [12]. Furthermore, it is important to work systematically to get new ideas to further the design [9]. Because creating something new in design is neither a matter of a stepwise refinement of a description of the existing situation, nor of a hierarchical decomposition of complex problems into solvable ones, new interactive applications must be designed and explored in an iterative process. In this paper we focus on the tools for getting new ideas in cooperative, iterative design.

\section{TOOLS FOR GETTING NEW IDEAS}

In the remainder of this section we will outline our sources of inspiration for the particular analyses that are to come.

$[9,13]$ argue that tools for thinking ahead, for supporting creativity is an area which still needs development. It is necessary to understand more about where these tools come from and how they might be used in a systematic and purposeful design activity, and not just at random.

These tools are not detached from the history and present tools of design, neither are they detached from the history 
and present activities of work, that are designed for. Engeström's [16] notion of springboard, a "facilitative image, technique or socio-conversational constellation ... misplaced or transplanted from some previous context into a new..." (p. 287), has been important when looking at which technical and social/use-oriented constructions serve usefully as springboards in design. The idea is to move away from stepwise derivations to ways of rethinking the whole of the new activity or parts of it in different, yet very concrete, ways. From a similar way of thinking both Schön [25] and Madsen [20] talk about seeing something as something else, and Madsen [20] proposes to use the dissimilarities in two referents of a metaphor as the source for creating something new (by seeing e.g. a library as a meeting place and a warehouse.).

We propose to look for things and notions that in similar ways help us see, or rather do, something in a new and different ways in the context of use. Reminding the reader of the need for cooperation and hands-on experience, such tools need to support action as well as reflection [13]. Furthermore, they are furthermore, as Bertelsen [2] discusses, placed in a boundary zone, where the different practices of designers, engineers, usability people and users meet. In order to support cooperation, they must, accordingly, be boundary artifacts, as Bertelsen [2] calls them with reference to Star's [26] boundary objects. They must in some ways support the joint action and reflection, at the same time as they serve action and reflection of each of the involved groups in their activities.

\section{Past, present and future}

Computer applications and other technical artifacts should, like any other artifact, be seen as historical devices that reflect the state of practice up until the time that they are developed [1]. Thus, to learn something about the present shape and use of a particular artifact, a historical analysis of artifacts as well as of practice is important. Furthermore, to find inspiration for future artifacts, the past generations of technology are informative. The history, however, is not just an absolute and given thing, and history does not only concern the past. [9] seeks inspiration in [24]. Mogensen [21] develops his Heidegger-inspired understanding in a similar fashion, to emphasize the relation between the past, the present and the future. The key point is that we are dealing with both experience and expectation as soon as we start researching a practice, and as soon as we e.g. introduce a prototype. Fundamentally, we cannot design from understanding the artifacts alone. Neither can we understand the artifacts only from understanding use as it is carried out "here and now". In this sense we need to go further, as e.g. Carroll's [14] "task-artifact" cycle (discussed in [1]).

For our purpose of finding tools that point ahead, we are suggesting that past generations of technology may inform innovation well.

\section{Theory as a possible source of inspiration}

Bertelsen [3] makes a thorough analysis of how theory in general, and Fitt's law in particular may appropriately be seen as a design artifact. Morgan [22] uses organizational theories as metaphors for diagnostic readings of an organization, and for what he calls imaginizing, which is basically designing or re-designing organizations. "One of the major strengths of the different metaphors explored in this book is that they open numerous avenues for the ways in which we attempt to organize practice. " (p. 335). Interestingly, Morgan suggests a place for theory, and not just for a collection of random metaphors. Furthermore, he uses the effect of theories contradicting each other as a means of creating openings for innovation.

$[9,10]$ propose to use theoretical checklists as input to CSCW design, an area that we have explored further as regards learning in use (see below). They similarly make use of the contradictions created through systematic application of particular perspectives as a way of pointing ahead.

For our purpose of this paper, the question is how to operationalize theories so as to inform design.

\section{The present points ahead}

We are assuming that the starting point of creative design is some amount of understanding of use, achieved through a combination of more or less systematic field work and participatory design. It is necessary to capture this understanding, to reduce the empirical situations to manageable dimensions as well as to clarify and complete the situations (See e.g. [9,17]). The issue of concern here is how this understanding can be used to point ahead.

[13] discusses how scenarios can be used in this effort. Making scenarios is a creative process: they are hypotheses, or qualified guesses about the artifact [9]. They serve to open the dialogue about future possibilities and current constraints. [13] proposes that we have to work with work situations and scenarios as constructions meant to stage acting in the future or to reflect on and illustrate problems with this action. Selecting and "cutting" the right situations out of many hours of video and observation material is in itself a construction process where the new is constructed, rather than a reproduction of the existing. Mainly the richness of detail, gained from the real situations makes them useful triggers of thoughts.

This paper will discuss further how to "design" present situations so as to serve design.

\section{The right tool for the job, extremes and multiple voices}

There is much more to a good scenario than choosing a characteristic work situation. Depending on the state of the prototype that one is dealing with and of the objective in terms of purpose of the design situation and scope of the prototype, it pays off to be very selective [13]. [9] proposes that representations are containers of ideas, rather than some sort of mapping of an existing or future situation or artifact. This suggests that we need to focus more on a variety of representations supporting different purposes and perspectives in the design activity.

Overemphasizing distinguishing features makes the point more easily understandable for participants. We advocate to create caricatures instead of such that are nuanced. $[9,13]$ develop the notion of plus and minus scenarios as one way of driving particular features to the extreme, instead of 
aiming for a neutral scenario, making it hard to distinguish between the useful and the non-useful. [13] argues that it is much easier for users and whoever else is going to relate to the scenarios to assess things when they see full-blown consequences than when the implications go a bit in all sorts of directions. Not that they "believe" in the caricatures, indeed they don't, but it is just much easier to use ones common sense judgement when confronted with a number of extremes, than when judging based on some kind of "middle ground".

As mentioned earlier, Morgan [22] uses the theoretical perspectives in a way where they may at time contradict each other. Engeström [16] and other have argued that this is actually what creates openings for creative innovation. Similarly, [9] propose to use the checklists to support contradiction and dialogue. The checklists were consciously organized to let different perspectives talk to each other.

[2] discusses how design takes place in a boundary zone where heterogeneous practices meet to create the new, emphasizing the multi-voiced nature of design. Engeström [16], and along with him Bertelsen [2], talk about heteroglossia, or multi-voicedness as a way of letting different voices participate in the creation of the new. Engeström's [16] notion of multi-voicedness deserves mentioned as a perspective on bringing the voices of various groups together, constructively, in design/development of a new work activity. [13] gives various suggestions to how scenarios, anchored in specific use/work situations may be used to support bringing these voices forth.

In the present paper we illustrate and discuss how to choose the right tools, in terms of constellations of scenarios, prototypes, etc. for the design activity in question. We will further illustrate how we have made use of extremes and supported the multiple voices of the particular design activities that dealt with.

\section{Tools develop}

Just as any other tools, the design tools that we present and discuss here develop in use, in the particular setting in which they are used. This has consequence, for us, as well as for any reader who might want to use some of these ideas in their own settings. We hope that presenting our own development process to the reader, we will leave ways open for further development of the tools, rather than stigmatizing the reader in a "does it work or not" choice.

\section{THE EMPIRICAL EXAMPLES}

The empirical material that we present and use in the following is a result of a project that we have been involved with for the past three years. We have been collaborating with the usability departments of Bang \& Olufsen A/S, Danfoss $\mathrm{A} / \mathrm{S}$ and Kommunedata, in an action-oriented research project that aimed to develop the work practices of usability [4]. The three involved companies do their work rather differently and work with different products ranging from computer software to hi-fi equipment and thermostats. Common to them, however, is that during our joint project they have been moving out of the lab and into the field ([7, 19]). They have committed themselves to collaborating with users as well as with designers and engineers, and they have moved from doing evaluation of products to doing design together with these groups [4].

Our attempt to move usability from evaluation to collaborative design has taken many experimental forms, and this paper will focus on only one of these; the development of cooperative, tangible tools for creation of ideas.

The remainder of the paper is structured as two sets of examples from two projects in two of the three companies. These examples will shed light on the theoretical issues discussed above and lead to a concluding discussion of the possibilities and constraints of such tools.

\section{THE PC-TV LIVING ROOM}

The project framing this case was the development of a Bang \& Olufsen PC-TV living room. The vision was to provide users of a traditional television set with access to PC functionality and applications when seated in the sofa in the living room. The total number of people involved in the project was around 10, half from the usability group, half from the multimedia department, and one from the communications department. From this case, we look at three interlinked design activities, involving us as researchers as well as Bang \& Olufsen usability designers and engineers, and to some extent the users. These activities are: "Talk to your TV", using workshop-stands and the construction and use of learning checklists.

\section{Talk to your TV}

In this activity we enrolled a small number of users (2 individual sessions and one session with 2 users together) and asked them to do two things together with us:

a. to find information using the tele-text and remote control of a TV-set provided by us. An example scenario was: how to find out about the weather in Sidney in connection with a trip there.

b. to find the same information "talking to the TV". We used a transparent "Wizard of Oz" technology, in that somebody in the room would actually press the relevant buttons on the remote control to get what was requested. In other words, we created an open and flexible prototype out of an existing TV-set.

Some users were proficient users of tele-text and some not, which we believed to be a strength because we wanted to get as many ideas as possible regarding the interaction with the tele-text. All users were also proficient WWW-users. This became apparent through a lot of comments and ideas. The users produced a number of ideas of interest to design. Some of these had to do with sequentiality of sub-pages, some with the overall structuring of the search, some with ways of stepping back, and of retrieving previously used pages, and some had to do with the lay-out of the remote control.

We found that through choosing an extreme, i.e. asking users to talk to their television in b, the users were provoked to think beyond existing possibilities both in terms of technical aspects and in terms of design. This happened especially when $b$ followed $a$. We experimented 
some with the order of $a$ and $b$, to investigate which setup mostly stimulated creative idea. We found when we started out with b, i.e. talking to the television, the users were quite restricted by existing limitations due to their familiarity with the existing design. When $b$ followed a however, it provided a contrast to the limitations of the existing design, and thus worked better as a springboard for the users in generating ideas beyond the existing design.

The scenarios were used to form an overall "story-line", which turned out to be a good idea. However, we used the same scenarios, that were rooted in the current tele-text functionality, in both $\mathrm{a}$ and $\mathrm{b}$. In retrospect we should probably have chosen two different sets of scenarios for the two sessions, and have made some more directed towards possible future functionality.

We edited a videotape that presented the innovative design ideas which came up in the "talk to your TV" activity. We presented this to the Bang \& Olufsen group as a source of inspiration for the design of the PC-TV living room and as an example of how users can contribute with creative ideas for design. Through this material, we sharpened the "voice of the users" not based on any claim of representativity, but as a source of potentially interesting design ideas. The video recordings of these experiments were a useful basis for being selective, emphasizing particular problems or situations when editing the video. The recordings are fictions in more than one sense: First of all, the original use experiments were constructions and nothing that could be called real use. Secondly, they were digested by us into a story that we wanted to tell. The main criteria for selecting what we wanted to tell was to overemphasize distinguishing features, so as to make the point more easily understandable for participants. In accordance with our earlier work [13], we found it much more effective to create simulations that are caricatures instead of such that are nuanced. Furthermore, the story of this material is not any more "true" and objective, by virtue of having been recorded on video. The design ideas developed by a group of designers still ultimately need to be tried out in real use situations in order to prove their worth. And the way we use video material in this case provide no way of escaping that.

The "Talk to your TV" project investigated extreme interaction modalities as springboards $[9,16]$ for users in generating design ideas. The experiences from "Talk to your TV" illustrate how we can create the new, inspired by the existing, once the setup of the confrontation between users and the technology is carefully considered. Moreover, the project exemplifies how something fruitful comes out in the meeting between contrasts, in this case the different interaction modalities. Finally, this initiative formed part of our contribution to move usability work from evaluation to co-design through experimenting with settings that support users in their role as creative partners in the design process. We did not set up the "Talk to your TV" sessions to extract a representative voice of the users that we could present to designers. Neither did this project focus on actual user involvement, field work and capture of real work situations, nor with other possible ways for designers, engineers and usability people to cooperate. Rather these simulations are constructions made with a purpose, in this case to illustrate alternative solutions regarding fundamental issues of HCI as outlined above.

In our experience, supporting user participation by giving users means for externalizing their design ideas by providing materials for sketching and modeling as ideas show up would be a valuable extension to the experiment. In this way the users could develop their ideas a little further and express their ideas in more tangible ways.

Furthermore, we see some potential in using the video more actively in the session, e.g. through working with the video recorded in the first part of the session in cooperation with the users as the basis for elaborating or developing on the design ideas expressed.

\section{Workshop stands}

As part of the design of Bang \& Olufsen PC-TV living room we arranged a design workshop [18] where different stands served to inspire the design work as described in the following. A group of people from the usability group, the multimedia department, the communications department and researchers met in a room equipped with products and prototypes of relevance to the PC-TV living room. In order to prepare the workshop, the different competencies in the project had been asked to prepare a stand each presenting their favorite related products or prototypes. The participants split in two multidisciplinary teams who visited in turn the stands.

The stands were: The voice of the users presented by the researchers, the prototypes of the technicians and the products of the designers.

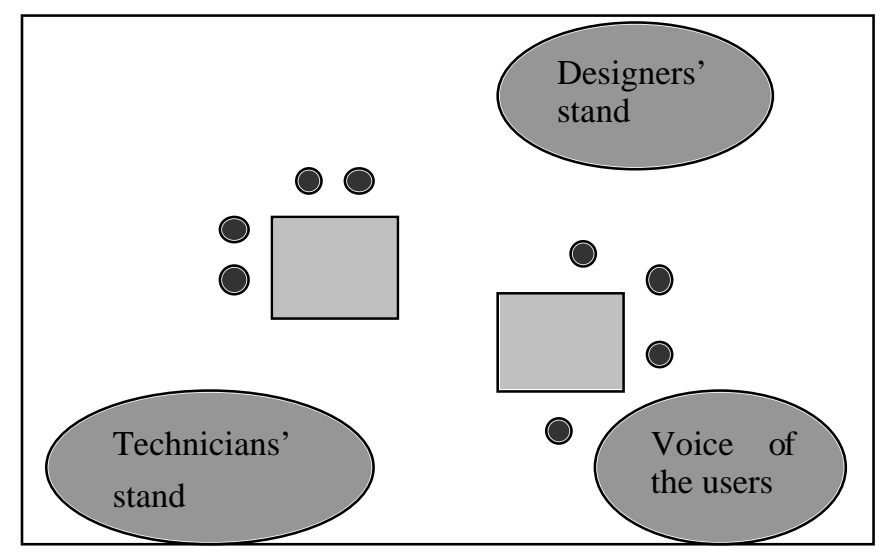

Figure 1 The layout of the design workshop room.

At the stand presenting the voice of the users, the video clips from the "talk to your TV" experiment were presented. The clips were supplemented with posters capturing the design ideas envisioned by the users. Together the video and the posters provided tangible means [27] for the discussions in the group of designers, engineers and usability people. However, we believe that had the video clips been shortened, from 10 minutes e.g. into 2-3 two-minutes sessions they would have been even more 
useful for this purpose. The technicians' stand displayed a wide variety of prototypes including various prototypes of remote controls. Finally, the designers presented an earlier product named the PC-TV office, which is the counterpart of the PC-TV living room, in that it brings the TV functionality to the PC for use in the office. At the stands of both the technicians and the designers were also posters capturing design rationale and design dilemmas of relevance to the design of the PC-TV living room.

In the first round of the workshop, the participants were in groups asked to take a round in the room, visiting the stands. At each stand they were asked to comment on the issues raised at the stand and to capture their discussions on post-it notes.

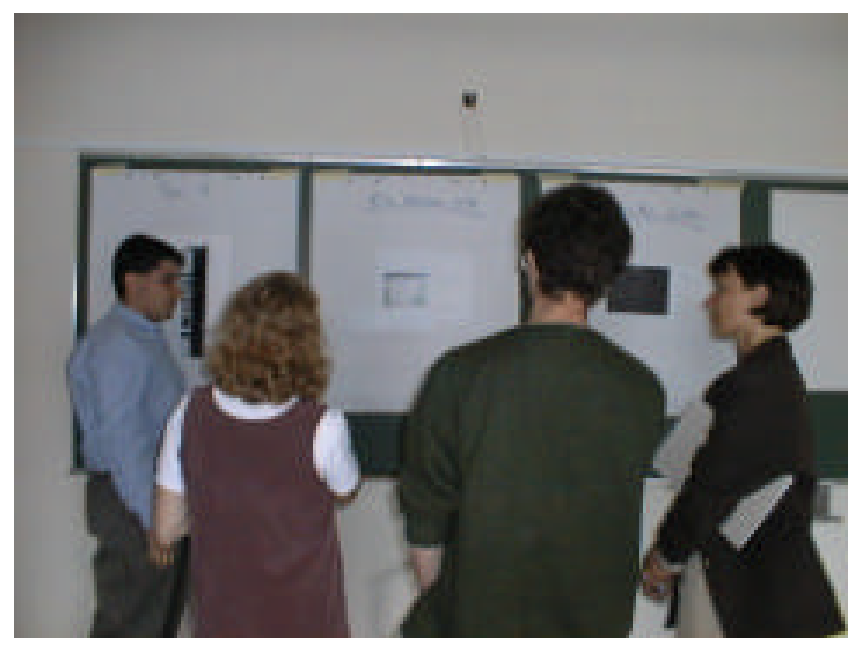

Figure 2 Discussions around posters at the designers' stand.

Based on the discussions held in this first round, two specific design issues were chosen for the two groups to work on. Each team was asked to produce their design solution in a tangible form, for instance as a paper prototype. After half an hour, each group presented their design proposal for the other team, and the groups then swapped design topics. For the second round a team could either start from scratch or start out from what the other team had produced. They had at their disposition various design materials including pens, paper, Scotch tape, postits, etc. In addition, screen dumps from the current prototype of the PC-TV living room were available.

The range of representations at the stands served as sources of inspiration and promoted the different perspectives in the design work. Through having tangible representations, all participants in the meeting were supported in promoting the different perspectives. In this way the different voices were not solely attributable to certain participants but, through the stands, all participants were supported in taking advantage of all perspectives.

For instance, when discussing how to provide access to web pages on a Bang \& Olufsen television, in particular how the navigation should be supported using a remote control, one of the participants in the workshop walked up and grabbed one of the early prototypes at the technicians' stand. He brought it to his group and acted out how he envisioned a design solution. Subsequently, one of the other participants requested the prototype and demonstrated a slightly modified version of this first suggestion. In this way, the discussion carried on for a while with the different parties supplemented and contrasted each other using the prototype from the stand as an important point of reference.

The material at the stands also made reference to the historical development of Bang \& Olufsen products. This in turn was fruitful since the old products served as a source of inspiration in the development of the new product. To illustrate this, the PC-TV office product presented at the designers' stand had been developed before the PC-TV living room project started. This product allows users to watch television on their PC. At several occasions the PCTV office was referenced in the discussion on how to design the PC-TV living room. In this way, on the discussions about whether there should be some sort of menu-bar to access Internet functionality on the PC-TV living room, the remote control representation on the $\mathrm{PC}$ version was referenced as a source of inspiration both positively and negatively. Positively, in the sense that the living room product could be inspired by the office version such that they both had the special Bang \& Olufsen identity and both appeared to be part of the company line. Negatively, in that at the same time the PC-TV office product served to emphasize the contrast to the PC-TV living room since the two products are designed for very different use situations and each need to have their own identity. Hence, through having earlier products available for direct reference, the workshop participants were offered inspiration for the design both in terms of supporting continuity as of taking up new challenges in design.

The workshop described was set up for a single day event and the stands were removed by the end of the day. An interesting extension to this approach is permanently to equip design rooms with stands or with a rich set of representations, products, prototypes and statements, which allow designers to be inspired from both looking back and ahead when designing new products. At this very moment Bang \& Olufsen is working on designing their own design room inspired by some of these thoughts.

\section{Learning checklists}

Learning in use, or self-explanatory interfaces is an important topic for the three companies, and Bang \& Olufsen TV design in particular (see also [5]). In order to explore how to design more learnable user interfaces for such a setting, we undertook a study of HCI literature about learning, and tried to operationalize these in checklists [9] that would be of use to the design activities in the company.

The development of the learning checklists has been an iterative process where we (the researchers) created an initial version based on literature studies. This version was reiterated in several design workshops in the project, and in one of the latter iterations used for the design of the PC-TV [11]. 
We developed four checklists that more than anything reflect areas focused on and insights to be gained from textbooks and scientific papers:

- questions of artifact/user interface

- questions of errors

- questions of differences between novices and experts

- questions of use/learning context

Obviously these lists (see an exerpt in figure 3) were not all-inclusive and they were a consequence of choices we made together with the usability people, regarding what would be useful in these particular analyses and design situations. Our idea was that the checklists could be used for focusing on empirical investigations of learning in use as well as for reflecting on possible hypotheses and design solutions.

In the PC-TV iteration, we analyzed a number of trial use situations of TV sets. The use situations all dealt with one or two Bang \& Olufsen TV sets that are handlingwise quite distinct.

The analysis of the empirical material was indeed post-hoc as regards the design of the two particular TV sets. In particular, we looked at five interesting situations of trial use, where a problem occurred that could be related to the relation between the user's background and the design of the particular artifact, or to forming and consolidation of operations.

These analyses were used to further inspire the design of the PC-TV living room, which includes a more complex interface than the "plain" TV.

Our experiences from this can be summarized in the following:

- analyzing use background is design in that it is necessary to make choices regarding which use backgrounds and relevant artifacts to focus on (see further discussion in [21]).

- in order to look ahead and identify potential competence of the users it is as useful to focus on metaphors and artifacts that are different from the one being designed as it is to focus on those which have similarities.

- confrontation of perspectives was informative for design. Using the checklists emphasizes the important point that one cannot necessarily accommodate for all concerns at once, and that these contradictory concerns need to be considered in the specific design.

To actually design the learnable PC-TV, is a long step from this analysis. However, the checklists helped in shedding light on where or what the users learn from, what analogies are of importance (both positively and negatively), and where learnability issues collide. We are continuing to fuse these findings into our discussions with Bang \& Olufsen.

The learning checklists have been thoroughly restructured in their continued use, and in our ongoing theoretical elaboration. This process is described in [11].

\section{Investigation of artifact/user interface}

1. Does the artifact allow for inspection of the result physically, "outside" the artifact? If not, how well will the later end-result be represented in the artifact? (is what you see what you get?)

2. Does the artifact allow for experiments, e.g. through undo? How does the artifact support the user in getting "back on track" after a breakdown in handling the artifact?

4. Does the artifact invite users to use experiences from other artifacts?

5. How extensive is the set of menus or commands? can the user be cut off from the use of certain parts of menus or commands, either through pre-defines settings or by his or her own choice?

\section{Investigation of errors}

The overall hypothesis is that all users err, as part of their exploratory use of an artifact, but that e.g. novices and experts may err in different ways.

1. Is the error conceptual/bound to a misunderstanding, or operational/bound to the handling of the artifact?

3. Does the error result in a breakdown in relation to the handling of the artifact or to an object of scrutiny, or is the error seen through a work-around?

4. Does the error relate to the user's understanding of/ acting in the domain of work, the particular artifact, or technology in a wider sense?

\section{Investigation of differences between novices and experts}

1. Does the user approach the artifact as neutral observer, wanting to investigate the artifact, or does she just start doing the job?

2. Does the user apply external theories or a repertoire of flexible strategies?

4. Can the user handle multiple, conflicting purposes of work or only one?

\section{Investigation of use/learning context}

2. Which materials are used for what and how is the artifact applied in relation to these materials and products?

5. Collaboration: is use individual or collective? do novices and expert take part in the same use processes?

Figure 3. Exerpts from the learning checklists 


\section{USING INTERACTION PERSPECTIVES TO TRIGGER IDEAS}

The basis for the second example was a design project at Danfoss. The User Centered Design Group at Danfoss and a group of researchers from the University of Aarhus were undertaking a study of work at a combined district heating and power plant. The overall aim of this project was twofold: to investigate the need for and consequently possible use of portable/handheld technology in the plant; and to utilize and develop methods for usability work in the field.

The field study was done over several rounds with 3-8 people from the research group spending several days in the plant following different workers in groups of two with video cameras [23]. This video was analyzed and a small number of key situations were transcribed as the starting point for further design considerations. These transcripts of dialogue between workers in the plant, pictures of the setting and the actual snippets of video constituted the work situation descriptions in this example.

The field study and video analysis provided us with a greater understanding of the work taking place in a process setting like a combined heating and power plant, and pointed out some areas in which mobile technology could be introduced to support their work practices.

\section{The Museum workshop}

As a parallel event to further our understanding of what constitutes a process environment and act as a source of inspiration, a workshop was held at the Danfoss museum. On display at the museum is virtually every kind of component ever produced at Danfoss and the tour through it shows the development of the company tied into the story of Mads Clausen, the man who founded Danfoss. The aim of this workshop was to sketchingly chart the development in Danfoss components, the technology and interaction concepts, as well as the development in the organization ('the Danfoss company spirit', or how Danfoss saw itself), and through the unfolding of the history find new inspiration for design.
In working with the development in technology and interaction concepts, we considered the role of technology in the society at particular points in time, illustrated by the science-fiction literature of that time (inspired [28]). With this timeline, we classified the interaction styles used in the components in relation to the technology view of the specific point in time, and created three character types to exemplify these.

\section{Design principles}

The generation of these characters triggered the idea of using interaction perspectives in a much more structured way as tools for creativity.

Basis for our effort was the four theoretical interaction perspectives (tool, media, system and dialogue partner) described in [12]. Briefly described, the four perspectives map out the basic relations between humans and artifacts as follows. In the Tool perspective, humans use tools to work on material (in analogy to how we use a hammer). In the System perspective, humans and machines are regarded the same type of components, i.e. the human are reduced to the 'language' of the machine. The Media perspective emphasizes humans interacting with humans through machines (seeing "undisturbed, direct communication as an ideal). Finally, in the Dialogue Partner perspective the human's interaction with the machine analogous to a dialogue between humans, i.e. using natural language.

Based on these theoretical constructs, four 'design perspectives' were created as two-page posters with the original, abstract description of the interaction perspective on the right-hand side and a character description to the lefthand side, focusing on his or her use of technology, which served as an exemplification of the perspective. Inspired by our work at the museum workshop, we chose characters originating from the science fiction literature and films, which also served the purpose of making them easily recognizable. We chose Flash Gordon as the personification of the Tool perspective, Spock for the System perspective, The Nethacker (based on various characters from William Gibson's universe) for the Media perspective, and the ship computer 'Mother' on the starship Nostromo (from Ridley Scott's film 'Alien') for the Dialogue Partner perspective.

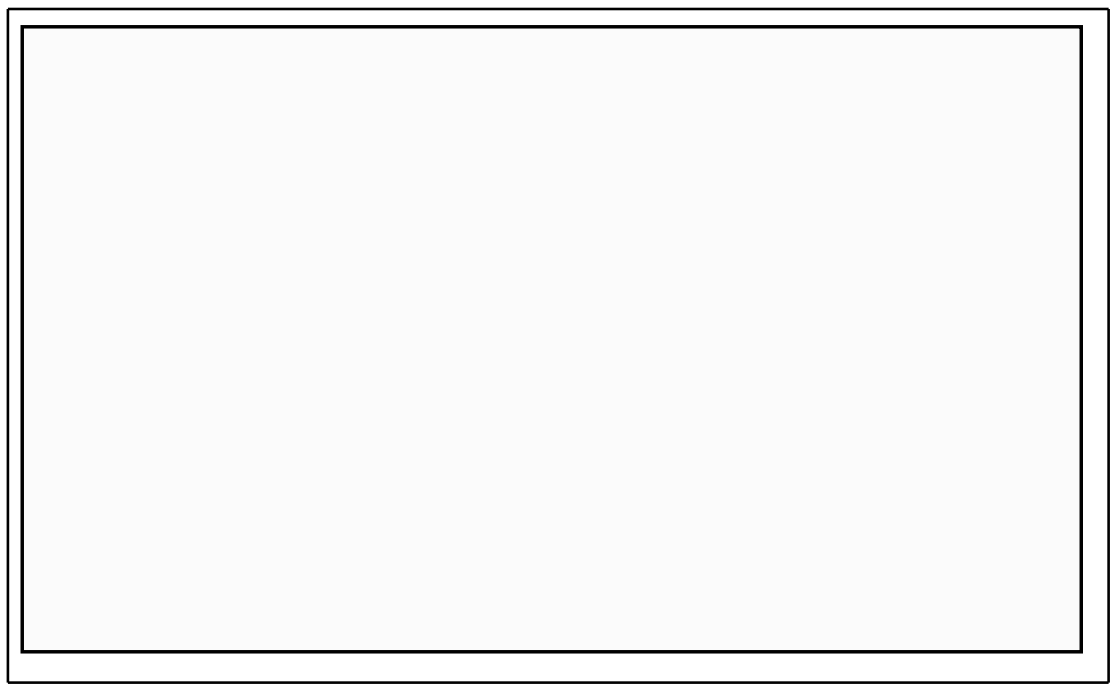

Figure 4, Spock 
We see these perspective/character pairs as a tool for sketching a 'design space' for the further exploration of the setting. The future scenarios and designs we created with them as brainstorming devices enabled us to look at the same setting, use a description or a problem from different perspectives. Utilizing theoretical constructs like the four original interaction perspectives in relation to a character enabled us to exemplify the strong and weak points by imposing them on a scenario in which the character could act. The theoretical description worked as a backdrop to consolidate the characters' behavior.

Furthermore, the coupling of perspective and character gave the participants a concrete anchor into the concepts. We experienced repeatedly that when using the perspective/character pairs, participants would refer to how the character would act in a given situation, rather than how the given perspective would apply, thus considering the concepts within the interaction perspectives as the characters' behavioral patterns. This is hardly surprising because the characters provided a very effective means of relating the abstract concepts to the concrete example of work. It stresses the value of providing good exemplification when working with interaction perspectives to inter-link the abstract and the concrete.

The historical frame, which initially inspired the choice of characters, showed itself as a double-edged sword. We realized that our choices of characters had some unintended negative effects: the sci-fi characters were too fixed within a certain time period, e.g. Flash Gordon made the Tool perspective seem 'old' or outmoded, a limitation which is not inherent in the original theoretical tool perspective. We want to maintain the recognizability of the characters without stigmatizing them by grounding them in a specific, historical context, which we seek to remedy in a later version of the perspective/character pairs.

Furthermore, it was difficult to find already defined characters whose 'personality' fits the perspectives fully. E.g. as regards 'Mother', they do not use normal language to communicate with it in the film but a complex command language and a standard screen and keyboard! However, our only plausible alternative, 'Hal', the ship computer from Stanley Kubric and Arthur C. Clarke's "2001 - A Space Odyssey" seemed to have to many negative connotations attached for it to be used constructively. Some of our characters were simply inappropriate for the concepts they were meant to exemplify.

Following the recommendations from [9] to use extremes to make a point, we plan to extend each of the four perspectives with a 'good guy' and a 'bad guy' description of them to juxtapose their positive and negative aspects. The positive and negative connotations associated with each perspective provide a more detailed image of the possibilities and limitations of them, and serve the purpose of distinguishing the individual design perspective even further from the rest.

\section{Using work scenarios to anchor perspectives}

At a second inspiration workshop, a group of interaction designers, industrial designers, HCI researchers, usability engineers and psychologists from Danfoss, Kommunedata, Bang \& Olufsen and the University of Aarhus was gathered to work with the first version of the design perspectives in relation to work at the combined heating and power plant. These were immediately nicknamed 'Flash Gordon and friends'. The participants were handed a small number of work situation descriptions. They watched video from the field study at the plant, and were asked to explore design possibilities for a portable piece of equipment from the point of view of the four design perspectives, one perspective in each of four groups. It is in this context essential to note that the work situations used in this workshop were not chosen at random from the vast quantities of video material from the field study, but situations carefully selected because they illustrated circumstances within which mobile technology might support the work [13].

The groups created scenarios based on the work situation description to situate their thinking about possible ways of interaction in this setting - where would the media perspective, emphasizing communication between people in the plant, head? Or, with the tool perspective, which tools would be needed, and for what purposes? The groups were further asked to present their design scenarios by acting them out, and obviously this was easier for some groups than for others. In particular, one group came up with a futuristic design scenario with negotiating sludge-tanks, and for them the specific dialogue of the original use setting was of little use. However, all groups found the scenarios to be a useful way of relating possible interaction designs to what actually happens in the plant, despite the very selective work situations.

We found that the restrictions inherent in working with one specific work situation description and one specific design perspective actually helped define the boundaries and create a common ground on which the participants could use their individual experiences and backgrounds in the negotiation of the design. This 'boundary zone' [2] was first defined through the negotiation between the participants of how the assignment should be understood and affronted. Later it served as a collaborative design space as the participants started sketching design ideas for the future scenario on paper and with simple props like pipe cleaners and plastic cups, elaborating on some and discarding others.

The choice of using the same work situation description across the groups rather than choosing work situation to fit the individual deign perspectives provided means of comparing the resulting design scenarios. Furthermore, the use of sci-fi characters, which are arguably caricatures, for the different types of interaction exaggerated the differences between the different perspectives, which made them easier to juxtapose and assess.

The intended outcome of this workshop was not to generate specific design solutions but rather to inspire and aid the 
process of generating new ideas for regarding mobile support for work at a combined heating and power plant. We see the use of caricatures in the design perspectives as an important tool in achieving this goal. Because the design perspectives quite clearly did not provide realistic views of the world, it was also clear for all participants that their utilization did not yield the solution to a design problem but rather the unfolding of a design space.

\section{CONCLUSIONS}

We have described and discussed a number of tools and how they support creativity in design. Common to them is that they support, and are developed to support, cooperation in design. Cooperation both at the level where they support meetings in the boundary zone of the overlapping practices of design, and at the level where they are part of cooperative activities in design. They help provide tangible artifacts that the groups of designers, users and usability people can get their hands on and explore in these cooperative activities. They provide input to these sessions, and they are part of shaping the results. And though we talk about creativity, and about what is really thinking tools [9], the results of using these are very concrete and support the next iteration in the iterative design loop.

The proposed tools are different, and none of them serve all purposes equally well. In the following we discuss the described tools from the point of view of how they support our initial theoretical points.

\section{Past, present and future}

Using the past to inform design has taken various forms in our work: The Danfoss museum is certainly one, where the relationship between the form and appearance of products were considered in relation to general stylistic trends, pointing ahead (See also [28]). However, as we point out, it is important not to make these past styles appear oldfashioned, if they are to serve design constructively.

In the Bang \& Olufsen example, the stands explicitly served for particular groups to extract the positive aspects of a particular past product, and confront these with the future product. In both the learning checklist analysis, and the "talk to your TV" example, people made references to past artifacts that they were reminded of, for good or bad, for reasons of similarity or difference. The latter is an important concern that has come out of our present work: The past does not only inform design as regards the good sides, it is equally, though perhaps less constructively, informative regarding the less attractive sides.

\section{Theory as a possible source of inspiration}

The checklists and interaction perspectives are two different ways of operationalizing theory. Through the personification, etc, the interaction perspectives seem much more readily available for being acted out and explored. This does not mean the checklists could immediately be given the same "flavor", simply because the questions they ask are not as coherent and clear-cut.
However, both of the types of operationalizations have been used, and are useful for confronting particular sets of concerns in a particular design.

\section{The present points ahead}

The TV sets in use give useful design ideas. In the "Talk to your TV" example it was clear that by starting with the present, well known use, the users were inspired to think ahead, when asked to talk to their TV. In contrast, when they were asked to talk first, they were much more trapped in the present, perhaps in demonstrating that they knew what tele-text was about. And, as discussed, through the analysis of the present, we are already shaping the future. The present day products which were presented at the stands also acted at tangible means in support of design in the Bang \& Olufsen workshop as in other examples we have seen [8].

Using transcribed situation out of use turned out to be a very useful basis for designers to explore the consequences of the interaction perspectives. The anchoring in the actual use made the designers fly, with both feet on the ground, and it was possible to discuss implications of the design choices, without this being pure speculation.

We find that what is useful overall in these examples, is that the references to the present are concrete and quite specific.

\section{The right tool for the job, extremes and multiple voices}

The right tool for the job, in our analysis, is one that gives a concrete, and often tangible focus, perhaps oversimplifying matters a bit, so as to illustrate extremes. We have made good use of clear-cutting perspectives, be these in terms of particular perspectives of certain groups as in the Bang \& Olufsen stands, or through opening up a broad design space with the different interface modalities in the "talk to your TV" example. We have developed theorydriven extremes as with the interaction perspectives, and we are in general proposing to work with extremes in terms of plusses and minuses, good guys and bad guys.

However, it is equally important to keep confronting these perspectives and not to go off in any one direction. This is indeed why the meeting of perspectives through cooperation of people in workshops is very important for the whole of the creative design process.

\section{Tools develop}

As we have illustrated the proposed tools for creativity are in continuous development. It is essential to continuously confront the tools with the particular design situations that one is designing for, and with the ongoing accumulation of experiences in these particular design activities.

\section{ACKNOWLEDGMENTS}

The project "Usability work in Danish industry" is sponsored by CIT/CMT through grant \# 23.

We thank all the BIDI-participants for their contributions; Pernille Marqvardsen, Kim Halskov Madsen, and Thea Borgholm for their contribution to the work presented here. 


\section{REFERENCES}

1. Bannon, L. \& Bødker, S. Beyond the Interface, Encountering Artifacts in Use. In Carroll, J. (Ed.). Designing Interaction: Psychological Theory of the Human-Computer Interface. Cambridge University Press, pp. 227-253, 1991.

2. Bertelsen, O. W. Elements to a theory of design artefacts: a contribution to critical systems development research, Ph.D.-Thesis, Aarhus University. DAIMI PB-531, 1998.

3. Bertelsen, O.W. Fitts' Law as a Design Artefact: A Paradigm Case of Theory in Software Design. In Blumenthal, B., Gornostaev, J. \& Unger, C. (Eds.). Human-Computer Interaction. 4th International Conference, EWHCI '94 St. Petersburg, Russia, August 1994. Selected Papers, Berlin: Springer Verlag, pp. 11-18, 1994.

4. Buur, J. \& Bødker, S. From usability lab to "design collaboratorium”: Reframing usability practice, paper presented at DIS 2000.

5. Bærentsen, K. Intuitive User Interfaces, paper accepted for Scandinavian Journal of Information Systems

6. Bødker, S. Ehn, P., Kammersgaard, J., Kyng, M., \& Sundblad, Y. A Utopian Experience, Bjerknes, G., Ehn, P. \& Kyng, M., (Eds.). Computers and Democracy - a Scandinavian Challenge, Aldershot, UK: Avebury, pp. 251-278, 1987.

7. Bødker, S. and Halskov Madsen, K. Context - an active choice in usability work, Interactions, July+August 1998, pp. 17-25.

8. Bødker, S. \& Grønbæk, K. Design in Action: From Prototyping by Demonstration to Cooperative Prototyping. In Greenbaum, J. \& Kyng, M. (Eds.). Design at Work: Cooperative Design of Computer Systems. Hillsdale, NJ: Lawrence Erlbaum Associates, 1991pp. 197-218.

9. Bødker, S. and Christiansen, E. Scenarios as springboards in design. In Bowker, G., Gasser, L., Star, S. L. and Turner, W. (eds.). Social science research, technical systems and cooperative work, Mahwah, NJ: Erlbaum, 1997 pp. 217-234.

10. Bødker, S., Christiansen, E. \& Thüring, M. A conceptual toolbox for designing CSCW applications, COOP' 95 , International Workshop on the Design of Cooperative Systems, (pp. 266-284), Juan-les-Pins, January 1995

11. Bødker, S \& Petersen M.G. Design for learning in use, paper in review for Scandinavian Journal of Information Systems.

12. Bødker, S. Through the Interface - a Human Activity Approach to User Interface Design. Hillsdale, NJ: Lawrence Erlbaum Associates 1991.

13. Bødker, S. Scenarios in user-centred design - setting the stage for reflection and action. Hawaii International Conference on System Sciences 32. CD-ROM. Version to appear in Interacting with Computers, 2000
14. Carroll, J. M., Kellogg, W.A. \& Rosson, M. B. The task-artifact cycle. In Carroll, J. M. (ed.) Designing Interaction: Psychology at the Human-Computer Interface, New York: Cambridge University Press, 1991, pp. 74-102.

15. Coad, P. \& Yourdon, E. Object-Oriented Analysis. Englewood Cliffs, NJ: Prentice Hall, 1990

16. Engeström, Y. Learning by expanding. OrientaKonsultit, Helsinki, 1987.

17. Kyng, M. Creating Contexts for Design. In Carroll, J. M. (Ed.), Scenario-based design. Envisioning work and technology in system development (pp. 85-108). New York, NY: Wiley 1995.

18. Madsen, K.H. and Petersen M.G. Reflections on three design sessions, Brewster, S. Cawsey, A. and Cockton, G. (eds.) Human-Computer Interaction - INTERACT'99 (Volume II), IFIP, 1999, pp. 185-190.

19. Madsen K.H. and Borgholm, T. Cooperative Usability Practices. Communications of the ACM, 42, 5, May 1999, pp. 91-97.

20. Madsen, K.H. A Guide to Metaphorical Design. Communications of the ACM, 37 (12) 1994, 57-62.

21. Mogensen, P. Challenging Practice: an Approach to Cooperative Analysis, Ph.D. thesis, Aarhus University: DAIMI PB-465, 1994.

22. Morgan, G. Images of organization, Beverly Hills CA: SAGE, 1987.

23. Nielsen, C. Testing in the Field. Proceedings of APCHI 98, IEEE Press, 1998, pp. 285-290.

24. Ricoeur, P. Time and Narrative (Volume 3). Chicago: The University of Chicago Press, 1988.

25. Schön D. A. The Reflective Practitioner-How Professionals Think in Action, Basic Books, New York, 1983.

26. Star, S. L. The structure of ill-structured solutions: boundary objects and heterogeneous distributed problem solving. In Gasser, L. \& Huhns, M. (eds.) Distributed artificial intelligence, vol. 2, London: Pitman, 1989, pp. 37-54.

27. Trigg, R., Bødker, S. \& Grønbæk, K. A Video-based Analysis of the Cooperative Prototyping Process. Scandinavian Journal of Information Systems 1991, vol. 3, pp. 63-86.

28. Øritsland, T.A. A Theory of Discursive Interaction Design. Mapping the development of quality and style in man machine interaction, Doctoral Thesis, Norwegian University of Science and Technology, Department of Product Design Engineering, Trondheim 1999 


\title{
Testing in the Field
}

\author{
Christina Nielsen \\ Dept. of Computer Science \\ University of Aarhus \\ Ny Munkegade, bldg. 540 \\ DK-8000 Arhus C \\ +4589423462 \\ sorsha@daimi.aau.dk
}

\begin{abstract}
:
It is widely acknowledged in the HCI community that much can be gained from bringing aspects from the field into the lab, and this principle is dominating within usability groups in Danish Industry. This paper describes three such Danish usability groups and their experiments with turning the tables by using aspects from the lab in the methods applied in the field during field work projects.

The context of use plays an important role for a richer understanding of the usability of particular products. As such implications of this is not surprising, neither theoretically nor empirically. What is interesting, however, is how findings of this type are instantiated in the particular cases; how the three usability groups have used the lab approaches to aid them in working in the field and how the new methods may enhance their existing methodological tool-kit.

The message of the paper is that there are a variety of ways in which the theoretically driven, pre-planned, and predirected may meet the situated and open-minded, both when usability work is conducted in the field and in the lab.
\end{abstract}

\section{Introduction}

This paper aims to describe and discuss the experiences and considerations held by three Danish usability labs that have experimented with stepping out of the lab and into the field, and particularly ways of bringing aspects from the lab into the field in such a situation. The experiences from this experiment are largely positive, but we do not see the solution as abandoning the old and familiar methods. Rather, we wish to look at ways in which we may successfully combine aspects from field and lab and create better settings for usability work.

We may for a moment look at the fundamental problem of field work, at least when taken to the extreme, e.g. through ethnomethodology (e.g. [10]): The open, non-directive search for particular phenomena is an interesting methodological approach, but in design/evaluation, a more goaldirected effort is often necessary. As [8] points out, designers, and we would argue usability workers too, face three challenges: the dialectics between abstract theoretical and situated practical understanding; between planning and responsiveness; and between using a framework or a description method to structure the analysis of the situation, and an open-minded "letting the situation speak to you".

Field studies provide insight into aspects of the actual usage crucial for successful design but hard to create in a lab, for instance interruptions, complex patterns of cooperation and the physical environment as well as provide usability people and designers with important insight into the complexity of real life activities, e.g. how use takes place in ways that are not anticipated and perhaps could not be so. Thus, doing field studies, facing the complexity and emergent nature of real use situations is a way of training sensitivity and open-mindedness so that usability workers, when faced with surprises in the lab, are ready to give up control and pre-planned actions, at least for a period, and dive into the situation.

In contrast, the lab excels in the level of control of a situation it is possible to attain, through e.g. capturing more aspects of tests on videotapes. The lab opens up to staging the situations much better than a field study by enabling the usability people to test specific use situations, to enhance the documentation process by using advanced logging devices linked to the video and to experiment with specific parts of a system and work methods.

The methods the usability groups within the three companies have based their work on are largely concerned with bringing aspects of the field into the lab, and to a lesser degree the other way around. The field studies described in this paper introduce experiments of bringing aspects from the lab into the field that offer solutions to the dichotomy of being focused while still letting the situation be open. 


\section{General presentation of the project}

Our project, BIDI (Usability work in Danish industry), is an action oriented research project that aims to develop the work practices of usability, based on our own theoretical and empirical work in the area $([5,6,7,14])$ as well as that of others. Our theoretical and methodological platform includes participatory design, activity theory and ethnographic method. The goals of the project are 1) to bring tests situations closer to the nature of the future situation of use, 2) to explore new kinds of user participation, 3) to explore how learning takes place and how new patterns of use evolve 4) to investigate usability issues related to new kinds of products beyond a conventional interface with screen, mouse and standard keyboard, 5) to support self reflection among usability professionals, 6) and to explore how field studies and lab test mutually may support each others.

The BIDI project is a collaboration between Bang \& Olufsen, Danfoss, and Kommunedata, the first 3 Danish companies to have usability lab facilities, and Århus University. The three organisations perform usability work rather differently, but they share an interest in moving further out of the lab and into the field and to increase the user involvement in their work.

\section{Bang \& Olufsen}

Bang \& Olufsen $(\mathrm{B} \& \mathrm{O})$ is a manufacturer of integrated video and audio products linked in a small network allowing them to share services. The prime characteristic of the products is that they are part of people's everyday environment.

The usability-work at B\&O is characterised by a high degree of specialisation: industrial designers design, engineers build prototypes, and the psychologist in particular does the testing. The lab facility is a "living room" wired with video and microphones, accompanied by an editing suite. $\mathrm{B} \& \mathrm{O}$ has a user panel from which to select people to bring into the lab, consisting partly of their own employees as, to $\mathrm{B} \& \mathrm{O}$, everybody is a potential user.

B\&O's prime concern in the field study was methodological: how does one do field work in the home of users, in situations where the actual use is sporadic and infrequent? Because of this particular concern, pure observation was abandoned immediately, and the person undertaking the field study decided to conduct a kind of in situ interviewing instead. Five families were visited, two B\&O customers and three from the regular test panel.

\section{Danfoss}

Danfoss is a manufacturer of mechatronics products like flow meters, temperature sensors and controls. Products are used in a diversity of settings ranging from private homes, apartment buildings, supermarkets, and district heating stations to waste water treatment plants. The products are often only a small part of highly complex systems.

The design and test practices at Danfoss are heavily influenced by the Scandinavian approach to HCI and systems design $[2,3]$. Laboratory tests are supplemented with a lot of field studies, bringing daily users, service people, sales people, product developers together in workshops. Drama pedagogy techniques and similar techniques are used experimentally in workshops, [9].

A study of the work at the Sønderborg combined heat and power plant was the setting for Danfoss' field study. It was carried out in several rounds encompassing 3-8 people spending several days in the plant, primarily observing key users of the existing system. This field study was the initial activity of "The Smart Window" project in which Danfoss wanted to explore portable interfaces of the future. Thus, the field study did not relate to an existing product but observed work practices of a possible future context for a Danfoss product.

\section{Kommunedata}

Kommunedata is the principle supplier of administrative systems for local city administrations in Denmark. They develop computer systems for a diversity of work settings including hospital, dental clinics, municipal offices, etc.

The usability work at Kommunedata is fairly formalised and most communication with the developers about tests is through test reports. Developers are brought into the test process but they mainly play an observing or occasionally a facilitating role. Going on field trips to potential users is the principal source of information for preparing for a test of a system. Focus groups have also been used to some extend for bringing users, usability workers and developers together.

Previously, the lab had tested a nursing/care plan system for hospitals, and several problems were then identified. This test was followed by a field evaluation where the focus was to see if the problems identified earlier still occurred after a period of use, and whether new problems had occurred. In the present field study Kommunedata wanted to move beyond this narrow focus, but at the same time build on prior experiences from the field setting and of the product. Another issue for Kommunedata was to develop their usage of collected data. The field work was structured as follows: two usability testers visited two particular wards at two hospitals, one day each place and observed the use of the system. 


\section{General overview of the field studies}

The general preparation of the field work experiment started with a couple of workshops in the BIDI project. All three companies conducted the field studies within the same period of time and immediately after a one-day seminar with Melissa Cefkin of IRL (Palo Alto) was held. The focus of the workshop was interaction analysis of video recordings as all three usability groups used video in their field studies.

Following the field studies, Kommunedata and Danfoss brought back some issues from the field study to discuss with the users. Kommunedata in particular found the approach of bringing central findings and questions back to the users so useful that they are now considering how this approach can be more frequently applied.

A month later, after the organisations had concluded the analysis of the field work, a two-day workshop was held with Jeanette Blomberg, Xerox PARC, with the particular focus on ethnography and design, and the combination of ethnographic and other methods such as interviews, prototyping, etc.

\section{Bringing the field into the lab}

It is widely acknowledged in the usability community that much can be gained from bringing aspects from the field into the lab, and it is chiefly this principle the three usability groups in question have built their usability methodologies on. In the following we will look at some of the techniques already used in this respect by the three usability groups.

Test and workshop surroundings are created with the specific goal of bringing the physical context of the field into the lab for a more realistic work setting when conducting usability work.

The usability groups often find inspiration for their test or workshop scenarios in the current work setting. Scenarios based on field studies are a way of enriching the testing in the lab, so as to bring in the users' perspective on their work/use situation instead of just the usability workers' and designers' understanding of their artefact. However, it is equally important to study how work practices change as new technology is introduced. If test scenarios in the lab are developed solely on the basis of the earlier (nontechnical) work practices, the issues that might arise from the introduction of the technology are not taken into account in later tests and therefore not included in the product. Therefore we would advocate field work as an integrated part of the usability tests throughout the development cycle.

As use situations often turn out to involve more than one active user, the co-operative aspects must be taken into consideration. Furthermore, prototypes need to be more complete in order to be suitable for co-operative situations, an aspect that is also part of the added complexity in test situations [1]. The usability groups approach these problems carefully and take great effort in supporting these aspects by e.g. creating scenarios for multiple users. We are convinced that good scenarios and simulation techniques where users act out more of their work situations $[4,9,15]$ are suitable for enhancing lab tests of co-operative situations and will continue to work with this issue.

Workshops actively setting the stage for use or simulated use are means frequently used as a way for users to become active participants in the testing and evaluation of particular products. Video clips of work may help set the stage for such testing together with scenarios, and users may further contribute by bringing their work tools and materials into the test situation as well as create their own scenarios.

These were all examples of how the three organisations generally take on usability work. It is now time to take a look at what experiences were earned from the field studies and how elements from lab practise have aided the field work.

\section{Bringing the lab into the field}

By setting up tests in the field rather than in the lab more realistic tests may be conducted. Artefacts or prototypes may be brought to the workplace and tried out in the actual context of work. As a side effect the artefacts may be spotted and commented by people from the workplace not originally involved in testing.

The context of use plays an important role for a richer understanding of the usability of particular products. As such implications of this is not surprising, neither theoretically nor empirically (for a discussion of context and the study of HCI in use, see [7]). What is interesting, however, is how findings of this type are instantiated in the particular cases, and how the three usability groups have used lab approaches to aid them in working in the field.

In the following we shall look at some of the ways lab approaches were introduced in the field studies and the consequences of this.

\section{Aspects of the lab used in the field}

Since people do not constantly operate their audio and video devices, the use of $\mathrm{B} \& \mathrm{O}$ products is fairly infrequent and fragmented which makes it harder to conduct observations of 'real' use if a field study is to be concluded within a realistic time frame. The same thing can be said to apply to the Kommunedata case as the nurses did not have time specifically dedicated for using the computers, but had to squeeze some typing in whenever possible throughout the day. Though rather extreme, in that the operation of e.g. radios is infrequent, short and fragmented, this problem is 
certainly more general as can be seen from the Kommunedata example.

In the B\&O study an approach based on recall interviews combined with informal simulations was chosen. It somewhat complicates the matter that the general type of field studies B\&O are interested in depend on getting access to people's homes, potentially at times where people are literally not dressed up for public appearance.

The primary concern for the $\mathrm{B} \& \mathrm{O}$ team was how to handle these situations in order to produce meaningful data within reasonable time limits? They got fine results from combining open-ended interviews with more structured simulations of e.g. yesterdays breakfast routine. The $\mathrm{B} \& \mathrm{O}$ field trip team also discovered that they got a much more open response if they started out with an informal chat with the users over a cup of coffee and went on to the simulations afterwards. This suggests that the order in which the tasks are performed is not completely without influence on the result.

Kommunedata chose a combination of interviews with the nurses and observation of their daily use of the system. They discovered that they got a lot out of changing from pure observation to asking users to think aloud in a way that was rather similar to their normal thinking aloud procedures used in the lab. However, we would like to stress again that an important part of a field study is to remain in the situation with an open mind and not just to delimit ones observations to what have been planned. Thus, it is necessary to abandon some aspects of lab testing whereas others may well be brought to bear on the field situation. Danfoss conducted their field study through video filming workers as they went about their daily business, combined with in situ interviews. This field study was primarily an experiment with ethnographic methods and as such drew less on methods from the lab. However, the usability group did include logging as part of the observation, i.e. the usability people aimed to take notes regularly while video filming to create a conceptual log for the video.

\section{Problems emerging in the field}

Having determined that field studies can provide us with information largely unattainable in the lab, the question now becomes how to conduct the field study? We shall look at some problems encountered in connection to field studies and some solutions to them.

How can fieldworkers be sure that data from field trips is 'genuine' and not corrupted by their interference? It is our claim that the usability worker should not be invisible in the setting; it is true that interference on a larger scale can affect the results but it is necessary to a certain degree to guide the field study towards the focal point. Being as neutral as possible might result in data that is hard or impossible to use; e.g. Kommunedata discovered they got much more out of their video tapes of the nurses using the system when they asked them to think aloud while working rather than just work. This kind of interference is sound because Kommunedata had previously gathered video tapes of nurses typing which conveyed no useful information for them whereas the think-aloud approach made them able to understand the nurses' motives and problems when using the system.

Other problems we face when engaging in field studies are related to the use of video to capture the scene. We shall look at two fundamental problems, namely how video can delimit the observation and how it may affect the users' behaviour.

Using the camera as the sole means of recording events, i.e. the "I am a camera"-approach, gives rise to the question of what might be missed when your limit your field of observation to be that which you see through objective of the camera. Furthermore, and more importantly, successfully operating a camera in this respect demands concentration which makes you less sensitive to e.g. peripheral activities or interesting comments from the user that might initiate a new discussion as is often the case with openended interviews. In the Danfoss study, a single usability worker not only had to operate the video camera continuously, but also take notes at intervals. It seems unrealistic that one person can be focused on the camera and at the same time remain open to the situation and what else may be going on in the surroundings. We opt for the presence of at least two people in these kinds of ethnographic field studies, so one can concentrate on operating the video camera and the other can be more openly aware of the situation.

We now address the question of how and to what degree the cameras affect people, and whether they should be there in the first place if they influence the behaviour of the participants. As an example, Kommunedata asked people when they entered the office if they minded being videotaped. Nobody said yes, on the other hand, often people worked very briefly and left again. Were they rushing the job because of the camera, or were they always that busy? In such a situation the camera should probably be omitted and replaced by note taking combined with the think-aloud approach described earlier, to the extend it does not prevent the user to perform other work tasks. However, if the users accept the camera as merely a mean of capturing what is going on, video tapes can be an invaluable source of information in a later analysis of e.g. use scenarios or recollecting details. In the B\&O field study, the camera worked well in combination with open-ended interviews and simulations of the users' daily routines because none of the users saw the camera as dominating or threatening.

There is no reason to believe that what we get through the camera in the field is more objective or real per se than what we get from a lab test. What needs to be considered in 
every instance is the balance between the negative and the positive sides of using video from the knowledge of the users and their environment and from that judge whether or not to bring a camera. For a more detailed discussion of the use of video as a recording medium in field studies, see [11, $12,13]$

\section{Aspects for the future}

Even though the three usability groups already had a wellfunctioning assortment of techniques for usability testing, the field studies opened up to ways of enhancing their 'methodological tool-kit', both through their own experience with field work but also through the exchange of examples with the other groups during the evaluation following the field studies.

The combination of simulations and open-ended interviews in one field study and think-aloud methods and observation of users performing work tasks in another proved to be a very efficient way of getting an insight in how users interact with their technology. This becomes evident when you consider the limitation put upon these field studies, namely the limited time-span within which they were carried out a working day spent at each field site at the most - and that this type of information is difficult to retrieve in general due to the infrequent nature of the use. As these limitations are hardly the ideal basis for a field study it becomes even more important to find ways of keeping a focal point in mind in order to obtain the necessary information. We believe the lab methods used in the field studies obtained this without compromising the openness of the situation and therefore let the usability workers approach the field with an open mind to what the field study may reveal of e.g. unanticipated use. We are supported in this by the usability groups' positive response to the results gained through these experiments and their readiness to adopt these techniques into their usability practise for the future.

We would once again like to stress the importance of weighing the situation with regards to using a camera. As argued before, it is unwise to use it at any cost because of the fundamental problems identified as potentially damaging to the situation; its presence may inhibit or influence the users, or the operation of it may make the usability worker more insensitive to e.g. peripheral activities or comments.

\section{Conclusion}

Field studies may be used to gain a deeper understanding of the artefact from the perspective of real use. The experimental use of lab approaches has shown ways of reducing the complexity inherent in real life work settings without putting unwanted restraints on the openness of the situations, involving only slight changes of the usability groups' current field study practise. As stressed, this becomes essential to the quality of data obtained when the field study is limited by e.g. time frames. We have argued the importance of usability workers, when faced with surprises in the lab, are ready to give up control and preplanned actions and stay with the complexity of the situation, and sketched how this may be accomplished through the description of the wide range of methods already used by the three usability groups. However, in addition to the enhanced lab methods we see more experiments with bringing usability work into the field and enriching the field methods with aspects of lab testing as necessary components of improving work and thus designing more usable artefacts.

The BIDI project as such has only just begun. The coordinated field studies are one example of activities that we have undertaken and a promising one indeed. Many methodological discussions have arisen on this basis and we shall continue to pursue these issues. The continuation of the project will certainly include more work with the combination of field studies and lab work in all possible settings.

\section{Acknowledgements}

This paper has been partly based on an earlier paper on the need for context in usability work and the advantages of field studies, written by Susanne Bødker, Kim Halsskov Madsen, Pernille Marqvardsen and the author. In gratitude to my former co-authors, I have chosen to retain the plural voice throughout the paper, as they have been key figures in the numerous discussions originating from the analysis and evaluation of the field work described and have untiringly offered their comments on early drafts of the paper. Also, special thanks to Marianne Graves Pedersen and Thea Borgholm for all their constructive critisism and never ending patience. Finally, I would like to thank the usability groups in the BIDI project for engaging in this project and for experimenting with new methods.

\section{References}

1. Bardram, Jakob E.: The Role of Workplace Studies in Design of CSCW systems: From Passive 'Implications for Design' to Active, Cooperative Design. In Proceeding of the 19th IRIS Conference, 1996.

2. Black, A. \& Buur, J. (1996) Making solid user interfaces work. Information design journal 8(2): 99-108.

3. Buur, J., Bagger, K. \& Binder, T. (no date) Turning usability testing into user dialogue, draft, Danfoss.

4. Bødker, S. \& Grønbæk, K. (1991). Cooperative Prototyping: Users and Designers in Mutual Activity. International Journal of Man-Machine Studies, 34, Special Issue on $C S C W$. Also in Greenberg, S. (Ed.) Computer Sup- 
ported Cooperative Work and Groupware, Academic Press, pp. 331-359, London 1991.

5. Bødker, S. (1991). Through the Interface - a Human Activity Approach to User Interface Design. Hillsdale, NJ: Lawrence Erlbaum Associates.

6. Bødker, S. (1993). Historical analysis and conflicting perspectives - contextualizing HCI. In Bass, L., Gornostaev, J., Unger, C. Human-Computer interaction. 3rd International Conference, EWHCI '93, Springer Lecture Notes in Computer Science vol. 753, pp.1-10.

7. Bødker, S. (1996). Applying activity theory to video analysis: How to make sense of video data in HCI, in Nardi, B. (ed.) Context and consciousness. Activity theory and human computer interaction, MIT press, pp. 147174.

8. Bødker, S. \& Christiansen, E. (in press). Scenarios as springboards in design. In Bowker, G., Gasser, L., Star, S.L. \& Turner, W. (Eds.), Social science research, technical systems and cooperative work. Erlbaum.

9. Grunnet, C. \& Skak, A. (1996): Drama in Design, Applying Improvisation in Product Design (Unpublished report). Institute of Dramaturgy, Århus University, Århus Denmark; and Man-machine Interaction Group, Danfoss, Nordborg Denmark.
10. Hughes, J. Randall, D \& Shapiro D. (1993). From ethnographic record to system design: Some experiences from the field. In: CSCW: An International Journal, vol.1 no. 2. USA.

11. Jordan, B. \& Henderson, A. (1995): Interaction Analysis: Foundations and Practice. The Journal of the Learning Sciences 4(1): 39-103.

12. Mackay, W. (1989): Video as a Research and Design Tool. Special issue ofthe SIGCHI Bulletin, Vol. 21:2.

13. Mackay, W. (1995): Ethics, Lies and Videotape. CHI'95 Proceedings: Conference on Human Factors in Computing Systems: Mosaic of Creativity, Denver, Colorado, USA, pp. 138-145.

14. Madsen, K.H. (1996): Initiative in Participatory Design. In Blomberg, J., Kensing, F. \& Dykstra-Erickson: PDC '96, Proceedings of the Participatory Design Conference. Palo Alto, USA: Computer Professionals for Social Responsibility (223-230).

15. Mogensen, P. (1992) Towards a Provotyping Approach in Systems Development. Scandinavian Journal of Information Systems, 4, 31-53. 


\title{
Dynamics in Wastewater Treatment:
}

\section{A Framework for Understanding Formal Constructs in Complex Technical Settings}

\author{
Olav W. Bertelsen \& Christina Nielsen \\ Department of Computer Science, Aarhus University, Denmark. \\ olavb@daimi.au.dk,sorsha@daimi.au.dk
}

\begin{abstract}
Based on the study of unskilled work in a Danish wastewater treatment plant, the problem of formalisation of work is discussed and extended to technical processes. Five symmetrical levels of dynamics in complex technical work arrangements are proposed as a tool for understanding the limits of formalisation and for designing formal constructs in such settings. The analysis is based on concepts of heterogeneity, granularity of goals and motives, and process and structure.
\end{abstract}

\section{Introduction}

An inevitable problem in the design of CSCW systems is that work is not standing still. Rather, work settings are dynamic: routines evolve over time and unusual situations force deviations from the routine. For this reason, purely formal constructs and descriptions of work have proven inadequate when designing effective, real world CSCW systems.

Suchman and Wynn (1984) set off the debate about the role of formalism in $\mathrm{CSCW}$, and their empirical studies clearly illustrated that there is more to office work than formalised, or formalizable, procedures. Heath and Luff (1992) continue this in their study of work in line control rooms on the London Underground, showing that even seemingly specialised routine tasks rely on 
peripheral awareness and the participation of others. Thus, impossible to subsume under formal constructs. Bowers et al.'s (1995) study of workflow systems in the printing industry demonstrates their inability to encompass and support the actual course of work. Such systems structure work from without, emphasising interorganisational accountability rather than the smooth execution of the work. Thus, the CSCW community has succeeded in questioning our ability to completely formalise CSCW.

However, as Schmidt (1997) correctly points out, concentrating only on the non-formalisable parts of work ignores the situations in which formalisation can be a resource and an important tool in cooperative work. He suggests that formal constructs, including written procedures, schemes, charts, workflow systems, and other artefacts, are important artefacts that support CSCW. This is particularly true in the case of complex manufacturing or process plants, where formal constructs, like blueprints or the physical plant itself, are fundamental features. Accordingly, Robinson (1989) argues that CSCW applications must support two levels of interaction, the formal and the cultural. Applications that support one at the expense of the other tend to fail.

Wastewater treatment plants are highly-distributed technical settings. Unlike office-work, the plant operates continuously, independently of the people employed there. Unlike control rooms, risk factors are minimal, since most of the work done at a wastewater plant is not time-critical. In addition, formalisation in wastewater treatment plants both intervenes with the technical aspects of the plant and of the work. Thus a wastewater treatment plant presents a technically and procedurally complex system that differs from the work settings typically found in the CSCW-literature. It is our claim that investigating into the limits of formalisation and the design of formal constructs in the wastewater treatment setting will present findings that add to the previous work of formalisation within CSCW.

This paper reports on our study of a modern wastewater treatment plant in Denmark. The following section describes the plant and its operation and sets the scope for our case study. We then look at different theoretical frameworks that offer ways of analysing the type of work that is wastewater treatment. The next section provides a framework for identifying levels of dynamics in wastewater treatment, based on the theoretical frameworks discussed. With this, we identify five symmetrical levels of dynamics in the case of wastewater treatment plants, on one hand questioning the general formalisability of technical arrangements, on the other hand pointing to a framework for understanding the limits of formalisation in CSCW-design. 


\section{A study of wastewater treatment}

The case study is part of a long-term research cooperation in the areas of HCI and CSCW involving Danfoss and the Computer Science Department at Aarhus University as well as several other partners. The purpose is to explore the theoretical notion and practical design of common information spaces. The project has focussed on field studies of three wastewater plants, conducted by researchers from the participating organisations. This paper reports on our observations of work at one of the plants. We selected 6 days, within a 5-month period, to follow workers through their entire daily routine. Different researchers followed different workers, using hand-held video cameras to capture the events. We later analysed the video, with special emphasis on the daily work practice, use of artefacts, and how workers dealt with the disruptions. We selected groups of clips to present to the plant employees during feedback sessions and user workshops. We also compared the work practices at this site with data collected by other project researchers at the other wastewater treatment plants.

The wastewater treatment plant

We conducted a study of a modern wastewater treatment plant in Denmark, paying particular attention to how formalisation and flexibility exist in the work practices, and how it affects the coordination of work. The purification process at the plant includes mechanical, chemical and biological phases. The resulting segmented sludge is used to produce gas, which produces enough electricity to run the plant. The remainder is pressed and taken away to an incinerator plant. The plant was one of the first to implement automatic process optimisation for the removal of nitrogen. The automation has been possible due to the development of new sensor technology, which allow for on-line measuring and control of the primary parameters of operation. Not surprisingly, the process optimisation has radically decreased the use of chemicals. The plant has an estimated capacity of 220.000 person equivalents. However, it is constantly running at $110-150 \%$ over capacity because the plant has not been able to expand to match the increase in the city's production of wastewater.

The work

The wastewater treatment plant employs a total of 8 people. The two managers are responsible for the overall management of the plant. The remaining six employees work in pairs, with the following areas of responsibility:

- chemical test lab, receiving the sludge-trucks, preliminary sorting area, sand trap

- outside plant areas, putrefaction tanks, sludge tanks, gas-turbine building, 
control room

- sludge press

The three pairs of workers are each responsible for tasks associated with a specific part of the treatment process. Individual workers may temporarily take on other tasks, as when someone is ill, but the overall division labour is quite stable. Within the bounds of the set of work tasks, individuals are free to 'juggle' the tasks as the situation demands. An important goal of this organisation of the work is to keep the relevant part of the plant in a condition that will allow the underlying purification process to run effectively, even when the worker responsible is home on nights or weekends. For example, the worker in charge of the lab spends two to three hours every morning collecting water samples and sludge and then analysing the quality of the water at different stages of the purification process. The worker in charge of the gas turbine area checks each of the different machines and collects the read-outs of how much gas has been produced during the last 24 hours. The plant manager's area of responsibility is wider, but the tasks are of the same nature. He starts every morning at his computer, getting an overview of the status of the plant by looking at his customised graphs and the lists of alarms.

Although each worker's daily routine of checking and maintenance is highly standardised, there is also a high degree of unpredictability at the plant. The majority of alarms received at the wastewater treatment plant are warnings, such as when the water level is at the maximum limit for a tank. Some alarms call for (relatively) immediate action, while others may be addressed over a period of days. Sometimes the worker can handle it himself, other times an outside specialist must be called. If the alarm is due to machine failure, several workers may completely break off their daily routine and enter into a cooperative problem-solving effort. Workers and managers specifically pay attention to warning alarms and physical signs of problems, since it is much more desirable to prevent rather than recover from machine breakdowns.

The wastewater plant is continuously engaged in a number of experiments to optimise the purification process, to produce cleaner water and decreased costs. Experimentation usually involves introducing new technology or work practices which may provoke unanticipated events and effects on everyday work. Outside visitors, such as school classes, also disrupt the normal routine, even though the visits are carefully planned and executed.

In general, the daily work routine has a dynamic structure. The workers need a deep understanding of the assignments and the plant itself in order to perform their tasks without continuously having to reinvent their work practices. This enables them to place equipment in the area for later use, and allows them to redefine the order of tasks in order to cope with the numerous events that cannot possibly be anticipated. 


\section{Perspectives on wastewater treatment work}

In the standard engineering literature wastewater treatment is described as a fixed series of well-defined components (e.g. Droste 1997). This analytic perspective is in marked contrast to the plant manager's perspective. He sees things as a result of a historical process, from the first basins built to a prediction as to where a new set of tanks will be added. The former view is static and formal; the latter is dynamic and situated in the current context.

The discrepancy between the static engineering view and the manager's historical conception is no coincidence but rather a result of different needs. The engineer focuses on optimal constellations of technical components, using the fixation of as many variables as possible as an important tool. The wastewater plant manager "lives" in the plant for a longer period. For him the engineer's plan is a starting point, what Star (1986) calls a border condition, among many others, against which running the plant is realised.

\section{Process and structure}

Both the systematic, static view and the historic, dynamic view are needed to understand and design technical systems; neither can be abandoned. Thus we need a conceptual framework that can deal with these simultaneously, and the dialectics between structure and process.

In analytical philosophy, process means mere movement, 'a sequence of events' (Blackburn, 1994). In dialectical materialism, process includes the sense of transformation of the given (Israel 1979). With this background, Mathiassen (1981) introduces and utilises an analysis of process and structure as a framework for understanding the development of computerised work arrangements. A model with structure in focus sets limits for sub-processes within the structure, but at the same time super-processes may change the structure. Structure is in this context denote the qualities we perceive as solid or stable but which are changeable. In the same way, a model with process in focus is changing subsumed structures at the same time, as it is itself structured by super-structures.

Mathiassen argues that the choice of whether to focus on structure or process depends on how well-known a situation is with respect to the object of activity, the means for realising the object, the constraints on the object, and the outcome of different actions, or to which degree a situation is established or emergent. Andersen et al. (1990), also reflect this relationship with regards to system development. In highly established routine situations, a high degree of formalisation is possible because both the problem and the working practice to solve it are known. In problem solving situations where the working practice is unknown, the degree of formalisation is completely dependent on the situation's emergent nature. In problem setting situation, which are highly emergent, 
formalisation will be counter-productive because neither problem nor means of solving it are known. The degree of uncertainty in a work situation is particularly interesting because its analysis is fundamental to understanding the (cooperative) work practices build around them.

\section{Human activity and the dynamics of collaborative work}

The three levels of uncertainty by Andersen et al. (1990) has some similarity with the hierarchical structure of human activity identified by activity theory (e.g. Engeström, 1987). Where Andersen et al. define levels of uncertainty according to goals and means being known or unknown, activity theory structures human acts according to their motivation and automaticity. Human activity is seen to be mediated by artefacts in a dialectical process of continuos and reflective recreation. Human activity is situated and can only be analysed in its social, historical and technical context. The basic unit of analysis is the connected structure of subject, object, instruments, based in socio cultural context - the activity system. At the topmost level of its hierarchical structure activity is motivated, directed to fulfil a need. Activity is realised through conscious actions directed to relevant goals. In turn, actions are realised through unconscious operations triggered by the structure of the activity and conditions in the environment.

Within this hierarchical structure, Raithel (1996) propose, a framework for understanding collaborative work, identifying three levels of collaboration: coordination, co-operation and co-construction. At the co-ordination level, collaboration is an integral part of routine work: the participants act according to scripted roles, defined by explicit written rules, the division of labour, traditions and tacit knowledge. At the co-operation level, collaboration is directed to a known object (or goal) shared by the actors, but the means are not shared or even known to all the actors. Thus, actors continuously modify actions based on intermediate results, adapting to others' actions and conceptualising their own actions in the process of realising the object. At the co-construction level new motives are created. Neither the object of work nor the means of obtaining it are fixed or shared between all actors. Instead they continuously re-negotiated and reconceptualised throughout the process to create a commonly shared set of objects and rules. This framework has been used in studies of court cases (Engeström et al. 1991), and in studies of the dynamics of collaboration in hospital settings (Bardram 1998). It can be understood as an elaboration of the uncertainty framework referred to above, pointing to the construction of goals and motives as central aspects of the dynamics of collaboration.

At the wastewater treatment plant, situations connected to breakdowns of machines are examples of co-operation. The breakdown changes collaboration from co-ordination to co-operation. Co-construction rarely occurs at the 
wastewater treatment plant but may be prompted by external factors like new technology, new environmental legislation or critical changes in the quantity and quality of wastewater from industry and the city. In such cases co-construction primarily involves the manager and people at the city wastewater office.

\section{Identifying dynamics}

As wastewater treatment is a dynamic setting with processes at many levels, from water flow to transformative changes of the overall purpose and structure of the plant, it is necessary to develop a detailed analysis of these dynamics. In identifying the dynamics in the wastewater treatment plant we have constructed the following checklist. The checklist is based on the concepts introduced above, and is suggested as a general tool for the analysis of complex technical work arrangements.

- Identify contextual units

- Consider granularity of goals and motives

- Identify processes

- Link processes with the structuring of contextual units

- Identify modes of formalisation

- Identify types of technical structuring

Identifying contextual units

Contextual units are units of the setting that make sense according to specific situations, tasks or purpose; heterogeneous and overlapping. According to Star (1989), boundary objects are objects used by different parties in different localities; robust enough to maintain identity across heterogeneous use, but plastic enough to adapt to the constraints and needs of the different parties working with them. Components of the wastewater treatment plant are boundary objects in the sense that are parts of overlapping contextual units. However, the interpretability is in general somewhat limited. As part of the daily round of one of the workers, a specific gas motor is looked at and listened to, thus part of the contextual unit of the daily round. However, the same motor constitutes it own isolated contextual unit in situations when it is taken down for repair. Further, the motor is part of the subpart of the plant transforming gas in the sludge into electricity. This gas production is a contextual unit from one perspective, but at the same time an important indicator of the load of the whole plant. Another example: the managers office is the centre and symbol of management and general monitoring of the plant, but it is also where one of the unskilled workers daily enters results from the laboratory tests into the process control computer system. The heterogeneity of contextual units is fundamentally different from the hierarchical decomposition seen in the mainstream of engineering literature. 
Consider the granularity of goals and motives

A specific alteration of the technical arrangement may appear as a transformation of the basic condition for one activity, while it from the perspective of another activity reflects maintenance of stability. Thus, introducing a new polymer into the wastewater cleaning process, as we saw at the plant, meant some of the workers had to extent their daily work routines to include new tasks. The introduction of the polymer changed their work practice. From the point of view of the city wastewater office, or the plant manager, however, the new polymer was perceived more as an adjustment than as a transformation. Such differences are related to the granularity of goals and motives. In dealing with this granularity we need an understanding of the historical development of the setting, its background and motivation (Markussen 1993).

\section{Identifying processes}

As discussed above process can be understood as mere movement in time and space. This notion of process is needed in understanding the technical arrangement of a wastewater treatment plant and in understanding the purification process as such; water flowing, phases oscillating, etc. Human work is another kind of process, possibly highly routinised, like the daily test sample collection round, but always motivated at some level. The question to ask for every process is whether it is causal, according to laws of nature or if it is intentional, dialectically directed by motives. In both cases, the technical structuring of the process, e.g. timing of sample taking determined by phases in the purification process, can be taken into account.

\section{Linking processes with the contextual units}

In linking processes to the structuring of contextual units we consider processes structured by the contextual units as well as processes changing or moving the structures of these units. The test sample collection round is structured by the distribution of test sample points around the plant. The arrangement of test points at the plant is changed by the development of new ways of testing, such as automatic sensors, and by new insights and requirements from the society. The process-structure diagrams described by Mathiassen (1981) supports this step, although it doesn't fully acknowledge the heterogeneous nature of the contextual resulting from variability of purpose, and the non-hierarchical features of the technical structure.

\section{Identifying modes of formalisation}

The identification of modes of formalisation is primarily related to the work going on in the considered domain, and can be treated in the terminology of constraints and possibilities (Mogensen 1994). In the study of wastewater treatment, it was 
particularly useful to analyse the modes of formalisation in terms sequentially, enforced or emerged, as well as dynamics or flexibility of routines. Large parts of the work of the unskilled workers at the wastewater treatment plant are formalised by daily rounds at the plant, by forms that have to be filled out. Most of the sequential formalisation at the plant could be rearranged, implying that these sequences serve more as well-structured checklists than scripts. The formalisation in relation to work at the laboratory is less flexible in that the formalisation here is embedded in the tools. Thus, the test tubes must be shaken, heated for 15 minutes, etc. in order to work at all.

Identifying types of technical structuring

The technical structuring is the structuring around the physical, chemical and biological processes as well as the structuring of the process control and automation system. This structuring can be analysed from the perspective of the present paper, limited to the basic considerations of the type of process, as well as from the expert perspectives of the relevant engineering disciplines. As an example, automation theory yields a distinction between the process (water flowing) and the control system, which is particularly useful. A feature of the particular technical structuring of the wastewater treatment plant was the number of false alarms that routinely had to be unset.

\section{Dynamics in Wastewater treatment}

The analysis of the case study can be summarised in two issues concerning dynamics. First we propose a five level model of dynamics, secondly we discuss the contradiction between maintenance and optimisation as an instance of the general contradiction between motives of different praxes.

\section{Levels of dynamics}

We have chosen the perspective of wastewater treatment work as a (dialectic) correlation between elements of structure and process that on the one hand shapes and delimits but also, and more importantly, has within it the ability to transform and transcend. We chose this view because it supports the understanding we have obtained of the work during the field study, namely as constantly adapting and changing to reflect several levels of other dynamic systems that affect different aspects of the wastewater treatment process. We now try to substantiate this perspective by mapping out the different kinds of dynamics and structures we see present in the wastewater treatment process, and we do this aided by the checklist. 
The technical process

The most basic level of dynamics in wastewater treatment, its sine qua non, is the movement of water through pipes and tanks and the alternation between phases, of e.g. nitrification and de-nitrification, in the purification process. In the same way movements of people working at the plant is a basic, and obvious, form of dynamics.

People moving around

Large parts of the work at the plant is associated with walking around, often moving through the same, remote parts of the plant several times a day. This is done to collect test samples, but more often just to monitor the condition of the plant and the process, as a vital part of preventing breakdowns and verifying system information.

\section{Technical re-arrangement}

During the period of our visits at the wastewater treatment plant, the technical structure of the plant changed. On our second visit, we saw a tank located in a driveway. The tank contained a polymer, an oil-based substance that separates water and sludge, decreasing the percentage of water in the sludge before it is processed in the bio gas generator. This was one of many experiments to increase the wastewater treatment capacity. When we visited the plant three weeks later, a shed had been build around the polymer tank. Thus, the experiment had attained a more permanent status. This example has two implications for the study of dynamics. First, that the technical structure is moving, and that the change may begin as experimental fluctuations and end as sustained change of the technical structure. Second, that movement in the technical the structure, e.g. the appearance of the polymer shed, for the chief biologist at the central wastewater office may be a case of mere adjustment of the established mode of operation. For the men at the plant, however, the shed and the new equipment in it was an alteration of the working environment, introducing new tasks in the day to day work, calling for adjustment of established practice, and the building of it was an object in itself.

Flexible routines

One worker, while checking the area around the sludge tanks, noticed that the surface water in the tanks was brownish. He immediately proceeded to the building the water would have come from to check a filter he suspected to be the cause of the water being discoloured, and which turned out to be in dire need of a rinse. He explained that if the water hadn't been discoloured, he would have gone down to check the filter anyway because that building is part of his area of responsibility, but that he would not have done so until much later. This situation 
may seem too simple to be of interest; one man works alone, going on a welldefined round. However, even though the contextual unit, namely the part of the plant associated with the tasks on the round, both physically and process-wise, and the goals, namely checking up on a number of things on the plant, are welldefined, we see that this situation reveals some interesting points with regards to the identification of modes of formalisation and the process.

Because he encounters the brown water, which we may call a causal process outside of but interfering with his actual work, his motive changes with regards to what needs to be done when and he initiates a change in his routine. Even though the daily round is well defined in terms of which tasks should be done and checkpoints visited, the routine still leaves plenty of flexibility for the reorganisation of the order of tasks. The alternative, which would be to perform the related tasks in a strict sequence, perhaps related to the physical layout of the plant would contradict an overall motive of work at the plant, namely to keep the purification process running continuously. The lack of response to warnings such as the brown water would seriously increase the risk of an actual machine breakdown. Going exclusively by the physical layout also renders the processlook at the purification process invalid, because it becomes impossible to look at connections between the components that are related in the process but not physically standing side by side. Most importantly, though, is that these reservations holds double for cooperative situations. If the workers have to leave their routines to collectively recover from a machinery breakdown, the flexibility is even more crucial.

After arguing that a high degree of flexibility is important in the everyday routines, we would like to emphasise that this is not the case for all aspects of wastewater treatment processes. It would be absurd to claim that flexibility is necessary in the physical flow of the water through the plant, thereby making it possible to send the water out into the bay before the chemical or mechanical cleaning process. This is also why we argue that the technical structure of the wastewater treatment process needs to be identified and juxtaposed with the continuously changing processes.

\section{Transformation of the domain}

Some of the most profound changes in wastewater treatment have come from the development of environmental legislation. The water quality plan passed by the Danish parliament in the late 80'es introduced new norms for pollution of water resources. One motive for this legislation was instances of severe extirpation of the fauna in several lakes, rivers and sea areas caused by too many nutrients in the outlet of water from houses, industry, and the primary production. Thus it was no longer acceptable to let 'black' water from the wastewater treatment plant out in the bay, neither legally nor according to public opinion. Depending on the degree of effort necessary for the wastewater treatment plant to reach the new legal level 
of nutrients, the technical process and the work routines changed in accordance to this; small changes on existing technology would not affect the purification process noticeably whereas the implementation of new technology and a radical change in the tasks performed or the staff involved would more or less completely change the process on a contextual or non-technical level. In the former case we wouldn't talk about the contextual unit of the plant being changed whereas the latter situation would call for a redefinition of several levels of contextual units, possibly including the wastewater treatment system for all of the city. From this example it becomes apparent that we must deal with a whole range of external influences that may affect the wastewater treatment process, possibly quite profoundly. Similar influences could be the consequence of the development of new technology making the purification process more efficient and economically attractive, even though the means for effective purification and economic gain rarely go hand in hand.

\section{Maintenance vs. optimisation}

In the following we discuss the tension between maintenance and optimisation as an instance of conflicting motives in wastewater treatment. Throughout our field study we have seen several examples of how the contextual units or work horizons may differ, especially between management and workers. Management and workers share the goal of making the plant run smoothly. Management also has the goal of improving how the plant runs, both economically and in terms of cleaner water. In specific situations, such as when experiments of adding a new polymer to improve the quality of the sludge (work horizon for management) causes the sludge to stick to the canvas in the press thus making it harder to empty it, this disrupts the work of maintaining the sludge press process (which is the work horizon for the workers in the sludge press). These types of disruptions, if not identified and handled, may in the last instance cause collaborative efforts to break down. To aid us in this identification and handling process we find it fruitful to consider two different work perspectives: maintenance and optimisation.

Maintenance focuses on keeping the wastewater treatment system (or parts of it) stable and running without breakdowns. The motive for optimisation is to change one or more processes to obtain a better end-result in terms of cleaner water. So managers may consciously introduce disturbances to optimise the running of the plant, whereas maintenance workers will try to eliminate disturbances and preserve the status quo. When the goal changes over time, the maintenance work changes to reflect this, so stability in this context does not equal a completely fixed state but rather a space defined by the levels of dynamics affecting the wastewater treatment process within which maintenance work operates. Similarly, optimisation work is delimited by the structures within the 
different levels of dynamics and thus not free to make arbitrary changes. Consequently, the two perspectives contain many identical elements, which makes it hard tell them apart. However, they differ on a few but significant counts, namely with regards to the motive and possibly the contextual unit in a given situation. The proposed framework offers methods for analysing work in relation to motivation and thus helps us assess which perspective is driving the different actors in a collaborative activity.

\section{Conclusion}

In line with the mainstream of CSCW research following Suchman's (1986) questioning of formal constructs, our study of the wastewater treatment plant establishes yet another case where deviations and situated action is a hindrance to complete formalisations. Further, we have questioned the applicability of formal constructs in relation to the technical arrangement based on the analysis of the various types of dynamics observed in the wastewater treatment plant, according to their degree of permanent change, motivatedness, and transformative feature.

It can be expected that the general technological development will bring the cost of relevant computer hardware down to a level where it will be feasible to introduce a higher degree of fine masked control technology, sensors, on-line meters, etc. in wastewater treatment plants. Our study points to the likely difficulties in implementing such formal constructs, not just in relation to the flexibility of work at the plant, but also in relation to the process system as such. Because of the dynamics of the technical arrangement, fine-grained control systems will need to be updated at a rate where it is not likely to pay off. For every modification of the plant, for every new polymer tank, the control system may need to be modified. Design approaches enabling technical tailoring based on strong modularisation and encapsulation, or approaches locating parts of the control system in the components, may help; however not when it comes to the more home brewed changes in the process system, and clearly not in relation to the flexibility of work routines.

The proposed five levels of dynamics, as well as the framework for identifying the dynamics, have helped us understand the domain of wastewater treatment. These conceptual tools may also be helpful in the design of CSCW-systems for complex technical settings, especially in handling formalisation and the design of formal constructs. In future activities in the wastewater project the reported analyses of levels of dynamics will be used and evaluated as a basis for design. 


\section{Acknowledgements}

We will like to thank the people at the wastewater treatment plant, and our colleagues in the wastewater project. Also, thanks to the anonymous reviewers for constructive criticism. Finally, we owe a special thank to Wendy Mackay for being extraordinarily helpful. Our work on the wastewater project has been supported by The Danish Basic Research Foundation, Centre for Human-Machine Interaction and The Danish National Centre for IT-Research, project no. 23 (Usability Work in the Danish Industry).

\section{References}

Andersen, N. E., F. Kensing, J. Lundin, L. Mathiassen, A. Munk-Madsen, M. Rasbech and P. Sørgaard (1990). Professional systems development. New York: Prentice Hall.

Bardram, J. E. (1998). Collaboration, Coordination, and Computer Support. An Activity Theoretical Approach to the Design of Computer Supported Cooperative Work. Ph.D. Thesis, Aarhus: Computer Science Department DAIMI PB - 533

Blackburn, S. (1994). The Oxford Dictionary of Philosophy. Oxford: Oxford University Press.

Bowers, J., G. Button, and W. Sharrock (1995). Workflow From Within and Without: Technology and Cooperative Work on the Print industry shopfloor. Proceedings of ECSCW95

Droste, R. L. (1997). Theory and Practice of Waster and Wastewater Treatment. NY: John Wiley \& Sons, Inc.

Engeström, Y. (1987). Learning by Expanding: An activity-theoretical approach to developmental research, Helsinki: Orienta-Konsultit Oy.

Engeström, Y., K. Brown, L. C Christopher and J. Gregory (1991). Coordination, Cooperation and Communication in the Courts: Expansive Transitions in legal Work. In The Quarterly Newsletter of the Laboratory of Comparative Human Cognition, Vol 13, Number 4.

Heath, C.C. and P. Luff (1992). Collaboration and control: Crisis Management and multimedia technology in London Underground line control rooms. CSCW Journal, 1 (1 - 2), pp. 69-94.

Israel, J. (1979). The Language of Dialectics and the Dialectics of Language. Copenhagen: Munksgård Humanities Press.

Markussen, R. (1993). A Historical Perspective on Work Practice and Technology: The Case of National Labour Inspection Service. In Andersen P. B., Holmqvist, B. and Jensen, J. F. The Computer as a Medium. Cambridge: Cambridge University Press, 1993. pp.457-477.

Mathiassen, L. (1981). Systemudvikling og Systemudviklingsmetode [English: System development and system development method]. Aarhus: Computer Science Department DAIMI PB-136 .

Robinson, M. (1989). Double Level Languages and Co-operative Working, Conference on Support, Society and Culture. Mutual uses of Cybernetics and Science - Proceedings. Amsterdam 1989. pp. 79-114.

Raeithel, A. (1996) From coordinatedness to Coordination via Cooperation and Co-construction. Paper presented ad Workshop on Work and Learning in Transition, San Diego, January 1996. 
Schmidt (1997) Of maps and scripts: The status of formal constructs in cooperative work. In S. C. Hayne and W. Prinz (eds.): GROUP'97, Proceedings of the ACM SIGGROUP Conference on Supporting Group Work, Phoenix, Arizona, 16-19 November 1997. ACM Press, New York, N.Y., 1997, pp. 138-147.

Star, S. L. (1989). The Structure of Ill-Structured Solutions: Boundary Objects and Heterogeneous Distributed Problem Solving. In L. Gasser and M. N. Huhns Distributed Artificial intelligence, volume II. London: Pitman Publishers, pp. 37-54.

Suchman, L. and E. Wynn (1984) Procedures and Problems in the Office. In Office: Technology and People, vol. 2, 1984, pp. 133-154.

Suchman, L. (1986). Plans and Situated Actions. Cambridge MA: Cambridge University Press. 


\title{
Augmented reality as a design tool for mobile interfaces
}

\author{
Olav W. Bertelsen \& Christina Nielsen \\ University of Aarhus \\ Department of Computer Science \\ Aabogade 34, DK-8200 Ảrhus N. Denmark \\ $+4589423188$ \\ \{olavb | sorsha\}@daimi.au.dk
}

\begin{abstract}
This paper challenges user interface paradigms for mobile devices, by using the technical classification of augmented reality interfaces as a 'thinking tool' to develop ideas for interaction with mobile devices. The paper presents future work scenarios from a wastewater treatment plant embodying PDA applications derived from the classification of augmented reality interfaces. The focus on physical interaction with objects of work and with the mobile device provides us with a range of interaction styles, based on e.g. gestures and manipulation of objects. Furthermore, issues of transparency and directness are addressed. The future scenarios indicate that the concepts of augmented reality support solving context problems in mobile design.
\end{abstract}

\section{Keywords}

Thinking tools, augmented reality, mobile computing, process control.

\section{INTRODUCTION}

It is widely acknowledged in the field of mobile computing that there is a need for new interaction paradigms $[5,7,12$, 9]. Solving this problem requires insights from a broad range of disciplines, including distributed systems, HCI, CSCW and participatory design [5]. Established concepts in desktop computing are not scaleable. E.g., the concept of direct manipulation that historically has served as the main vehicle for understanding the graphical workstation is not applicable in the design of small mobile devices [9]. This difficulty is due to the tunnel vision imposed by, otherwise valuable, established cultural norms like the desktop metaphor, the workstation concept, and the general thinking in terms of database access.

Augmented reality is an approach to information systems design augmenting physical objects instead of replacing or representing them by purely computer based systems. The argument is that non-computer based artefacts in the workplace often mediate work in subtle ways that are impossible to transfer to new computer based artefacts [10].

Published in: Proceedings of the Third Conference on Designing Interactive Systems (DIS 2000), D. Boyarski \& W.A. Kellogg (Eds.), ACM ISBN: 1-58113-219-0, 2000, pp. $185-192$.
In a work-oriented terminology $[4,14]$, augmentation can be understood as a basic feature of human action in the sense that human action always is mediated by historically developed artefacts which are invisible during use. Augmentation and augmented reality can be seen as a general attitude to design, realised through refinement of mediating artefacts, acknowledging the historical crystallisation of work into successive generations of artefacts $[1,2]$.

Mackay [10] introduces augmented reality as a classification of three technical approaches to design of interactive devices, spanning a continuum of technical substrates for mixed environments: augmenting the user, the physical object and the environment (see Table 1 below). These strategies describe the technical locus of the interface assuming the analytical separation of function and interaction in the computer artefact. From the work-oriented point of view, introducing a new artefact is always a matter of augmenting the acting subject.

In this paper, we explore new interface principles for small mobile devices derived from the concept of augmented reality interfaces. We use the concept as a tool for divergent thinking, in line with the use of metaphors in participatory design [11], and springboards in developmental work research [6]. By definition, the concept of augmented reality cannot be applied to small mobile devices; thus we abstract defining features from the three directions in augmented reality interfaces and apply them in the different technical setting. Subsequently, the principles are further investigated through future scenarios of PDA support for wastewater treatment work built on the augmented reality classification transformed to small mobile interfaces.

\section{AUGMENTED REALITY IN A PDA}

In applying the concept of augmented reality as a thinking tool for the design of mobile artefacts, the specific technical substrates in which augmented reality interfaces are implemented are bracketed out. What we hold on to is the principle of interaction with or through physical objects (already existing) in the work setting. Below, we explore the three directions in augmented reality interfaces described by Mackay [10]. We use this classification to develop metaphors for mobile applications not based on the idea that the PDA is miniature workstation. 


\begin{tabular}{|l|l|l|l|}
\hline Augment & Approach & Technology & Application \\
\hline User & Wear devices on the body & $\begin{array}{l}\text { VR helmets Goggles Data } \\
\text { gloves }\end{array}$ & $\begin{array}{l}\text { Medicine, } \\
\text { Field service, Presentations }\end{array}$ \\
\hline Physical Object & Embed devices in objects & $\begin{array}{l}\text { Intelligent bricks, Sensors, } \\
\text { receptors, GPS, electronic } \\
\text { paper }\end{array}$ & $\begin{array}{l}\text { Education, } \\
\text { office facilities, Positioning }\end{array}$ \\
\hline $\begin{array}{l}\text { Environment surrounding } \\
\text { objects and users }\end{array}$ & $\begin{array}{l}\text { Project images and record } \\
\text { remotely }\end{array}$ & $\begin{array}{l}\text { Video cameras, Scanners, } \\
\text { Graphics tablets, Bar code } \\
\text { readers, Video projectors. }\end{array}$ & $\begin{array}{l}\text { Office work, Film-making, } \\
\text { Construction, Architecture }\end{array}$ \\
\hline
\end{tabular}

Table 1. Examples of augmented reality interfaces, with relevant technologies and applications (adopted from Mackay 1998).

\section{Augmenting the user}

The strategy of augmenting the user means that the interface to the computer system is attached to the user as e.g. VR helmets, goggles or data gloves. When implemented in a PDA, this strategy is transformed to applications where the PDA is physically attached to the user (possibly hand held). The PDA functions as "glasses" extending the users perceptual capabilities in (into) the domain (work object), and as "gloves" extending the users capabilities in acting onto the domain. Interaction may be carried out through gestures performed holding the PDA.

Because the PDA acts as an extension to the user, the connection between PDA and object is hidden and indirect. Within this strategy, we may include context specific access to a more general information system.

The augmenting the user approach to PDA design could lead to applications resembling a well-designed remote control for a TV set. The remote control is in the TV viewing situation a transparent, almost invisible, extension of the viewer. The viewer manipulates the TV-set directly through gestures with the remote control. This sense of direct manipulation is obtained through the layout and shapes of the buttons.

Another existing example is the way wireless controls of lifts are attached to the worker operating the machine from a distance.

\section{Augmenting the object}

The strategy of augmenting the object means that the interface to the computer system is attached to, or embedded in the object. When implemented in a PDA, this strategy is transformed to applications where the PDA is provisionally attached to the object. Interaction with the PDA (or the wider information system) is carried out through manipulation of the physical object to which the PDA is attached, and through showing information on the object by way of the PDA display. Thus, the PDA augmenting the object, turns the physical object into an interaction device and at the same time makes the object more accessible for the user.
Because the PDA becomes embedded in, or rather attached to, the object, the connection between the PDA and the object is visible and direct.

The augmenting the object approach to PDA design could lead to applications resembling the help and guidance system in many modern photocopiers. When a compartment is open, the display on the copier indicates which one and points to its physical location. In case of a paper jam, the computer system guides the user through a sequence of physical actions triggered by the user manipulating e.g. hatches in different areas of the machine.

Another approach based on augmenting the object could be to take the idea of augmented paper [10] to the extreme by simply substituting existing notepads with a PDA based application. Obviously, this is not augmented reality in any strict sense of the concept.

\section{Augmenting the environment}

The strategy of augmenting the environment means that the interface to the computer system is embedded in the environment surrounding users and objects, projecting images and recording remotely. When implemented in a PDA, this strategy is transformed to applications where the PDA is provisionally placed in the environment of the work situation. Interaction with the PDA (or the wider information system) is carried out through manipulation of the physical objects that are tracked, by means of technologies in a continuum from bar code readers to cameras with image recognition build into the PDA, and through projecting information onto the object. For the latter, a lot of development of basic technology is required - although more realistic, low cost solutions are being developed, e.g. the Gesture Laser [15].

Because both user action and objects have to be tracked, and images ideally should be projected onto objects, this strategy is the most demanding to implement.

The augmenting the environment approach to PDA design could lead to applications resembling the set-up at a workstation at an assembly line, where mechanical/electronic devices are assembled. Such devices 
typically consist of a number of printed circuits, connectors and shielding. The assembly is done by hand and requires different electronic circuits depending on the type of device. At a specific workstation for assembling flow meters we have seen that, to aid the assembly procedure, each primary component (not including screws, bolts and nuts) is equipped with a bar code, which must be entered into the computer responsible for testing the assembled product. The assembly procedure cannot be completed until all primary components have been entered into the system, and the computer clearly indicates if wrong components have been scanned. In a sense, the computer is tracking the physical objects required for a specific flow meter and even though, it has no direct, online connection to the components, e.g. through sensors.

\section{EXPLORING THE THREE STRATEGIES}

During the past year, we have been engaged in a study of wastewater treatment plants. Wastewater treatment is a low risk process running continuously day and night. Work in the plant is distributed to a degree where it seems to go on elsewhere, no matter where you look. People working on the plant have two general modes of relating to the plant and the process. Totally mediated, i.e. through the process control system or totally unmediated, by looking at and smelling the water. The workers do not seem to have one favourite tool; e.g. illustrated by one of the workers making a sludge sample in a used plastic glove and stirring the sample with a pen. For a more detailed description of the project and the study, see (Bertelsen \& Nielsen 1999).

In order to develop further the interface principles derived from the concepts and classification of augmented reality, we develop scenarios for support of situations in the wastewater treatment plant. The scenarios are based on applications for a standard PDA, in this case a 3Com Palm Pilot ${ }^{\mathrm{TM}}$ IIIx.

Additional features to be built into the PDA are held to a minimum and are as far as possible taken to be the same across the future scenarios. That is to emphasise our focus, namely the new interaction principles for the PDA rather than futuristic gadgetry. Thus the way the PDA is interfacing with the environment is limited to the standard infra red port, a bar code reader, a standard cell phone and a modem.

\section{Augmenting the user}

In implementing the principle of augmenting the user in a PDA supporting work in a wastewater treatment plant, we take the simple approach of the remote control. We use one of the more peculiar situations we observed in our field study, a repair situation, as our example/template to illustrate and develop the approach.

The situation was a case of simple repair work. A wire operating the scrapers in one of the clarifier tanks was broken, causing the tank to shut down automatically. A team of blacksmiths' was called in to fix the problem. As part of the repair, it was necessary to operate the winch. The winch motor was, however, only controllable from a terminal in the central control room. Thus, the smith had to make a telephone call to the central control room which, incidentally, was occupied by a worker, and ask him to start the motor. Unfortunately, this had no effect on the motor. The worker in the control room suspected a failure in the process control system and called the foreman, who was working outside the plant that day, to let him know about the problem with the system. The foreman explained that the winch usually gets stuck if it gets into one of the extreme positions. He asked the worker to tell the smith to call him on the telephone so that he could guide him through releasing the wire. The worker in the control room was now waiting for the smith to call and tell him to start the motor again, but nothing happened until the smith called to inform him that he was done with the repair. In addition to the information on how to unblock the wire, the foreman had explained to the smith how to short circuit a few cables in the motor to bypass the central control of the motor locally.

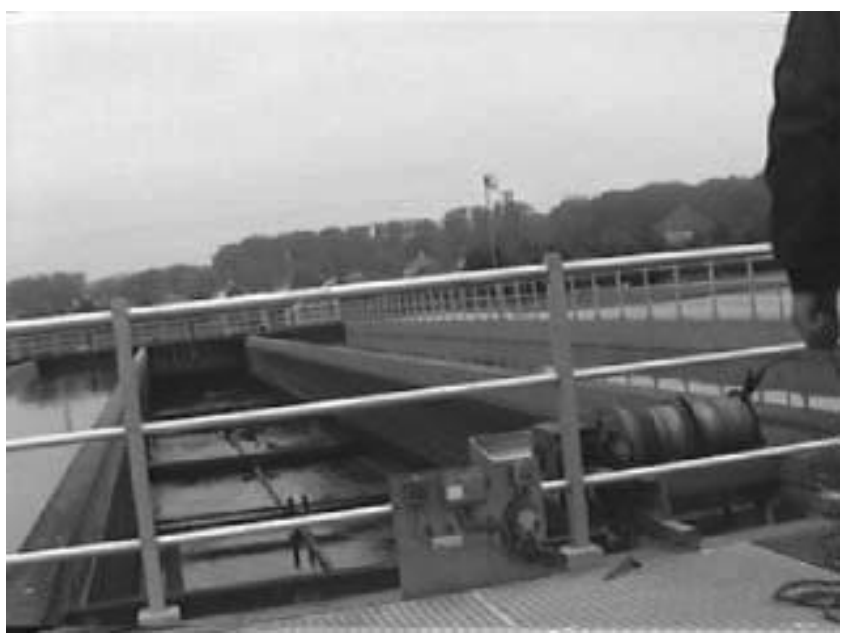

Figure 1: Blacksmith fixing a broken wire in a clarifier tank

By centralising and co-ordinating control of individual component, the process control system ensures that interdependencies are not violated. Mobile control is a highly problematic possibility to integrate into a process control system in that it may violate the purpose of having a process control. However, the situation with the broken wire illustrates the dilemma inherent with centralised control. Either the smith would be on the telephone with somebody in the control room (which is what happens over and over again in all the wastewater treatment plants our collages and we have studied), or he would "hack" the control system, which would be a potential security problem. The challenge is to find a solution that maintain the consistency and security of local control, without 
imposing cumbersome procedures that invites the operators to bypass parts of the system.

This challenge is addressed by the following future scenario with a PDA-application based on the augmenting the user strategy. The "standard PDA" is extended with a bar code reader and a modem for the cellular telephone the smith is carrying anyway. During repair of the wire, when the smith needs to operate the winch he reads the bar code on the winch and calls up the process control system through the telephone. Together with the identification of the particular component, the smith is working with the PDA sends identification of the smith. Thus, the process control system has information enough to determine which kind of access the smith needs to the component. The process control system returns a list of the parameters the smith can access, in the case of the winch, start, stop, reverse and frequency of the motor, and it suggest a binding of the parameters to standard PDA key. Now, the smith can start, stop and reverse the motor through the up/down scroll button on his own PDA. The overall system consistency is maintained by only letting the smith control locally task and location specific parameters.

This application augments the smith in interacting directly with the motor in a gesturelike fashion. In the workoriented terminology introduced above, this means that the PDA is handled through unconscious, automated operations (scrolling up and down).

It transcends the local control versus system consistency problem by letting the user interact directly on the relevant component through his own interaction device, but still letting the process control system inhibit dangerous violations of interdependencies in the system.

The PDA screen shown in figure 2 is designed for a Palm Pilot. However, an implementation with WAP technology, would probably prove even more suitable.

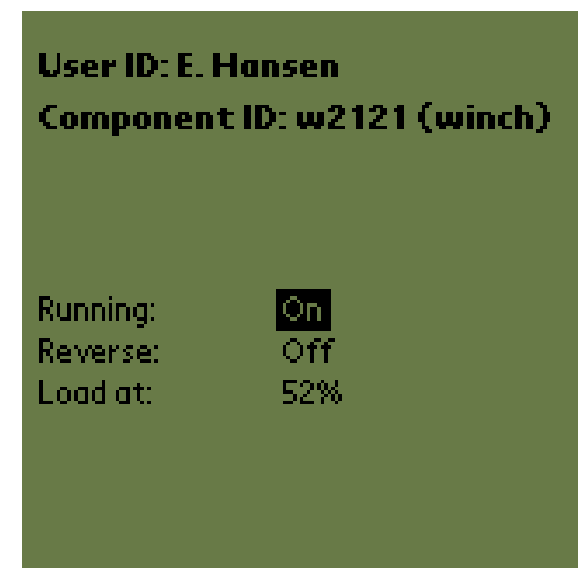

Figure 2: Display from a PDA application based on the augmenting the user strategy

\section{Augmenting the object}

In implementing the principle of augmenting the object in a PDA application supporting work in a wastewater treatment plant we develop two future scenarios. The first scenario is based on the photocopier example above in the sense that it supplies local display and control, the second is based on the concept of augmented paper.

\section{Local display and control}

The first future scenario build on the augmenting the object strategy is derived from the photocopier control display example above. It addresses the lack of local display and control in newer generations of frequency converters

A wastewater treatment plant is equipped with a large number of electrical motors most of which are driven by alternating current. To regulate the speed of such a motor the frequency of the power supply must be regulated by means of a frequency converter.

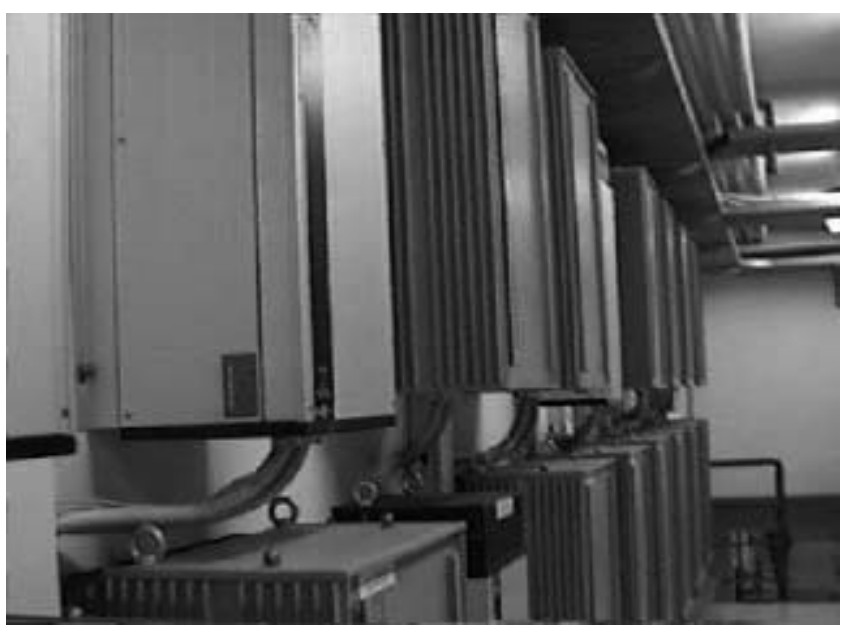

Figure 3: An array of frequency converters

Contrary to the newer models, older frequency converters are often equipped with a small display and controls for operating it directly. The lack of local control and display in the newer models is not a problem; in most situations, it is controlled from a process control system. However, in the occasional situations of breakdown, calibration, maintenance, etc., local control of the unit is needed.

This occasional access to direct operation of the frequency converter can be obtained with a PDA based application augmenting the object, in this case the frequency converter (see figure 4).

The wastewater worker or the external specialist who needs local control of the frequency converter reads the bar code on the unit and attach the PDA and cell phone to the housing. Now, the PDA calls up the process control system through the cell telephone modem, and "negotiates" the amount of control of the frequency converter that can be given locally. Upon initialisation, the controls on the new PDA-based 
local interface consist of the subset of control over the frequency converter it makes sense to have locally, depending on who the person is, which dependencies there are in the actual state of the plant, and the purpose of working on the PDA. Some of these aspects may have been decided beforehand and entered into the process control system centrally.

The frequency converter is augmented with the interface of the PDA that during the situation becomes a part of the component rather than a personal digital assistant. The advantage of this scenario over the direct local control is that dependencies in the plant are not violated by the users' local control. In general, mobile control of process control systems is considered problematic. In this scenario, the dangers are avoided through strong context specificity of control. The cost of the scenario is low because the wastewater treatment plant is extensively wired to the process control system.

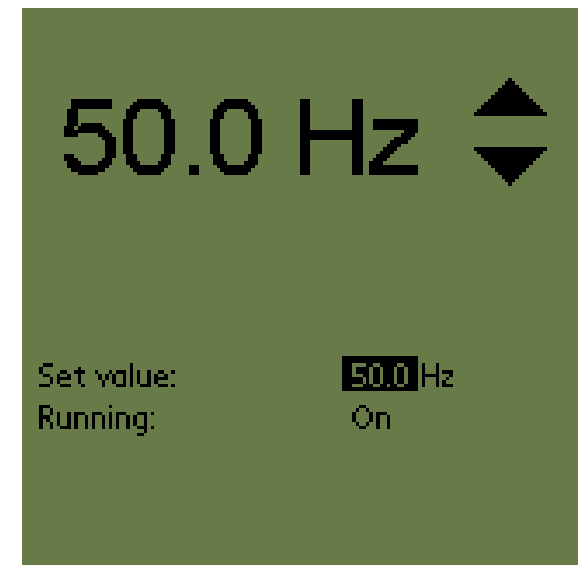

Figure 4: Display from a PDA application based on the local display and control version of the augmenting the object strategy

\section{Augmented paper}

The second future scenario exploring the principle of augmenting the object as a principle in PDA support for wastewater treatment work is based on the concept of augmented paper.

Each day, one of the workers reads the meters related to the production of electricity at the plant. The worker notes the numbers on a protocol sheet, take all the numbers to a note pad on a table performs some calculations, and writes the numbers in a paper record. Finally, he carries some of the numbers on a scrap of paper to the house where the computer is located; there he inputs data to the process control system.

Our study of wastewater treatment work indicated the importance of several hand-written paper records for test results as well as for the gas and electricity production.
These records, however, were also input to the Process control system and therefore the object of rewriting two or three times. This led to discussions of whether the rewriting was a necessary evil caused by the lack of technological support or whether it in fact served other purposes than simply transferring the numbers from one medium to another. To test this hypothesis, we implemented a prototype for an augmented paper record based on the CrossPad technology. The CrossPad was trained to read and recognise the hand-written record and propagate/transfer it the computer system. We set up a scenario where the CrossPad served as a mobile link between the meters and the Process control system, rendering the rewriting obsolete but retaining the paper record. When we presented this solution to workers and managers at the wastewater treatment plant, it was refused. To them, there was no point in hanging on to the paper records if it was possible to solve the authentication issue in another way. Furthermore, they did not believe that rewriting numbers guaranteed that workers actually think about the numbers.

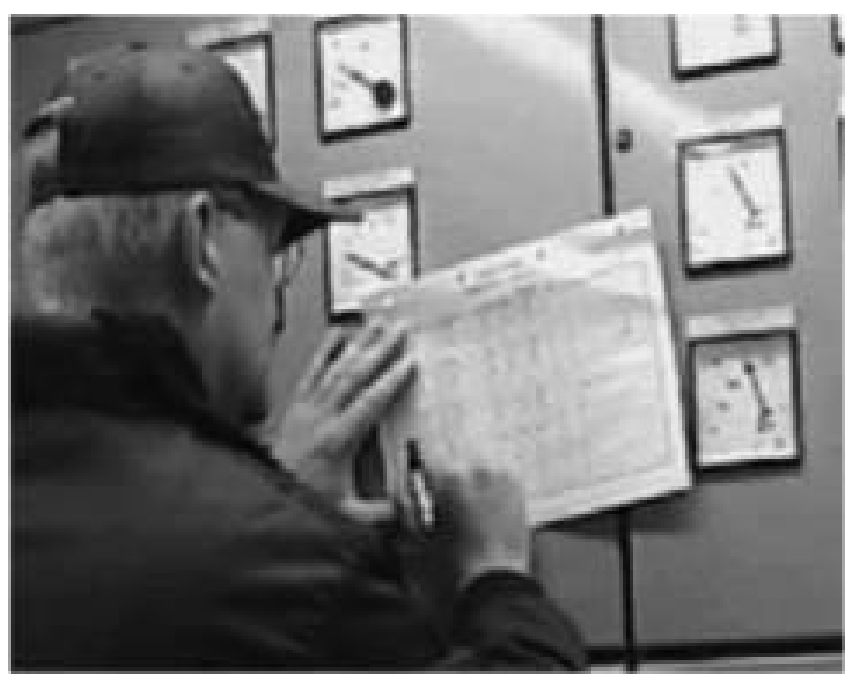

Figure 5: Wastewater operator reading the gas meters

The radical application, based on the augmenting the object strategy, of support for reading the electricity production related meters eliminates the former object and replaces it with the PDA. In the meter-room, the worker reads the bar code on the desk for the PDA to invoke the electricity and gas production record. As he reads the meters, he writes the reading on the number-pad on the PDA screen. Upon reading the meters, the PDA calculate the results and present the worker with the results together with the results from the previous day. The worker leaves the meter-room and goes to the central control room where he "beams" the results into the process control system by way of the infra red port build into the PDA. This application could as well be classified as augmenting the user. 
The PDA would ideally have a number keypad, but for the sake of consistency across examples, we keep with the standard PDA (see figure 6). Again, a WAP based approach is an elegant alternative.

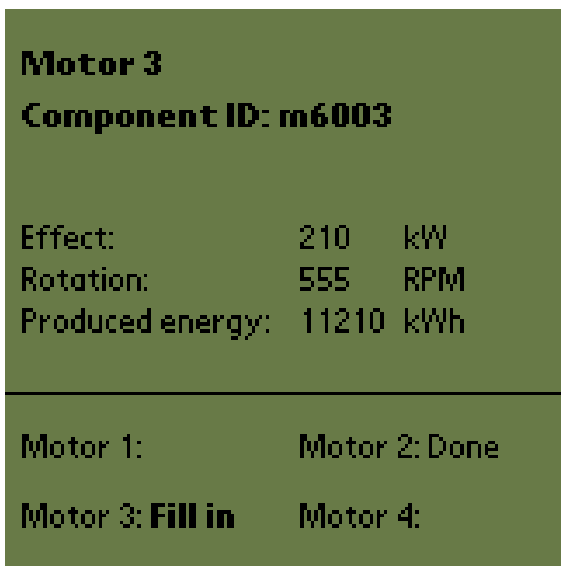

Figure 6: Display from a PDA application based on the local augmented paper version of the augmenting the object strategy

\section{Augmenting the environment}

In implementing the principle of augmenting the environment in a PDA supporting work in a wastewater treatment plant, we take the simple approach of the assembly station, and use it as the basis for the design of an automatic, context sensitive on-line manual.

A wastewater treatment plant is a complex technical system. Becoming familiar with the technical system is not done overnight but is a yearlong learning process. The scope of the task has been very aptly put by one of the unskilled workers at the studied wastewater treatment plant:

"I have been working on this plant for four years and am starting to 'know' the plant, but I think it will take another two years before I know it well enough - where all the machines are, etc. For example, we have pipes running through this building and they are normally working fine so you can basically work here for years without knowing there's a (throttle) valve up there [pointing]" (..) You never find out before something happens (..) We work with 50.000 components - you don't learn about them on your first day".

One of the responsibilities of this specific worker is to mind an array of motors producing electricity from gas produced from sludge in the plant. Maintenance of the gas motors is divided between workers at the plant, the municipal blacksmith department, and technicians from the manufacturer. Minor repair and maintenance tasks performed by one of the unskilled workers are coordinated with major repair, inspection and maintenance, in order to reduce down time. One of the frequent tasks is the cleaning and adjustment of spark plugs in the motor.

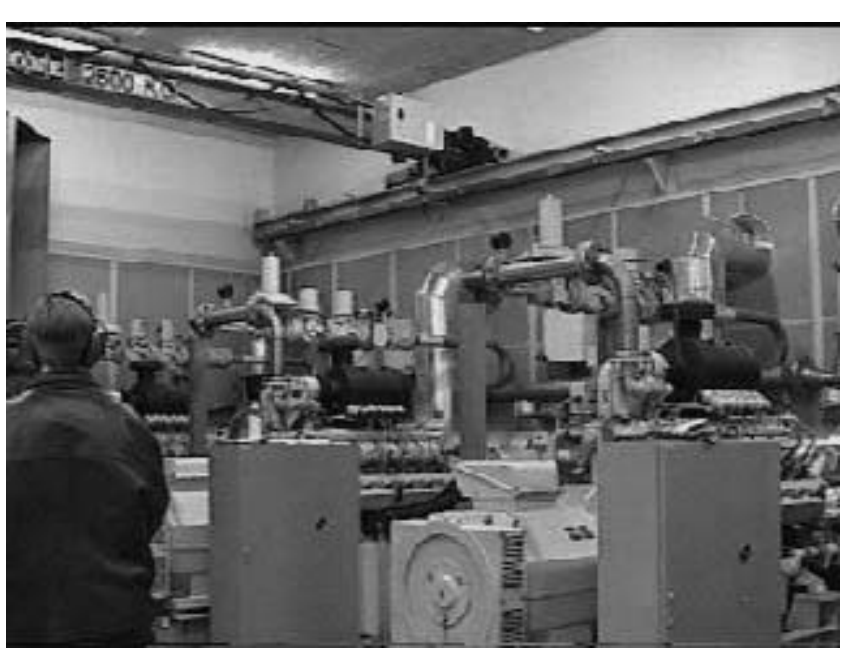

Figure 7: The gas motors

The principle of augmenting the environment through the PDA may be implemented to aid this assignment in the following manner. The wastewater treatment worker enters the area with the gas motors and starts the procedure by turning off the relevant motor manually. He then scans the bar code on the motor with his PDA, connects to the process control system through the mobile phone attached to it and checks on it that the shut down has been acknowledged there. He places the PDA on a shelf next to the motor so the display is visible from his current position. The PDA displays a simple blueprint-type drawing of the motor, highlighting the front panel, and a short textual description of how to remove it (see figure 8). After having removed the front panel he runs its bar code past the scanner on the PDA; the display changes to show the next step of the disassembly procedure. In this manner, he works his way into the motor to the spark plugs. The PDA presents instructions in which order to remove and replace the spark plugs, triggered by scanning the individual units. He then acknowledges on the PDA that no more motor components will need replacement, and is now guided through the procedure of reassembling it, scanning the components in reverse order. For users experienced with a specific type of motor and task, the online manual serves only as a peripheral guide with the purpose of making sure the relevant motor components are removed and (in particular) re-inserted. For novice users, the online manual may serve as a component specific, context dependent learning guide.

This future scenario illustrates how we may support the vast learning task involved in maintaining the multitude of components in this wired wilderness through externalising the relevant information through the PDA. 
A far more elegant solution, but far from realistic today, for this application would be to embed a camera with effective pattern recognition features to seamlessly do what the worker in the example has to do by hand and bar code reader.

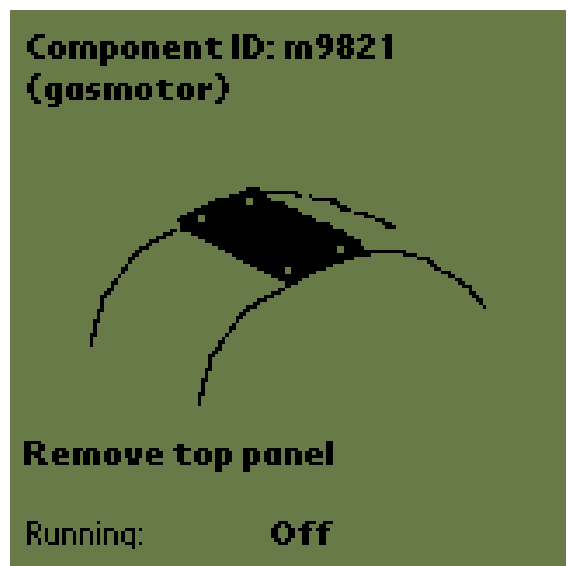

Figure 8: Display from a PDA application based on the augmenting the environment strategy

\section{DISCUSSION}

We have presented future scenarios for wastewater treatment work with PDA applications developed by using the technical classification of augmented reality interfaces as a thinking tool. The applications in these scenarios are designed for a standard PDA extended with a bar code reader and a modem for a cellular telephone. Thus, we have been emphasising solutions that can be implemented with limited resources today. The use of bar codes is clumsy, but has the advantage of being cheap, and making the choice of context totally explicit. In this respect, our contribution is in radical contrast to achievements like the Cy-Phone, which is an all-purpose personal tool based on Pico Cells [13]. Our future scenarios address some of the specifics of wastewater treatment work: the distributedness, the number of different component the workers have to deal with, the wired wilderness enabling most of the designs. In a setting with a lower degree of interdependency and "wiredness", PDA support might be different. However, the principle of designing PDA applications as augmentation of the user, physical objects or the environment is likely to be applicable in a broader context.

The applications in the four future scenarios have been developed into horizontal prototypes, i.e. screen layouts with no underlying functionality. In general horizontal prototypes and mock-ups are suitable means of testing design ideas with users. However, in this particular case, we believe that some amount of functionality and integration with the process control system is needed investigate into the ideas beyond the level waving our arms. This is an obvious problem because outside interaction with a control system can have dangerous effects, and because it requires access to the control system software.

Using the concept of augmentation and the classification of augmented reality interfaces as a thinking tool gave us several advantages. Using the augmented reality principles as thinking tools sparked our imagination and at the some time steered us clear of pure science fiction.

Initially, the concept "augmented reality" seemed to be impossible to apply in PDA design; it seemed that a PDA application would always end up being based on the "augmenting the user" class of interfaces. This apparent impossibility turned out to be an important source of creativity. This technique is generally applicable. That is, when established design principles impose tunnel vision on designers, proceed by selecting technical concepts that obviously not fit the design problem, and then structuring the new solutions according to the misfit concepts.

We saw that the classification of augmented reality interfaces seemed to blur when applied to PDA design. However, taking the second scenario as an example, even if the PDA based record looks like an augmentation of the user the design is still based on automating and augmenting the paper based record. This seeming confusion is due to augmented reality being a pragmatic technical classification of a class of interfaces technologies.

Focussing on interaction with physical objects in the work setting provided us with specific boundaries to work within and thus became an effective guide in deciding what to include in each of the PDA applications. Thus, the concepts of augmented reality worked as a tool for handling the context problem. Most of the information and control made accessible with the suggested PDA applications is present in the existing process control system. The strong focus on interaction with physical objects around the plant, however, helped in specifying actual physical and situational context for the applications in the future scenarios.

The three different strategies of augmenting the user the object and the environment enabled us to transcend the image of interaction with a PDA as the users introvert fiddling with his little pen on his personal four square inch pad. Through our future scenarios, a broader range of physical postures in interaction with a PDA emerged: hand waving, writing, walking around, etc. The original formulation of augmented reality was primarily a concept of interface technology, the way we have used it in this paper turns it into an interaction style concept. Thus, augmented reality may be abstracted into interaction concept independent of the concrete technical substrate of implementation.

As stated in the introduction, direct manipulation as a general user interface principle falls short in relation to mobile devices. In particular the lack of screen space 
inhibits detailed representation of the object of work at the screen. Basing PDA design on concepts of augmented reality interfaces, forced us to think beyond direct manipulation; it simply does not make sense to represent the object of work naturalistically on the screen if it is physically present in the situation of work. However, as illustrated in our future scenarios, principles of direct manipulation interfaces, e.g. directness and transparency, apply nicely for mobile devices just as well as for fullfledged augmented reality systems.

\section{ACKNOWLEDGMENTS}

We thank the people at the wastewater treatment plant for their time and effort. Susanne Bødker, Wendy Mackay, Astrid Søndergaard and Christian Yndigegn have all been a great inspiration in the wastewater project. Christian Yndigegn programmed the augmented paper prototype for the CrossPad. We acknowledge the effort of the people at Danfoss and at Malmö University College. The Danish Basic Research Foundation, Centre for Human-Machine Interaction and The Danish National Centre for IT-Research, project no. 23 (Usability Work in the Danish Industry) have supported our work on the wastewater project.

\section{REFERENCES}

1. Bærentsen, K. (1989). Menneske og maskine [Man and Machine]. In Hedegaard, Hansen \& Thyssen (eds.). Et virksomt liv [An active life]. Aarhus: Aarhus University Press, pp. 142-187.

2. Bertelsen, O. W. (1996). The Festival Checklist: design as the transformation of artefacts. In Blomberg, J., Kensing, F. \& Dykstra-Erickson (eds.). PDC '96, Proceedings of the Participatory Design Conference, Palo Alto: Computer Professionals for Social Responsibility, pp. 93-101.

3. Bertelsen, O.W. \& C. Nielsen (1999). Dynamics in Wastewater Treatment: A Framework for Understanding Formal Constructs in Complex Technical Settings. In Bødker, S., M. Kyng \& Kjeld Schmidt (eds.). ECSCW '99, Proceedings of the Sixth European Conference on Computer Supported Cooperative Work, 12-16 September 1999, Copenhagen, Denmark. Dordrecht: Kluwer. pp. 277-290.

4. Bødker, S. (1991). Through the Interface: a human activity approach to user interface design. Hillsdale: Lawrence Erlbaum Associates.

5. Dix, A., K. Chervest, N. Davies and T. Rodden (1998). Exploiting context in HCI design for mobile systems. In Johnson, C. (ed.) Proceedings of First Workshop on
Human Computer Interaction for Mobile Devices. Department of Computing Science, University of Glasgow.

6. Engeström, Y. (1987). Learning by expanding: an activity-theoretical approach to developmental research. Helsinki: Orienta-Konsultit Oy.

7. Johnson, P (1999). Usability and Mobility; Interactions on the move. In Proceedings of the Second Workshop on Human Computer Interaction with Mobile Devices, 31 August 1999, Edinburgh, Scotland.

8. Kristoffersen, S. and F. Ljungberg (1998). "Representing modalities in mobile computing," In B. Urban, T. Kirste and R. Ide (eds.) Proceedings of Interactive applications of mobile computing. Fraunhofer: Institute for Computer Graphics.

9. Kristoffersen, S. \& Ljungberg F. (1999). "Making Place" to Make IT Work: Empirical Explorations of HCI for Mobile CSCW. In Proceedings of International Conference on Supporting Group Work (GROUP'99), ACM Press.

10. Mackay, W. (1998). Augmenting Reality: Linking real and virtual worlds A new paradigm for interacting with computers. In Proceedings of AVI'98, ACM Conference on Advanced Visual Interfaces, New York: ACM Press.

11. Madsen, K.H. (1994). A guide to Metaphorical Design. The Communications of the ACM, pp. 57-62.

12. Olsen, D. Interacting in chaos (1999). In Interactions Vol. 6, No. 6 (Nov. 1999), pp. 42-54.

13. Pulli, P., T. Pyssysalo, K. Kuutti, J. Similä, J-P Metsävainio and O. Komulainen (1998) CyPhoneFuture Personal Telecooperation Device. In Proceedings of the XV IFIP World Computer Congress, Vienna, Austria and Budapest, Hungary, August 31 - September 4, 1998, pp. 529-540.

14. Winograd, T. \& Flores, F. (1986). Understanding Computers and Cognition -- a new foundation for design. Norwood, N.J: Ablex.

15. Yamazaki, K., A. Yamazaki, h. Kuzuoka, S. Oyama, h. Kato, H. Suzuki, H. Miki (1999). GestureLaser and GestureLaser Car: Development of an embodied space to support remote instruction. In Bødker, S., M. Kyng \& Kjeld Schmidt (eds.). ECSCW'99, Proceedings of the Sixth European Conference on Computer Supported Cooperative Work, 12-16 September 1999, Copenhagen, Denmark. Dordrecht: Kluwer, pp 239-258. 


\title{
Designing for mobility \\ - an integration approach supporting multiple technologies
}

\author{
Christina Nielsen \& Astrid Søndergaard \\ Department of Computer Science, \\ Aarhus University, \\ Åbogade 34A \\ 8200 Århus N \\ Denmark \\ phone: +45 89425632 \\ sorsha@daimi.au.dk and astrid@daimi.au.dk
}

\begin{abstract}
Based on an empirical study of a wastewater treatment plant we present an integrated prototype for PCs and PDAs. It supports getting an overview of the wastewater treatment process and making system information available in the environment outside the control room. The prototype is build on the understanding that support for mobile work must be realised through a combination of different technologies enabling users to meet the changing demands in a work situation. With the design we seek to reflect the position of the mobile device in the existing 'web of technology' and show how the concept of integration can be a driving force in design, allowing us to see heterogeneous devices as parts of a whole rather than independent entities. Furthermore, the prototype challenges the notion of working 'anytime, anywhere', which is presented as an ideal by many (communication)-technology companies today.
\end{abstract}

\section{Keywords}

Mobile computing, mobility, distributed work, integration, user interface design, "web of technology"

\section{INTRODUCTION}

The CSCW community has in recent years been criticised for neglecting to support mobility as a vital and integral part of collaboration in a distributed setting. Most systems designed to support cooperative, distributed work are 'workstation-centric' i.e. largely concerned with providing still more complex support tied to a personal computer, which makes them ill suited for supporting the mobile aspects of work (Bellotti \& Bly 1996, Fagrell et. al. 1999, Heath \& Luff 1998). These critical voices are meeting the challenge and, through excellent empirical studies, have pointed out important implications for design when supporting mobility in $\mathrm{CSCW}$ applications. However, what we find is missing from this discussion is the relation between the existing technology and the technology being introduced in the work setting. When looking to support mobile work by means of introducing new technology, e.g. a mobile device, we need to consider how this new technological artefact should relate to the existing technology as well as how it will affect the work practice. We refer to this relationship as 'the web of technology' and argue that if we neglect to take this into consideration in the design process, it poses a serious threat to the understanding that support for mobile work must be realised through a combination of different technologies, supporting:

"... an individual's ability to reconfigure him or herself with regard to ongoing demands of the activity in which he or she is engaged." (Heath \& Luff 1998)

We report from an empirical study of a wastewater treatment plant where work is highly dependent on being able to move around on the plant area to get site-specific information in combination with using system informa- 
tion available only through a central PC. This type of mobility corresponds to what Bellotti \& Bly (1996) identified as 'local mobility', where people move between buildings or rooms in a local environment. Furthermore, it carries aspects of both local and remote mobility (Heath \& Luff 1998), in that the work require them to move around locations outside of the plant and still having contact to colleagues and being able to access information in addition to moving around on the plant itself. In this context, we have found the term 'integration' very useful. We use 'integration' to denote things being part of a whole without losing their individual identities, both on the technical level and more importantly in relation to the interface design.

Roman et al (1999) explores the challenges of integrating a PDA in a distributed environment. They argue the importance of using PDAs as 'enabling bridges' to services rather than treating the PDAs as isolated entities which seems quite similar to our view of integration. However, consistency in their system is supported by contents alone. We find that visual representation is an important element in maintaining a sense of integration across different devices.

We introduce a mobile device to support two vital aspects of the work, namely making system information available locally and providing the workers with an overview of the status of the process. Getting information when and where you need it has also been the focus of a number of research papers dealing with knowledge management in a mobile environment, e.g. (Fagrell \& Johanneson 2000, Fagrell et al 1999). We see a number of similarities between these studies and our work, especially with regards to the problems of decontextualising information, and look towards it for inspiration.

We argue that when introducing a mobile device it is not necessarily the case that it should be possible to access or control all information available through the central system. On the contrary, our study shows that sitespecific tasks require site-specific information and thus workers need locally relevant information to get their work done. Placing the mobile device in the web of technology led us to introduce it as an extension of the existing control and regulation system. It is necessary to emphasise that the information you get access to via the mobile device is in fact the information from the control system for the workers to trust it. Therefore the design reflects it being an integrated part of the control system rather than an independent device with the ability to access system information. Furthermore, we wish to emphasise that interface design on a mobile device can- not be reduced to down-scaling the interface design from the PC system, nor is it the reverse. The interface design must take advantage of the specific technologies. With our prototype, we debate how to present the information on both the mobile device and the desktop computer system without losing the sense of integration and overview. Björk et al (1999) also deals with presentation of information of heterogeneous devices or more precisely the need for "automatic on-the-fly transformations of existing web content to mobile formats". Based on focus-context techniques developed for traditionally sized screens, it is a fine example of the type of design we are arguing against.

In the following section we outline the case study and empirical findings and relate these to access to information spaces as they exist on the wastewater treatment plant. Based on a future scenario, we discuss the role of the mobile device in the work context and how this affects the user interface design for the new, integrated system. Then we present the prototype and discuss how insights from the empirical work and design considerations have been incorporated into the interface design. We report on the users' response to the prototype and conclude the paper with a general discussion of mobility in distributed cooperative settings and the notion of integration in supporting it.

\section{CASE STUDY}

The studied wastewater treatment plant (MR) is one of the largest and, technically, most modern wastewater treatment plants in Denmark. The purification process at the plant includes mechanical, chemical and biological phases. The resulting segmented sludge is put in fermentation tanks to generate gas, which produces enough electricity to run the plant. The digested sludge is pressed and taken away to an incinerator plant. MR was one of the first wastewater treatment plants in Denmark to implement automatic process optimisation for the removal of nitrogen. The automation has been possible due to the development of new sensor technology, which allows for on-line measuring and control of the primary parameters of operation. Not surprisingly, the process optimisation has radically decreased the use of chemicals. The plant has an estimated capacity of 220.000 person equivalents. However, it is constantly running at 110 - $150 \%$ over capacity because the plant has not been able to expand to match the increase in the city's production of wastewater.

The case study is part of a long-term research cooperation in the areas of HCI and CSCW involving research- 
ers from Danfoss, the Computer Science Department at Aarhus University and the Art, Culture and Communication department at Malmö University College, and four wastewater treatment plants in Denmark and Sweden. We spent 40-50 hours within a 5-month period doing participant observation at the site, following workers through their entire daily routine. Different researchers followed different workers, using hand-held video cameras or a digital camera to capture the events. We analysed the video, using the techniques described in Bødker (1996) and Buur \& Søndergaard (2000). Video clips were presented for the plant employees at 3 feedback sessions/user workshops at MR. Furthermore, we compared the work practices at this site with data collected by other project researchers at the other wastewater treatment plants and held 3 project workshops emphasising design and evaluation with participation from all the cooperating parties.

\subsection{Division of labour}

MR employs a total of 8 people consisting of the manager, the foreman and six "waste water operators", who take care of the wastewater process per se. In addition, MR has a service contract with a group of electricians and a group of blacksmiths that are summoned to take care of problems relating to the electrical system and heavy machinery repair respectively. These groups of electricians and blacksmiths work for all 8 wastewater treatment plants in the county.

The manager and the foreman are responsible for the overall management of the plant and overlook the various experiments that are initiated to optimise the quality of the water being led out and the cost of cleaning it, e.g. through experiments with new types of additives like polymers. They are furthermore the representatives for MR when dealing with e.g. The Wastewater Treatment Office and other local council- and governmental offices, i.e. the larger wastewater treatment system of which MR is a part.

The remaining six employees work primarily in pairs, each of the three pairs being responsible for tasks associated with a specific part of the treatment process. Individual workers may temporarily take on other tasks, as when someone is ill, but the overall division of labour is quite stable. However, within these bounds they are free to 'juggle' the tasks as the situation demands. The levels of dynamics in wastewater treatment work are further explored in Bertelsen \& Nielsen (1998).

\subsection{The complexity of wastewater treatment}

Wastewater treatment is a hugely complex, technical process and becoming familiar with the immense technical system that controls it is a yearlong learning process. The scope of this task has been very aptly put by one of the workers at MR as:

"I have been working here for four years and am starting to 'know' the plant, but I think it will take another two years before I know it well enough - where all the machines are, etc. For example, we have pipes running through this building and they are normally working fine so you can basically work here for years without knowing there's a (throttle) valve up there [pointing]" (..) You never find out before something happens (..) We work with 50.000 components - you don't learn about them all on your first day".

This example points out an essential aspect of work at a wastewater treatment plant, and most other process plants, namely the ability to 'see through' the chaos of information available by knowing how to filter it. This, however, is an ability that takes years for the workers to harness. The task is further complicated by the fact that most component specific information cannot be accessed locally but is available only through the central control system. We shall look into this in more detail in the following.

\subsection{Central control and distributed work}

The output from the staggering number of components is sent to a central computer, $\mathrm{PC}$, on which the control and regulation system for the wastewater treatment process runs. The overall control of the purification process is thus centralised. Regulation of the wastewater treatment process takes place only through the control system in the control room. However, this stands as a glaring contrast to the way we observed work being done during our field study: the workers very rarely spent time in a control room more than five or ten consecutive minutes but were primarily working in the area because their daily routines depend on having direct access to the local environment and the components in it. The specific sites at the plant, like the primary clarifier, provide the workers with audio-visual information not measurable by the sensors e.g. the way the water looks and smells, the way a motor sounds while running and oil leaking from a gasket. We have seen countless examples during our field study where walking around in the environment contributes with valuable information, as the following examples show: 
As part of his daily round, Bob was checking the area around the sludge tanks and noticed that the surface water in the tanks was brownish. He immediately proceeded to the building the water came from to check a pump he, rightfully, suspected to be malfunctioning because of the discoloration. He explained that if the water had not been discoloured, he would have checked the pump anyway because that building is part of his area of responsibility, but he would not have done so until hours later.

Thus, visual clues in the area prompts Bob to alter his routine in response to what he has encountered in the area.

Dan, who works in the building next to the lab, calls Robert, who is doing the daily laboratory tests, over to tell him that the contents of the primary clarifier looks strange today: it foams and is almost as grey as cement. They briefly discuss what could cause this and decide that the best cause of immediate action is for Robert to pay extra attention to the laboratory test results today.

In this situation, no immediate action is taken because even though the water looks odd, this alone does not provide enough information to determine a course of action. Robert needs the results from the laboratory, too.

This point to an important aspect of the work, namely that the information available in the area along with the information provided by the control system form the basis for how work is performed, and in most cases, any one source is not sufficient for deciding how to progress. However, at present the information obtained from walking around in the area is completely detached from the information from e.g. the sensors, which are only available in the control system. This makes the task of getting an overview of the 'state' of the process extremely complicated. To support the ability to 'see through' the chaos of the information it is of vital importance to provide such an overview. One of the aims of the prototype is to show how this may be accomplished by bringing the two bodies of information together in an integrated system.

\section{DESIGNING FOR LARGE AND SMALL SCREENS}

Our empirical findings show that how well a plant runs depends upon a vast amount of factors that mutually influence each other. All these factors make up what we call the overall information space of the wastewater plant. In other words, the overall information space of the plant contains all the information that constitutes the overview of the entire wastewater treatment process.
The different sites at the plant can be viewed as representing different places to access information. The variation in what kind of information is accessible and where it is accessible indicates that there are a number of smaller information spaces distributed at the plant. The examples from the case study illustrate that at a specific site at the plant, it is possible to access a definite amount of information. As we saw earlier the information can be accessed through multiple information sources, i.e. through the colour of the water, the smell, the measurements in the lab, or the information in the central computer system. Each of these sources reveals a larger or smaller part of the overall information space. They themselves represent in fact information spaces by providing information at the specific site.

To examine and discuss how a mobile device can be seamlessly integrated with a larger system, we need to develop a future scenario based on the daily work routine at the plant.

In the future scenario all the information that is currently available in the central system is still accessible through the PCs placed in the office building. The major difference from the current situation is the automation of the laboratory work and the utilisation of a mobile device for accessing system information. Online sensors will do all the measurements currently done in the laboratory and the data from the sensors will be send directly to the central system. When the worker walks his daily round at the plant he can access the data in the central system through a mobile device that he brings with him. This will provide him with updated information about the plant on the spot where he needs it.

\subsection{The mobile device - a new access point}

In the future scenario online sensors have replaced the work in the laboratory where the water is analysed today. This changes the current organisation of the information spaces at the plant because the worker will in theory be able to access all information available in the central system. But does the worker actually need to access everything when he walks his daily round? If we consider the theory of smaller information spaces being a part of the overall information space we will argue that since the worker brings the device with him on his round the information he needs will be site specific. Thus it is not necessary for him to access all information in the central system from his mobile device. Let us illustrate this by an example. Consider the situation previously described where the colour of the water is brown. When the worker notices this at his daily round 
he will in the future scenario be able to immediately access relevant information that might explain why the water is brown. In this particular situation he is at the sludge tank and needs information measured by the sensors at this specific site. The sensors measure what chemicals the water contains and that is exactly what the worker needs to know at this point. He does not need to access any information about for example the use of electricity at the plant. Instead he needs a precise overview of the current situation at the specific site - he needs access to this particular information space at the plant.

Thus the mobile device should provide access to an integrated, context specific part of the overall information space and not work as an alternative and independent entrance to this.

\subsection{Presenting complex information}

We now return to the question of how information should be presented on the mobile device and the central PCs? Two essential aspects affect this scenario considering the interface design. Firstly, how do we present complex information on large and small screens in unison, and secondly, how do we communicate the information in a way that supports the users' obvious need for moving around the area and use the non-system information available to them.

From our empirical study we have identified overview and integration as key features to be supported in the interface design. If we look at the user interface of the current system it is characterised by a large amount of detailed information. It has been developed for a normal PC monitor and is not suitable for a transformation to a small screen. There would simply be too much graphics squeezed into too little space on a small display and the information provided by the graphics would not be understandable (Jones et. al. 1998). The interface on the current system is a mix of geographically grounded and completely abstract information and it is not only inappropriate on any displays of smaller devices, nor does it provide the users with an appropriate conceptual model of the process. For this reason alone it becomes obvious why the approach to merely downscale a desktop interface design for a palm-top device must fail. It would simply not provide a sense of overview.

Recently developers have been working on how to transform information presented on the desktop computer to fit on a handheld device. As previously mentioned the WEST-browser is one way of making an already existing design fit into the small display of a handheld de- vice. Another example is the PalmORB and $2 \mathrm{~K}$ system, which similarly provide the user with a sense of consistency between the desktop PC and the handheld device. We do not believe that the solution in all cases is to develop a new interface design for the small device and let this exist in parallel with the interface design of the central system, with which it is supposed to be integrated. Instead we want to create a graphical match or a similar, compelling visual connection between the interface design on the large and small screens to obtain a sense of integration between devices.

A new graphical design for both the PC and the handheld would give us the possibility to communicate information not only through numbers and text but also through the graphical shape. The design should reflect that every distributed interface is a part of a larger whole to recreate a sense of the information provided is part of the overall condition of the plant.

The interface design should fit both the large and small screens. The graphical design should not only communicate the measured data in a strict functionalistic way. The connection between the large and small screens in terms of the interface design should be the use of the same fundamentally graphical shape. More delicate information may be expressed through, for example, the use of colours. The next question is now how do we translate our considerations on overview and integration into the actual design of the prototype?

\section{THE PROTOTYPE}

With the design of the user interface we aim at representing different views into the information spaces of the plant.

The prototype is implemented on both a PC and a PDA. The prototype was made for the PowerMac in Director and PhotoShop, and implemented on the Palm IIIx in Java with Waba. 
We provide the following three views:

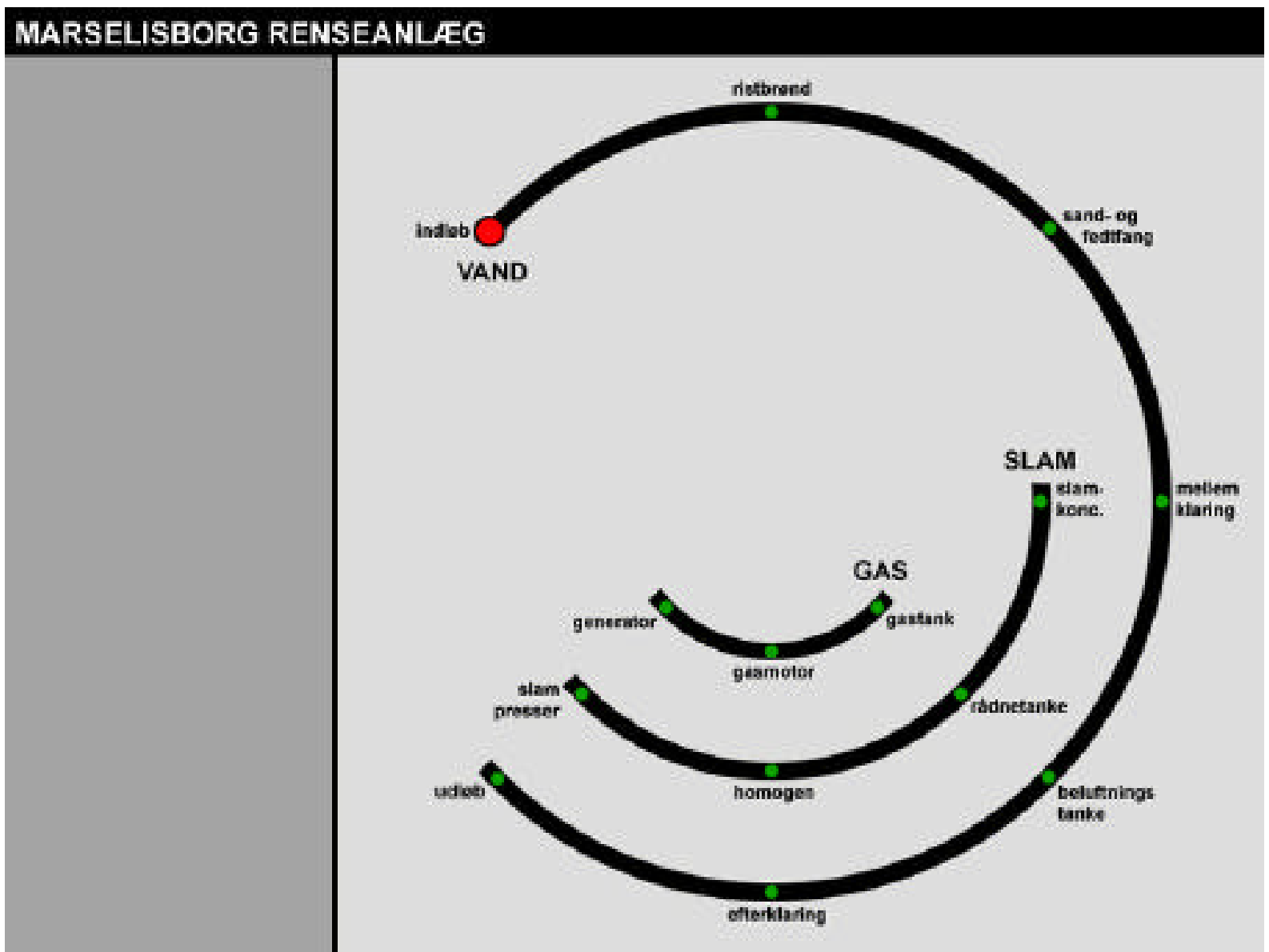

Figure 1. First view - PC Plant overview

The first view (see Figure 1 and Figure 2) is the 'plant overview' and it provides access to the three main phases of the wastewater treatment process, namely water, sludge and gas. Each important step in these three phases is indicated by a coloured dot - a green dot if everything is working fine, a red dot if the alarm on the sensor has been triggered. However, we use a PDA with a monochrome display and thus we can not provide the user with a coloured dot. Instead we illustrate an alarm on the PDA by showing small dashes from the dot (see figure 2). In this way the worker can immediately take note of the alarm through any view on the display. By pressing one of the dots on the circle it is possible to access the second view that provides more specific information about a particular step in one of the phases.

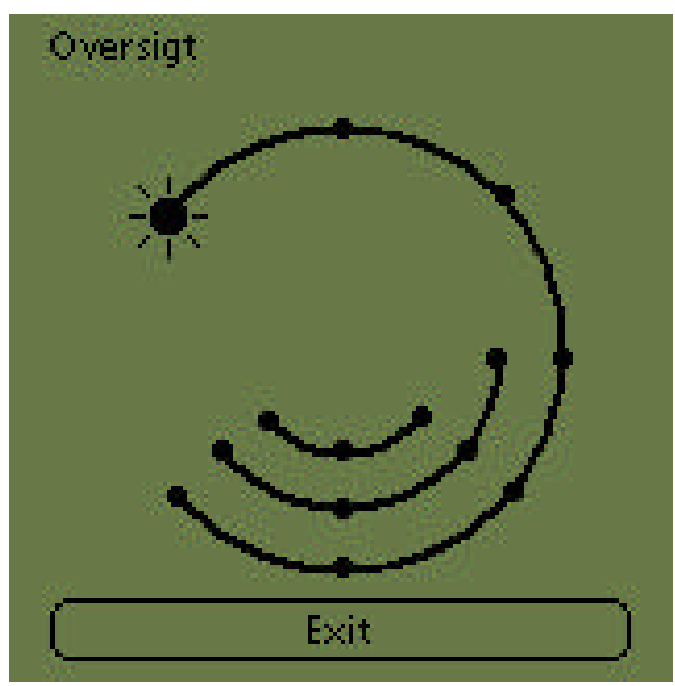

Figure 2. First view - PDA plant overview 


\section{MARSELISBORG RENSEANLEEG}

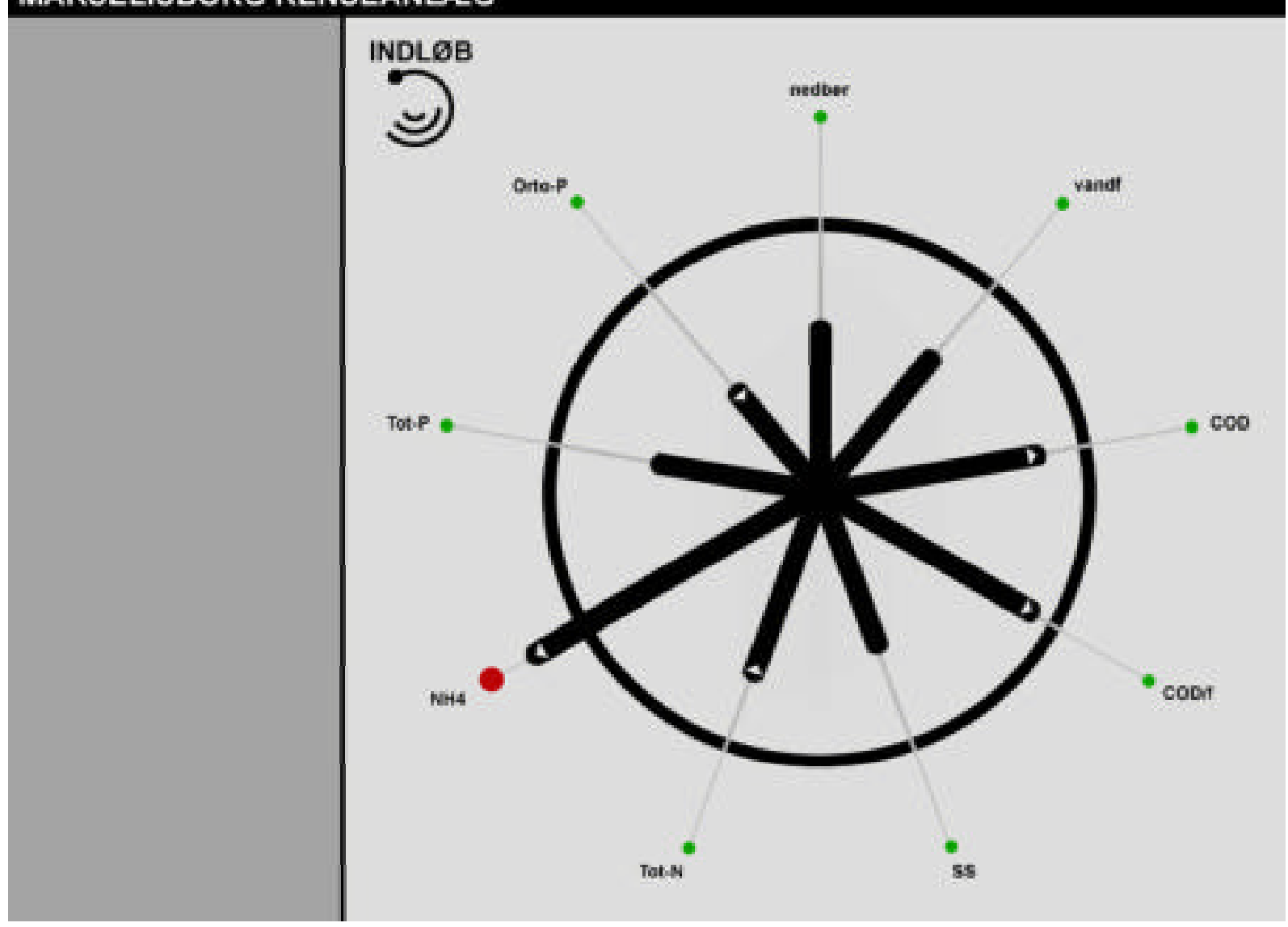

Figure 3. Second view - PC inlet water

The second view (see Figure 3 and Figure 4) provides access to the measurements done by the sensors at specific sites. In this case it is the inlet water (first step in the water phase in the outermost ring). This view represents the output from the sensor at the site of the inlet water. This view consists of 9 values corresponding to the fictitious online sensors at the inlet site. Again a coloured dot at each measurement is indicating if everything is working fine or if an alarm has been triggered. At the monochrome display the alarm is shown by the measurement-indicator that crosses the circle line when the measurement is beyond the threshold. By pressing one of these dots (on the PC display) or measurementindicator line (on the monochrome display) it is possible to access more detailed information about the specific measurement.

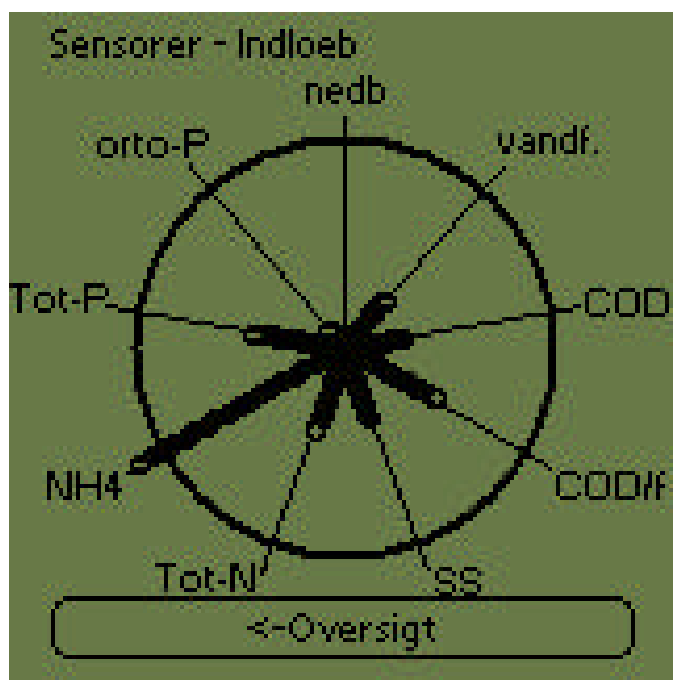

Figure 4. Second view - PDA inlet water 


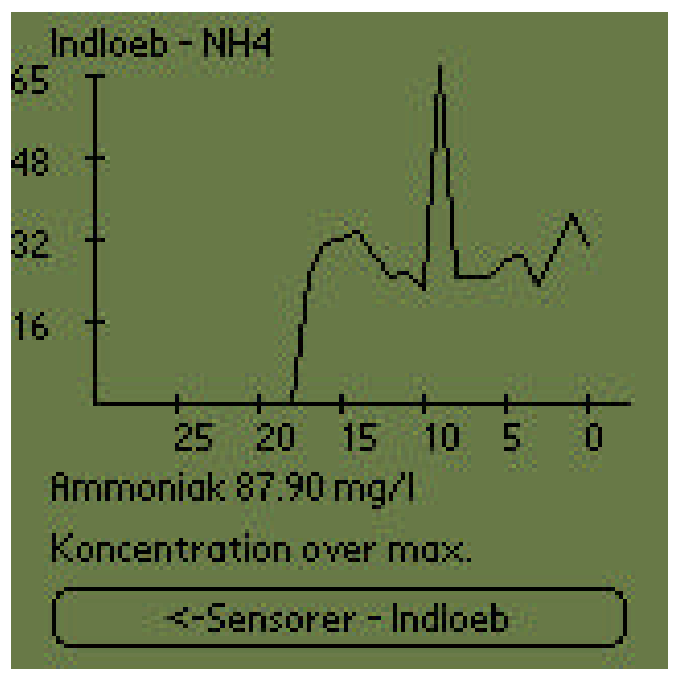

Figure 5. Third view - PDA single sensor information

The third view (see Figure 5) provides information from a single sensor. If one of the measurements in the inlet water e.g. the ammonium level has gone beyond the threshold value the worker can take a closer look at the development of this value over a certain time span and get more detailed figures concerning the present level.

\subsection{Overview}

As we have described earlier the work practices we aim to support rely on the ability of quickly getting an overview of the state of a process.

We found that the shape that could present the actual data in an efficient way and communicate a sense of overview was the circle. The circle is efficient when working with small screens because it is curved and it is practical when you want to show a linear process on a limited amount of space. Furthermore it is efficient when trying to show relations. The three phases represented on the first view have mutual relations: At a certain point in the water process (illustrated by the outermost ring) the sludge process starts (illustrated by the middle ring) and at a certain point in the sludge process the gas process starts (illustrated by the innermost ring). Furthermore the circle provides you with 'at a glance' overview. Consequently the processes at the plant in the first view are visualised through circular lines with mutual connections (see Figure 1 and Figure 2 ). The second view is based on the circle as well - nine measurements from the inlet water grow out from the centre of the circle, i.e., conceptually, out of the same water sample (see Figure 3 and Figure 4). The third view provides such specific information that using a regular system of co-ordinates creates it (see Figure 5).

\subsection{Integration}

Furthermore, choosing a graphically simple layout enables us to use the same layout on the mobile device as on the central PC. This brings us to the second key aspect addressed by the prototype design, namely designing for supporting a sense of integration between the mobile device and the PC. We want the design to show a clear link between the system on the PC and the mobile device. Using the same graphical representation for a collection of devices is a direct way of denoting integration between them. The design for the PC has empty space at the left of the screen as opposed to the design for the PDA. With this space we indicate that here is room for buttons, text, etc. that would provide the user with access to other parts of the information in the central system. The key issue in this prototype is that both the PC and the PDA are showing the same graphical representation on at least some part of the display in order to support the integration between the two.

\subsection{Feedback from users}

We presented the prototype at a workshop with participants from our collaborating partners and users from two of the four participating wastewater treatment plants. During the workshop we played through use scenarios with the users, bringing the mobile device with us out into the plant.

In terms of overview the reactions towards the overall design was quite overwhelming, especially from the managers from both wastewater treatment plants. They found that our design provided them with a much better overview of the state of the wastewater treatment process than the current control system interface with its strange mixture of geographically grounded information and abstract, process-oriented information. The new interface thus presented a more comprehensible conceptual model. The graphical design provided them with an overview that worked both on the PC and on the PDA. One thing they lacked, though, was a little more information on the PDA. In the first view (the overview of the processes) they needed some abbreviated names to mark the different sites at the plant just as it is provided on the PC interface. The transition between the desktop based system and the mobile device was conceptually smooth to the users because the same graphical design was used on both displays. This supported the understanding that they were bringing parts of the overall information space 
with them out into the field when they carried the mobile device with them to a specific site of the plant.

We also discovered that they did not need the third view (Figure 5) when they were at a specific site at the plant. They found it important to access the first and second view (Figure 1-4) where they could see whether there was an alarm or not and if there was what the alarm was about. But the third view provided too specific information which they instead preferred to access indoor in the warm office where they could sit down in front of the central PC and more comfortably examine the specific situation in detail.

\section{DISCUSSION}

We have presented a prototype that provides access to system information outside the control room. When providing a new entrance point into the overall information space, it is vital for us as designers to negotiate with the users how to prioritise the information, for example, which types of information must be available always and which may be available at a lower level. Throughout the study we have worked with the users to identify their set of priorities, which we have sought to implement in the prototype.

The feedback from the users indicates that in a specific situation like this when the workers bring a small device into the environment the information on the device and the contextual information in the environment will work together. This dynamic determines what kind of information it is needed to access where. Furthermore, the feedback workshops with the users made us realise that when they are outside, they need an overview of the process, not a detailed view of all the components. For the more detailed and cross-referential view, they prefer the PC system. This supports our understanding that the mobile device should not have access to all the information in the central control system because it is used for quite different tasks. This contradicts the general fascination with the idea that mobile technology will enable us to do anything, anywhere at anytime (see for example Palm, IBM \& Nokia). This notion makes us consider the mobile device as an independent access point into the information space and does not allow us to place it in the existing web of technology. Wiberg \& Ljungberg (1999) argues that "only a tiny part of service work is possible to perform anytime, anywhere. Most of the work is dependent on spatial factors" They narrow down the scope of anytime anywhere but the discussion about time and place still lacks an aspect. So far the discussion asks 'when' and 'where' but it does not ask 'what'.
Mobility should be supported by the ability to access information on the move, but time, place and amount of information determine how it should be supported. The mobile device itself and its ability to access the information space should not define mobility. Instead, the amount of information needed should determine the mobile device. The PDA has its limitations. It proved to be useful at the plant because of the amount of information needed. But had the workers needed more information the PDA were maybe to small etc.

One of the main experiences from this project is that supporting wastewater treatment work or similar kinds of process control work must focus on providing the users with a wider range of entry points into the information. The technology should let them take advantage of both the superior overview provided by the desktop computer's large screen and support their skills at drawing valuable information from moving around in the environment, e.g. the sight and smell of the water and the sound of motors running.

The rapid development in all computer-related areas, particularly mobile technology, provides us with the technological basis for supporting mobility in distributed work. However, the design of such support is complicated by the lack of design principles, which has been the focus of much of the mobile literature, e.g. (Dix et. al 1998, Kristoffersen \& Ljungberg 1999, Kristoffersen et. al 1998). It presents us with the task of dealing with and designing for a highly heterogeneous collection of devices with different physical attributes, using different formats and providing different services. Olsen (1999) describes this as 'interacting in chaos'. Take as an example one of the latest advances, the WAP technology that makes it possible to access the Internet on mobile devices. In theory, this enables the user to order flowers, check plane schedules and download and read the complete works of Charles Dickens on his or her mobile phone. However, it is far from all of these tasks that are convenient to do through a mobile phone with its restricted display size. The mobile device is seen as an independent 'information technology unit' with universal access to information. This perspective adds to the information chaos we, as users of information technology have to deal with.

Thus we are now faced with the challenge of considering issues of e.g. diversity, inconsistency and integration (Johnson 1999). To transcend the chaos and create a sense of coherence in the access to the information space through heterogeneous devices, we see much promise in using the strong connection between placing new tech- 
nological device in the existing web of technology and the notion of integration. By making this our starting point we are brought to consider the relationship between the different types of technology mediating the use activity as a natural part of designing technological support for use practice. In our case we needed to convey a strong sense of integration between devices, but in others the integration may be weak or non-existent. What is important is that we ask the question.

\section{ACKNOWLEDGEMENTS}

We would like to thank the people at the wastewater treatment plant, and our colleagues in the wastewater project. Furthermore, we owe a great deal of thanks to our work group at IRIS'23 who provided us with excellent feedback. Finally, thanks must go to our anonymous reviewers. Our work on the wastewater project has been supported by The Danish Basic Research Foundation, Centre for Human-Machine Interaction and The Danish National Centre for IT-Research, project no. 23 (Usability Work in the Danish Industry).

\section{REFERENCES}

Bellotti, V. and S. Bly (1996). Walking away from the desktop computer: Distributed collaboration and mobility in a product design team. In Proceedings of CSCW'96, K. Ehrlich \& C. Schmandt (Eds.), ACM Press, pp. 209-218.

Bertelsen, O.W. \& Nielsen, C. (1999). Dynamics in Wastewater Treatment: A Framework for Understanding Formal Constructs in Complex Technical Settings. In Proceedings of ECSCW'99, S. Bødker, M. Kyng \& K. Schmidt (Eds.), Klüwer, pp 277 - 290.

Björk, S. et al (1999). WEST: A Web Browser for Small Terminals. In Proceedings of UIST'99. Asheville, NC, pp. 187 - 195.

Buur, J. \& Søndergaard, A. (2000). Video Card Game: An augmented environment for User Centered Design discussions. In Proceedings of DARE 2000, ACM, 2000, Elsinore, Denmark, pp. 63 - 70.

Bødker, S. (1996). Applying Activity Theory to Video Analysis: How to Make Sense of Video Data. In Human-Computer Interaction. Context and Consciousness Activity Theory and Human-Computer Interface. Nardi, B.A (Ed.) The MIT Press, pp. 147-174

Dix, A. \& Beale, R. (1996). Information Requirements of Distributed Workers. Remote Cooperation. CSCW
Issues for Mobile and Teleworkers. London, SpringerVerlag, pp. 113-144.

Dix, A. et. al (1998). Exploiting Context in HCI Design for Mobile Systems. In Proceedings of the First Workshop on HCI and Mobile Devices, 1998, Glasgow, Scotland

Fagrell, H., Kristoffersen, S. and Ljungberg, F. Exploring Support for Knowledge Management in Mobile Work. In Proceedings of ECSCW'99, S. Bødker, M. Kyng \& K. Schmidt (Eds.), Klüwer, pp. 277 - 290.

Fagrell, H. \& Johanneson, E. (2000). NewsMate: Knowledge Management for mobile journalists. In Proceedings of IRIS 23, L. Svensson et al. (eds.), pp. ??

IBM: http://www-3.ibm.com/pvc/index-flash.shtml

Jones, M. et. al. (1998). Improving web interaction on small displays. Technical Report, Middlesex University. http://www.cs.mdx.ac.uk/research/web8.pdf

Johnson, P (1999). Usability and Mobility; Interactions on the move. In Proceedings of the Second Workshop on Human Computer Interaction with Mobile Devices. 1999, Edinburgh, Scotland

Kristoffersen, S. \& Ljungberg F. (1999). "Making Place" to Make IT Work: Empirical Explorations of HCI for Mobile CSCW. In Proceedings of GROUP'99, ACM Press.

Kristoffersen, S. et. al. (1998). Developing Scenarios for Mobile CSCW. In Proceedings of the First Workshop on HCI and Mobile Devices. 1998, Glasgow, Scotland

Luff, P. and C. Heath (1998). "Mobility in Collaboration," In Proceedings of CSCW'98, S. Poltrock and J. Grudin (Eds.), ACM Press, pp. 305-314.

Nokia: http://www.nokia.com/wap/products.html

Olsen, D. Interacting in chaos (1999). In Interactions Vol. 6, No. 6 (Nov. 1999), pp. $42-54$

Palm: http://www.palm.com

Román, M. et al. Integrating PDAs into Distributed Systems:2K and PalmORB. In Handheld and Ubiquitous Computing. Proceedings of First International Symposium, HUC'99, H. Gellersen (Ed.), Springer. pp. 137149.

Wiberg, M. \& Ljungberg, F. (1999) Exploring the vision of anytime, anywhere in the context of mobile work, In Knowledge Management and Virtual Organizations, Y. Malhotra (Ed.), The BizTech Network 